Portland State University

PDXScholar

Spring 7-19-2019

\title{
Use of Two-replisome Plasmids to Characterize How Chromosome Replication Completes
}

Nicklas Alexander Hamilton

Portland State University

Follow this and additional works at: https://pdxscholar.library.pdx.edu/open_access_etds

Part of the Biology Commons

Let us know how access to this document benefits you.

\section{Recommended Citation}

Hamilton, Nicklas Alexander, "Use of Two-replisome Plasmids to Characterize How Chromosome Replication Completes" (2019). Dissertations and Theses. Paper 5064.

https://doi.org/10.15760/etd.6940

This Thesis is brought to you for free and open access. It has been accepted for inclusion in Dissertations and Theses by an authorized administrator of PDXScholar. Please contact us if we can make this document more accessible: pdxscholar@pdx.edu. 
Use of Two-replisome Plasmids to cCaracterize how Chromosome Replication Completes

by

Nicklas Alexander Hamilton

A thesis submitted in partial fulfillment of the requirements for the degree of

Master of Science

in

Biology

Thesis Committee:

Justin Courcelle, Chair

Jeffrey Singer

Rahul Raghavan

Portland State University

2019 


\begin{abstract}
All living organisms need to accurately replicate their genome to survive. Genomic replication occurs in three phases; initiation, elongation, and completion. While initiation and elongation have been extensively characterized, less is known about how replication completes. In Escherichia coli completion occurs at sites where two replication forks converge and is proposed to involve the transiently bypass of the forks, before the overlapping sequences are resected and joined. The reaction requires RecBCD, and involves several other gene products including RecG, ExoI, and SbcDC but can occur independent of recombination or RecA. While several proteins are known to be involved, how they promote this reaction and the intermediates that arise remain uncharacterized.

In the first part of this work, I describe the construction of plasmid "minichromosomes" containing a bidirectional origin of replication that can be used to examine the intermediates and factors required for the completion reaction. I verify that these substrates can be used to study the completion reaction by demonstrating that these plasmids require completion enzymes to propagate in cells. The completion enzymes are required for plasmids containing two-replisomes, but not one replisome, indicating that the substrate these enzymes act upon in vivo is specifically created when two replication forks converge.
\end{abstract}

Completion events in E. coli are localized to one of the six termination (ter) sequences within the 400-kb terminus region due to the autoregulated action of Tus, which binds to ter and inhibits replication fork progression in an orientation-dependent manner. In the second part of this work, I examine how the presence of ter sequences affect completion on the 2-replisome plasmid. I show that addition of ter sequences modestly decreases the stability of the two-replisome plasmid and that this correlates with higher 
levels of abnormal, amplified molecules. The results support the idea that ter sites are not essential to completion of DNA replication; similar to what is seen on the chromosome.

Rec-B-C-D forms a helicase-nuclease complex that, in addition to completion, is also required for double-strand break repair in E. coli. RecBCD activity is altered upon encountering specific DNA sequences, termed chi, in a manner that promotes crossovers during recombinational processes. In the third part of this work, I demonstrate that the presence of chi in a bidirectional plasmid model promotes the appearance of overreplicated linear molecules and that these products correlate with a reduced stability of the plasmid. The effect appears specific to plasmids containing two replisomes, as chi on the leading or lagging strand of plasmids containing one replisome had no-effect. The observation implies chi promotes a reaction that may encourage further synthesis during the completion reaction, and that at least on the mini-chromosomes substrates, this appears to be a destabilizing force. 


\section{Dedication}

I would like to thank my adviser, Dr. Justin Courcelle, for never giving up on my continuous progress and providing me the resources and much needed advice and expertise, along with a ton of patience, that I required to better myself in my graduate tenure. Secondly, I would like to thank my other committee members Dr. Rahul Raghavan and Dr. Jeffrey Singer for their patience, and assistant with my various learning endeavors including classes and facilitating seminars. In equal addition I would like to thank Dr. Charmain Courcelle for the limitless hands-on training and continuous support with countless "upping my game" pep talks which was necessary to overcome many of my selfmade obstacles; additionally, helping engineer some rather difficult plasmids. I would also like to thank my lab mates, Dr. Brian Wendel (who first synthesized the two bidirectional plasmids) and Jessica Cole, who have made the hardest challenge of my life achievable and have installed a new and intense appreciation for scientific research and comradery. Lastly, I want to thank my husband, Jeremy Hamilton, who has spent countless hours encouraging and supporting me through the rough days, celebrating my triumphs, and overall being a pillar of figurative and actual physical strength for me; I could not have done this without him, everyone mentioned above, and of course the unconditional love and support from family and friends not mentioned. Thank you all! 


\section{TABLE OF CONTENTS}

PAGE

Abstract i

Dedication iii

List of tables vii

List of Figures viii

Chapter I: Research purposes

Introduction

01

Figures

Chapter II: Materials and Methods

Bacterial strains and plasmids

14

Transformation efficiency assay

16

Plasmid stability assay

Total genomic DNA extraction

17

Southern analysis of plasmid replication intermediates

18

Copy number analysis

18

Strain Growth assay

18

Tables

20

Chapter III: Results

Part I: One-replisome to two-replisome plasmids during completion of replication

Plasmids containing two replisomes can be stably transformed, replicated, and grown in cells similar to the one-replisome plasmid.

Plasmids replicated by two replisomes are less stable than one-replisome plasmids and contain more aberrant, multimeric species. 
Similar to the completion of replication on the chromosome, amplifications and genetic instability on the two-replisome plasmid are driven by an aberrant RecA-mediated recombination mechanism.

Transformation of plasmids with two replisomes, but not one replisome, depends on the enzymes required to complete replication on the chromosome.

Part II: The effect of Replication fork traps and the Completion reaction

Two-replisome plasmids with two addition ter sequences, terB and ter $C$ from the Escherichia coli chromosome, are replicated and maintained at similar frequencies as two-replisome plasmids without replication fork trap capabilities.

Plasmids replicated by two replisomes with the addition of ter sequences contain more RecA-driven aberrant, multimeric species.

Part III: The effect of $c h i$ sequences on completing replication

chi sequences located at sites where replication forks converge promote a RecA-mediated aberrant replication that correlates with instability

Addition of a ter $B$ and $\operatorname{ter} C$ trap reduces the destabilizing effect of $c h i$ by limiting the amount of aberrant replication that can occur

Figures

\section{Chapter IV: Discussion}

One-replisome to two-replisome plasmids during completion of replication

$\underline{\text { Replication fork traps and the completion reaction }}$ 
Chi sequences and the completion of replication

Chapter V: References 


\section{List of Tables}

Page

2.1 E. coli strains used in this study

2.2 Plasmids used in this study 


\section{List of Figures}

Page

1.1A Schematic of the Escherichia coli circular chromosome containing a single bidirectional origin of replication and ter sequences which block replication progression in an orientation-specific manner.

1.1B Replication profiling reveals that $\operatorname{rec} B C$ is required to maintain the region where replication forks converge on the chromosome, whereas $r e c D$, or $s b c D C$ and xonA are required to resect over-replicated DNA that arises in this region. Genomic DNA from replicating cultures was purified, fragmented, and profiled using high-throughput sequencing.

1.1C Model of completion of replication.

3.1A Schematic of pBR322, containing a unidirectional origin of replication, and pCL01 which contains a $\lambda$ bidirectional origin of replication.

3.1B Strains containing the two-replisome plasmid grow similar to those containing the one-replisome plasmid or no plasmid; E. coli strain included ampicillin cassette in this assay.

3.1C Plasmids containing two replisomes can be stably transformed at frequencies similar to those with one replisome.

3.1D The two-replisome plasmid is maintained at a copy number similar to the one replisome plasmid.

3.1E The copy number of each plasmid, relative to the chromosome is plotted.

3.2A In the absence of selection, the two-replisome plasmids are lost more rapidly than the one-replisome plasmid.

3.2B The fraction of cells retaining the one-replisome and two-replisome plasmid is plotted over time. 
3.2C The instability of the two-replisome plasmid, relative to the one-replisome plasmid, correlates with the presence of more abnormal, multimeric species.

3.2D The fraction of unit length, non-monomeric plasmid in cultures containing the one-replisome and two-replisome plasmid is plotted.

3.3A Inactivation of RecA restores the stability of the two-replisome plasmid to levels that approach that of the one-replisome plasmid.

3.3B The increased stability in the absence of the aberrant recombination pathway correlates with an increase in unit-length monomeric plasmids.

3.3C The fraction of non-monomeric plasmid in each culture is plotted for the onereplisome and two-replisome plasmid in the presence and absence of RecA.

3.4A Transformation of plasmids with two replisomes, but not one replisome, depends on the enzymes required to complete replication on the chromosome.

3.5A Diagram of plasmid constructs comparing 2-replisome plasmids to its counterpart with ter insertions $(\operatorname{ter} B+\operatorname{ter} C)$.

3.5B The fraction of cells retaining the two-replisome plasmid in the absence of selection is plotted over time.

3.5C Increased amounts of RecA-dependent, non-monomeric plasmid species are observed in the presence of ter traps.

3.5D The fraction of non-monomeric plasmid species in each culture is plotted.

3.6A Diagram of plasmid constructs comparing 2-replisome plasmid, pCL01, no chi control, pCL03 where chi is mutated near the ori site, pCL05 where chi is mutated opposite of ori site. 
3.6B Diagram of one-replisome plasmids containing a chi inserted into the leading, pCL07, or lagging strand, pCL08, pBR322 template.

3.6C When present in the terminus region, chi destabilized the two-replisome plasmid.

3.6D When present in the terminus region of the two-replisome plasmid, chi induces the formation of an aberrant linear plasmid multimeric species.

3.6E The amount of the linear plasmid multimeric species observed is plotted.

3.6F The stability of the one-replisome plasmid is not affected by the presence of $c h i$.

3.6G No multimeric species are induced by chi on one-replisome plasmids.

3.6H The amount of the linear plasmid multimeric species observed is plotted.

3.7A Diagram of two-replisome plasmids containing either a chi site in the terminus region or ter traps or both.

3.7B There is less destabilization by chi observed in the presence of a ter trap.

3.7C The amount of the linear plasmid multimeric species observed is plotted. 


\section{Chapter I}

\section{Research purposes}

\section{Introduction}

The DNA of a genome must be accurately replicated and passed on to daughter cells each generation. In addition to the challenge of accomplishing this task, DNA is also constantly bombarded by chemicals and radiation that compromise its integrity. These include chemicals found in tobacco smoke that oxidize bases or induce single strand breaks, UV-C radiation that induces pyrimidine adducts, deamination by hydrolysis in the presence of acid or heat, and harmful chemical metabolites that can react with the DNA to form adducts (Sachs et al., 1992; Friedberg 1995; Leanderson and Tagesson, 1992; reviewed in Sinha et al., 2002; reviewed in Zeman et al., 2014; Gorden et al., 2018). Therefore, cells contain numerous enzymatic systems that ensure the DNA is faithfully copied and can be repaired when damaged. Some of these regulatory mechanisms include proofreading during and after replication, nucleotide excision repair, mismatch repair mechanisms, and global stress responses such as the SOS and SoxR/OxyR response during DNA damage (Hopefield et al., 1976; Wang and Smith 1986; Gonzalez et al., 1998; reviewed in Crowley and Courcelle, 2002; reviewed in Hanawalt et al., 2003; Heyer et al., 2010; reviewed in O'Donnell et al., 2013; Lee et al., 2015). An additional process that presents challenges to maintaining genomic stability is the completion of DNA replication (Wendel et al., 2014). The mechanism by which completion occurs has only recently been recognized and far less is known about this process than the associated steps of initiation or elongation. However, these events must occur thousands of times per division in human cells; implying that it must occur with high efficiency (Hopefield 1974; Errico and Constanzo, 2012; reviewed in Costa et al., 2013; Wendel et al., 2014). Each singular 
convergence must somehow recognize replicated regions, resolve torsional complexities created by the supercoiling of two convergent replisomes, ensure that any overlapping or redundant sequences are resected or degraded, and finally joining the nascent strands at the precise point where all sequences have doubled (reviewed in Courcelle et al., 2015).

Our lab has recently identified several enzymes that are required for this reaction to occur in Escherichia coli. These include RecBCD, RecG, ExoI, and SbcDC (Wendel et al., 2014; Wendel et al., 2018). Of these enzymes RecBCD appears to play a critically central role, as cells lacking RecBCD have severely reduced viability and growth rates, and fail to maintain the region of the chromosome where replication completes (Wendel et al., 2014). Interestingly, RecBCD also has a long-established role in double strand break repair and homologous recombination (Klein and Kreuzer, 2002; reviewed in Smith 2012; Wendel et al., 2014). The enzyme complex has a number of remarkable activities, including two helicases with differing polarities, as well as both exonucleolytic, and endonucleolytic activities. Despite decades of characterization, both in vivo and in vitro, many of the molecular aspects and intermediates for which RecBCD catalyzes recombination remain uncharacterized. Considering RecBCD's newly identified and critical role in completion of replication, it seems likely that its functional role in both processes will be similar if not identical. Thus, characterization of the completion reaction presents a real opportunity to learn more about the cellular role and function of this complex enzymatic machine.

In this work, I examine two DNA sequence motifs that are known to affect RecBCD function in recombination or completion. Chi sequences are nonpalindromic G-rich octamers that are heavily enriched and over-represented in the leading strand template (Blattner et al., 1997). They alter RecBCD activities, and during recombination processes, determine where cross-over events are joined between two parental molecules (Lam et al., 
1974; Henderson and Weil, 1975; Stahl and Stahl, 1977). They are hotspots for spontaneous recombination events mediated by RecBCD (Kuempel et al., 1977; Horiuchi et al., 1994). The other sequence motif that was examined is the ter sequence. These are 23-bp sequences that bind Tus protein and block replication forks in the terminus region of the chromosome in a polar manner and have been identified throughout the chromosome as can be seen in Figure 1.1A. To further characterize the completion event and the cellular role of RecBCD, I engineered these sequences into "mini-chromosomes", or plasmids, that we adapted in our lab to examine completion events on defined substrates. While the completion reaction is independent of recombination (Courcelle et al., 2015), the two processes share many of the same enzymes, suggesting they are likely to function on similar substrates or intermediates, even though the end products of these reactions are quite distinct. While little is known about completion, recombination has been extensively studied over the last decades, and I briefly review aspects of this process in E. coli below.

\section{Basics of Homologous Recombination}

Homologous recombination is a highly conserved process found across all domains of life. It plays a critical role in the production of genetic diversity during meiosis and sexual cycles in eukaryotes and prokaryotes, and the gene products are important for maintaining genomic integrity and survival in the presence of DNA damage (Boyce and Howard-Flanders, 1964; reviewed in Bianco 1998; Sung and Klein 2006; reviewed in San et al., 2008; Amunugama and Fishel, 2012). Common to all homologous recombination systems is a core recombinase capable of searching DNA for homologous regions, performing DNA strand pairing and exchange (reviewed in Bianco et al., 1998; Meselson and Weigle, 1961). Fascinatingly, this conserved archetype is found in nearly all organisms; eukaryotes depend on Rad51 and Dmc1, archaea rely on RadA, viruses 
like $\mathrm{B}=$ bacteriophage $\mathrm{T} 4$ need UvsX, and RecA is associated with the bacterium Escherichia coli (Lee et al., 2015; reviewed in Bianco et al., 1998; Qi et al., 2015; Seitz et al., 1998). A physical and biochemical comparison of a few of these recombinases suggests highly conserved functionality; implying that studying one will give insight into the others (Reviewed in Bianco 1998).

rec $A$ was originally identified as a mutation in a screen for recombination deficient strains of $E$. coli K-12 as monitored by conjugation of a mutagenized F- strain with a Hfr strain (Clark and Margulies, 1965). In control experiments, the authors demonstrated that the donor DNA was taken up by the recipient cells, leading the authors to infer that the defect in $\operatorname{rec} A$ mutants was related to a failure in their ability to exchange or recombine DNA strands (Clark and Margulies, 1965; Howard-Flanders and Theriot, 1966B).

Purified RecA has the ability to form filaments. The monomeric form of RecA has two binding sites, one capable of binding to another RecA monomer and the other capable of binding to either ssDNA or a ssDNA-dsDNA complex. These properties are thought to allow RecA to form extended filaments that are able to survey and identify homologous sequences and pair them together with single stranded regions (Chen et al., 2008; Savir et al., 2010; De Vlaminck et al., 2012; Lesterlin et al., 2014). Once the homology is found the DNA strand exchange occurs through a process in which the RecA filament displaces single-stranded DNA binding protein (SSB) (Mackay et al., 1974) creating a three-stranded D-loop intermediate (Cox and Lehman, 1982; Stasiak et al., 1984). DNA binding, exchange and release are regulated through ATP hydrolysis via creating DNA duplexes where base pairing is not only subject to Watson-Crick strategies but reliant on the intact strand, which plays an important role in differentiating between homologous and non-homologous sequences (Chen et al., 2008). 


\section{$\underline{\text { RecBCD creates 3' ssDNA substrates for RecA in DNA repair }}$}

In E. coli three different homologous recombination 'pathways' have been characterized, which act on different substrates or conditions to promote RecA-mediated recombination: RecBCD, RecET, and RecFOR (Smith 1989; Kiem and Lark, 1990; Clark 1991; Shiraishi et al., 2006).

Early genetic screens identified mutations in each of these three pathways. $\operatorname{rec} B C$ mutations reduced conjugation or transductional recombination by more than three orders of magnitude (reviewed in Anderson 1997A). In the absence of $\operatorname{rec} B C$ the remaining $0.1 \%$ of recombination was dependent on recFOR or $r e c E$ genes (Birge and Low, 1974). The recombination defects in $\operatorname{rec} B C$ mutants could also be suppressed by mutations in $s b c D C$ or xonA (Allgood and Silhavy, 1991). Several early studies suggested that these mutations activated the RecF or RecE pathways since the recombination remained dependent on these proteins (Karu and Belk, 1982; Lloyd and Thomas, 1983; Clark et al., 1993). RecE and T were subsequently found to be prophage genes that were absent in many of the strains used (Clark et al., 1993; Handa and Kobayashi, 2005A; Shiraishi et al., 2006). Genes that were placed into the RecF pathway were often suggested to be responsible for repairing singlestrand gaps or plasmid recombination (Kushner et al., 1971; Stahl et al., 1977; reviewed in Smith 1989; Keim 1990). However, more recent studies have shown that the RecF pathway genes are intimately associated with replication (Stahl et al., 1972) and much of the recombination associated with these genes appears to occur through the initiation of replication when single strand 3' ends are paired with homologous duplex (Courcelle et al., 1997). In the presence of DNA damage that blocks DNA polymerase, RecF pathway genes are associated with processing and maintaining the arrested replication fork structure in a manner that allows the blocking lesions to be repaired so that replication may resume 
(Courcelle et al., 1997; Courcelle et al., 1999; Courcelle and Hanawalt, 1999; Courcelle et al., 2001; Courcelle et al., 2003; Chow and Courcelle, 2004; Courcelle et al., 2006).

RecBCD, the enzyme pathway of interest, is essential to maintain the chromosome during the completion reaction, forms an ATP-dependent helicase-nuclease heterotrimeric complex that contains a slow 3'-5' helicase and nuclease on the RecB subunit (Yu et al., 1998; Amundsen et al., 1990; Taylor et al., 2003), a fast 5'-3' helicase on the RecD subunit (Amundsen et al., 1986; Taylor et al., 2003) and a sequence-dependent recognition site for a unique octamer called Crossover hotspot instigator (chi) in the RecC subunit (Lam et al., 1974, Amundsen et al., 1990; Taylor et al., 2016; Amundsen et al., 2016), and an exonucleolytic and endonucleolytic activity in the RecB (Yu et al., 1998).

Biochemically, the enzyme complex was initially thought to be made up of two subunits, RecB and RecC (Amundsen et al., 1986). RecD was subsequently identified as a 58-kDa polypeptide that dissociated at higher salt concentrations during purification (Amundsen et al., 1986). Over the years, RecBCD's helicase and nuclease activities have been dissected through both genetic and biochemical characterization of point mutants.

It was observed that in the absence of the RecD subunit, no nuclease activity was detected, in vitro or in vivo, leading early work to infer that RecD likely contained the nuclease (Biek and Cohen, 1986). However, a point mutation in $\mathrm{RecB}_{\mathrm{D} 1080 \mathrm{~A}}$ was also seen to attenuate nuclease activity (Anderson et al., 1999). Subsequent work demonstrated that RecB contained the nuclease, which was activated by the presence of RecD (Anderson et al., 1999). This was later confirmed from X-ray crystallographic imaging of the subunit revealing components necessary for nuclease activity similar to other nucleases (Singleton et al., 2004). 
In vivo and in vitro, the nuclease activity of $\mathrm{RecBC}$ is also attenuated upon encountering a chi site (Dabert et al., 1992). This led to some to suggest that RecD dissociated from the complex at these sites (Stahl et al., 1990). However, in vitro comparisons of RecBC(D-) purified enzyme do not entirely mimic those of the RecBCD following chi, leading to the idea that the subunit may remain associated in an altered conformation (Thaler et al., 1989; Anderson et al., 1997B). This view was additionally supported in single molecule studies using fluorescent tagged RecBCD molecules demonstrating that RecD remained associated as it approached and passed chi (Handa et al., 2005B).

How the enzyme complex degrades DNA as it unwinds has also been debated. Some suggest RecBCD degrades both strands of DNA up to encountering a chi site, at which point only 3' strand is degraded (Dixon and Kowalczykowski, 1993). A second model purposes that the enzyme primarily unwinds the DNA, and cuts at chi (Singleton et al., 2004). Support for both models can be observed in vitro and appears to be primarily depend on the $\mathrm{Mg}^{+2}$ and ATP concentration used in the reaction (Taylor and Smith, 1995; Fan and Li, 2009).

\section{$\underline{\text { RecBCD change linked by Crossover Hotspot Instigator (chi) }}$}

The conformational changes and altered activities of RecBCD are all triggered by the ssDNA recognition of a non-palindromic, chi sequence 5'-GCTGGTGG-3' (Smith et al., 1981; Stahl et al., 1990; Taylor and Smith, 1992; Dixon and Kowalcyzkowski, 1993; Bianco et al., 1997; Kulkarni and Julin, 2004; Amundsen et al., 2007A; Handa et al., 2012; Taylor et al., 2016). The RecC subunit recognizes chi, inducing a pause in the processive unwinding (reviewed in Bianco et al., 1997; Dohoney and Gelles, 2001; Handa et al., 2012). A conformational shift in RecD subunit (Anderson et al., 1997B; Handa et al., 
2005B; Yang et al., 2012) alters the enzyme's activity effectively slowing down the processivity by inactivating the fast $5^{\prime}-3$ ' helicase RecD activity and shifting the leading translocation motor to that of the slower helicase in the RecB subunit (Anderson et al., 1997B, Spies et al., 2003; Handa et al., 2005B; Spies et al., 2007; Yang et al., 20012). Additionally, this conformational change modifies the location of the nuclease activity in RecB such that DNA is incised a few nucleotides before chi on the opposite strand (Spies et al., 2005; Cheng et al., 1987; Dixon and Kowalczykowski, 1993; Anderson et al., 1997B). RecB's slow helicase is seemingly the only activity unaffected by the chi (Cho et al., 2018). The net result of the single helicase action is the creation of a 3' loop ssDNA, which is thought to produce a substrate for RecA loading (Wong et al., 2006).

chi was first identified as a mutation arising on lambda $(\lambda)$ phage genome that increased the plaque size during infection (Lam et al., 1974). The molecular process by which $c h i$ affected this is through the protection of the $\lambda$-phage DNA by inactivation of the RecBCD nuclease, allowing $\lambda$ to persist and initiate lytic rolling circle replication (Chattoraj et al., 1979; Stahl 1979; Murphy 1991; Dabert et al., 1992; Köppen et al., 1995; Kuzminov et al., 1994).

Although extensively characterized, aspects of chi's functional role in the E. coli life cycle remain unaddressed. The non-palindromic sequence means that chi affects RecBCD in an orientation specific manner and is found several times more frequently on the E. coli chromosome than would be expected to occur (Malone et al., 1978; Stahl and Stahl 1977; Kobayashi et al., 1982; Blattner et al., 1997). Additionally, these sequences are heavily over-represented specifically on the leading strand template of the E. coli genome (Blattner et al., 1997). The reason for this orientation specific effect and strand bias is difficult to explain based on current models of recombination. 


\section{$\underline{\text { RecBCD's new found role in completion of replication }}$}

Although all previous work has focused on RecBCD's role in double strand break repair via homologous recombination, this multicomponent enzyme has recently also been characterized to be essential to complete DNA replication by accurately resecting and rejoining over-replicated replication forks (Wendel et al., 2014). This new role was initially inferred from observations that the growth and viability of $\operatorname{rec} B C D$ mutants was severely impaired and plasmids were less stable in the mutants of recD (Wendel et al., 2014). These phenotypes are not seen in $\operatorname{rec} A$ mutants, meaning that some functions of RecBCD appear to be independent of double strand break repair or RecA. As see in Figure 1.1B, using highthroughput sequencing to compare the copy number of the sequences around the chromosome of $E$. coli showed that $\operatorname{rec} B C$ mutants were unable to maintain the region of the chromosome where replication forks converge (Wendel et al., 2014). Importantly, no defects are observed in $\operatorname{rec} A$ mutants, arguing that the inability to maintain this region is not associated with double strand breaks (Wendel et al., 2014). Other mutants, including $\operatorname{rec} D$, xonA $s b c D C$, and $\operatorname{rec} G$, exhibit an over-replication of this region on the chromosome (Wendel et al., 2014; Wendel et al., 2018). However, much is yet to be determined; including the biochemical mechanisms by which RecBCD and these other enzymes catalyze this reaction (Fig 1.1C).

\section{Could chi be involved in completion as well?}

Considering RecBCD's new-found role in completion, and its known interactions with chi, it seems reasonable that chi may affect the completion reaction (Stahl 1979; Kobayashi et al., 1982; Wendel et al., 2014).

In order to examine this question, in this work I describe the construction of plasmid "mini-chromosomes" that contain a bidirectional origin of replication that can be used to 
examine the intermediates and factors required for the completion reaction. I initially verify that these substrates can be used to study the completion reaction by demonstrating that these plasmids require completion enzymes to propagate in cells. The completion enzymes are required for plasmids containing two-replisomes, but not one replisome, indicating that the substrate these enzymes act upon in vivo is specifically created when two replication forks converge. I then utilize these plasmids to examine how chi and or ter sequences affect the ability to complete replication in the presence and absence of the various genes required to complete replication on the chromosome. 


\section{Figures}

Figure 1.1A)

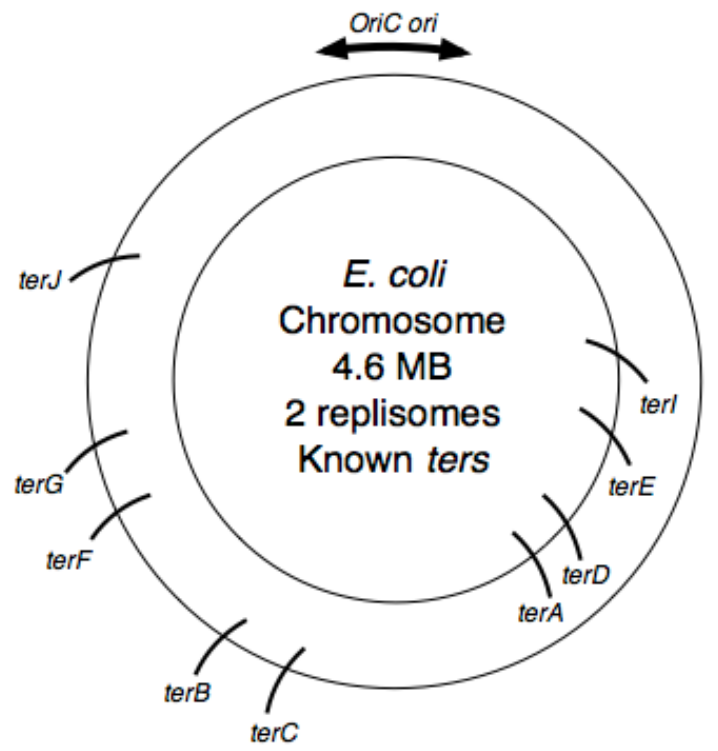

Figure 1.1B)

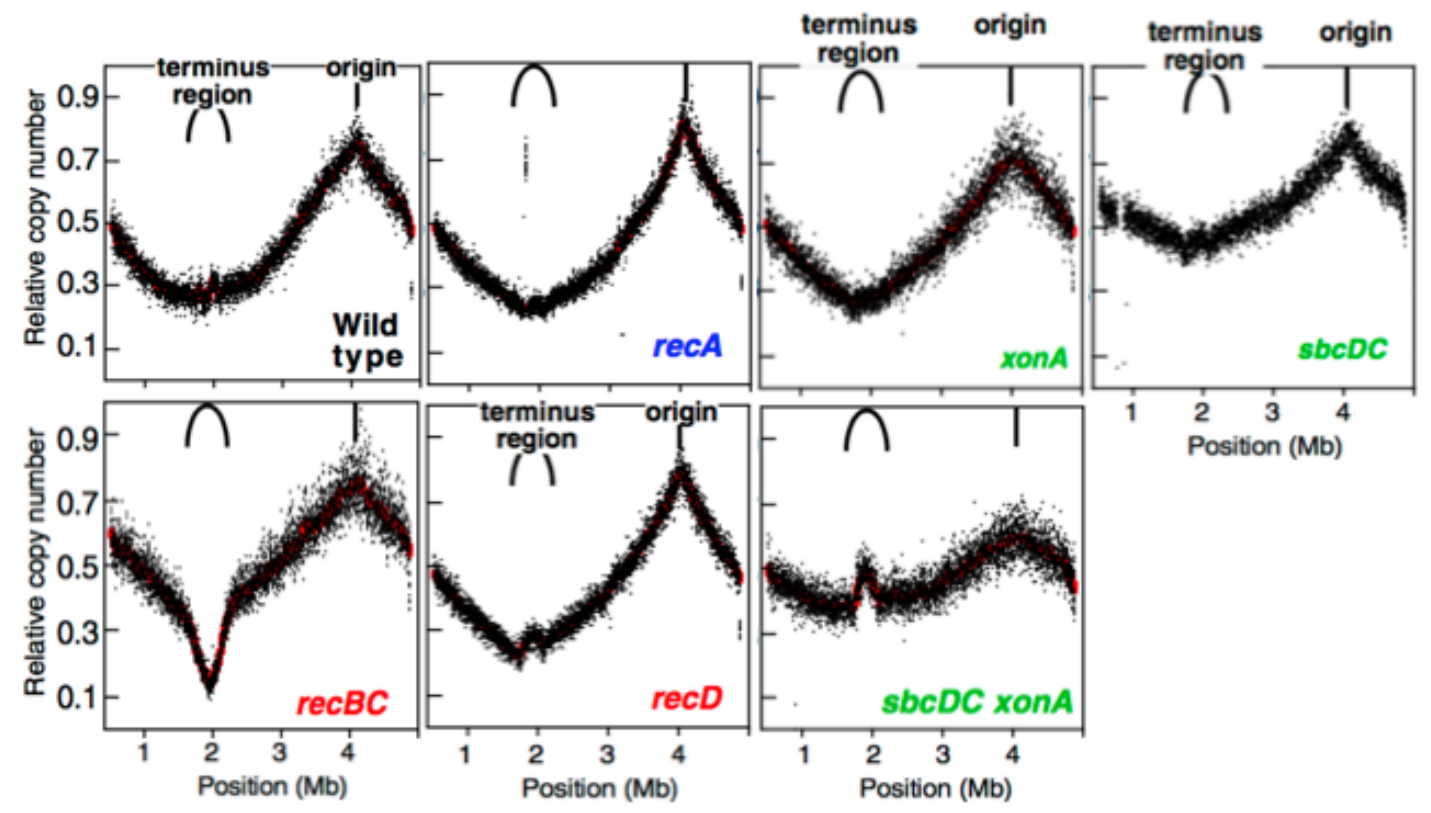


Figure 1.1C)

i.

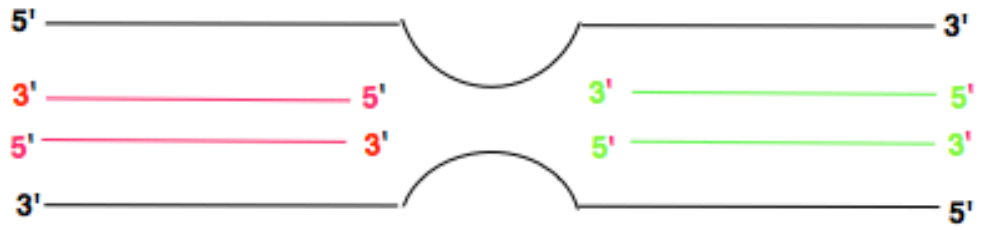

ii.

Replisome Convergence

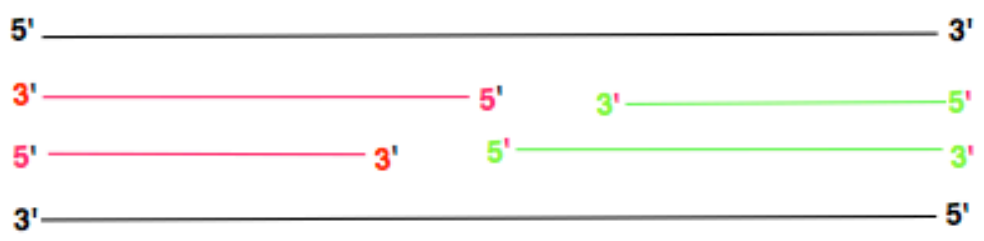

iii.

Transiently bypass each other

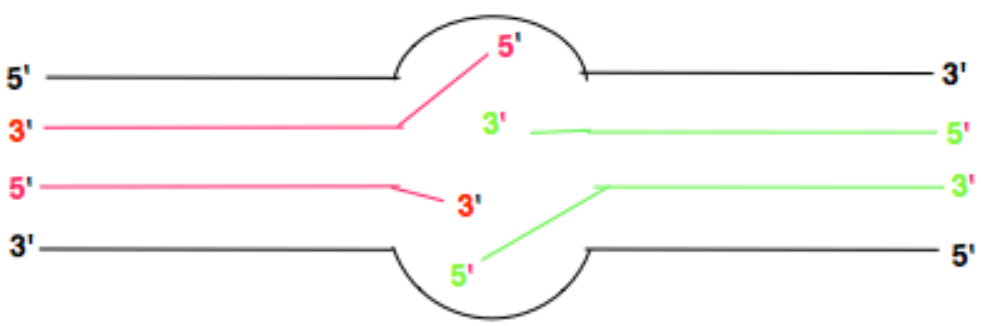

iv. Initial rejections and Exol + SbcCD Incisions

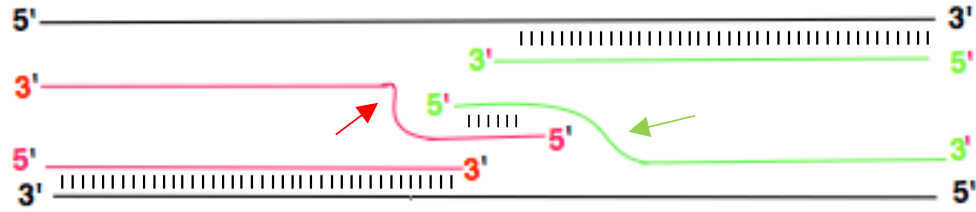

v.

Continued resection and joinging via RecBCD

$\mathbf{5}^{\prime}$

$3^{\prime}$

$3^{\prime}$

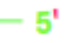

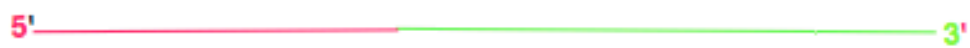

$3^{\prime} \longrightarrow 5^{\prime}$ 
Figure 1.1: The current model for the accurate completion of DNA replication involves RecBCD, ExoI (encoded by $x o n A$ ), and SbcDC in E. coli. (A) Schematic of the Escherichia coli circular chromosome containing a single bidirectional origin of replication and ter sequences which block replication progression in an orientationspecific manner. (B) Replication profiling reveals that $r e c B C$ is required to maintain the region where replication forks converge on the chromosome, whereas $r e c D$, or $s b c D C$ and $x o n A$ are required to resect over-replicated DNA that arises in this region. Genomic DNA from replicating cultures was purified, fragmented, and profiled using highthroughput sequencing. Sequence read frequencies, normalized to stationary-phase cells, are plotted relative to their position on the genome (Wendel et al., 2014). (C) Model of completion of replication. (i-iii) Replication forks converge, bypass each other in the terminus region creating over-replicated regions of the genome. (iv) ExoI and SbcDC incise a structure created by these over-replicated regions to initiate resection. (v) $\mathrm{RecBCD}$ is required to complete resection and promotes joining of the convergent nascent strands. 


\section{Chapter II}

\section{Methods and Materials}

\section{Bacterial strains and Plasmids}

The strains used in this study were all derivatives of W3110; SR108 is a strain incapable of synthesizing its own thymine; thyA36 deoC2 (Mellon and Hanawalt, 1989). All other mutants are derived from this parent and described in Table 2.

Plasmid constructions were performed according to published protocols for in vivo recombineering (Sawitzke et al., 2012), construction by amplification (Casini et al., 2014), and Gibson assembly (Gibson et al., 2009). Plasmid and their features used in this study are listed in Table 2.2. All plasmids containing unidirectional origins of replication were derived from pBR322 (Ampicillin and Tetracycline resistance, pMB1 origin), which has been described previously (Bolivar et al., 1977). pCL07 contains a chi sequence engineered into leading strand of parent pBR322. pCL08 contains a chi sequence engineered into lagging strand of parent pBR322. To accomplish this, primer pairs 5'catgcceggttactggaacggctggtggttgtgagggtaaacaactgg-3' + 5'-cgccgcatacactattctca-3' and 5'ccagttgtttaccctcacaaccaccagccgttccagtaaccgggcatg-3' + 5'-tgagaatagtgtatgcggcg-3' were used for pCL07 and pCL08 respectively, with pBR322 as a template and amplified for 25 cycles using Pfu Turbo Polymerase (Agilent). PCR products were examined and purified by agarose gel electrophoresis. The amplified fragments were combined with DpnI digested pBR322, and the fragments were then joined and transformed using Gibson assembly (New England Biolabs) to generate pCL07 and pCL08. Plasmids were sequenced to verify sequence changes.

All plasmids containing bidirectional origins of replication are derived from pCB104 (Potrykus et al., 2002) and contain an ampicillin-resistant cassette from pBR322. 
pCL03 was constructed using primer pairs 5'-gtcggttcagggcagggtcgtggacggtctgacagttaccaatgc-3' and 5'-ggcggtttgcgtattgggcgeggtctgacagttaccaatgc-3' to amplify the $\operatorname{ampR}$ gene from pBR322. $0.2 \mu \mathrm{g}$ gel purified PCR product was then combined with $0.5 \mu \mathrm{g}$ BamHI-digested pCB104 and amplified for 25 cycles using Pfu Turbo Polymerase (Agilent). PCR products were examined by agarose gel electrophoresis and products running larger than $5 \mathrm{~kb}$ were gel purified and transformed into recombineering strain DY329 (Yu et al., 2000) to generate the ampicillin resistant plasmid, pCL03. pCL01 was made by removing a chi sequence proximal to the origin using primer sets 5'attgctgataaatctgga-3' $+5^{\prime}$-ctttggaatccagtccctcttcctcctgctgatctgcgacttatcaac-3' and $5^{\prime}-$ tccagatttatcagcaat-3' $+5^{\prime}$ '-gttgataagtcgcagatcagcaggaggaagagggactggattccaaag- $3^{\prime}$ to amplify overlapping fragments of the plasmid template using Pfu Turbo Polymerase (Agilent). The fragments were then joined and transformed using Gibson assembly (New England Biolabs) to generate pCL01. pCL05 was constructed by inserting a chi sequence into the terminus region of plasmid pCL03, using plasmid pairs 5'-ctgcgctcggecettccggctgccaccagcattgctgataaatctgga-3' + 5'-tccagatttatcagcaatgctggtggcagcggaagggecgag-cgcag-3' and 5'-gttgataagtcgcagatcagcaggaggagaagagggactggattcc-aaag-3' $+5^{\prime}-$ ctttggaatccagtccetcttcctcetgctgatctgcgacttatcaac-3' to amplify overlapping fragments which were joined and transformed using Gibson assembly (New England Biolabs) to generate pCL05; mutation to inactive $c h i$ near $\lambda$ bacteriophage origin of parental plasmid pCL03 as well as mutation to active chi inside the ampicillin cassette. pCL02, pCL04, and pCL06 are identical to pCL01, pCL03, and pCL05 but contain terB and terC sequences inserted flanking the $a m p R$ in the terminus region. pCL04 was constructed using primer pairs 5'-gtcggttcagggcagggtcgtggatccactttagttacaacatacttattcgcggaaccctatttgttt-3' and 5'ggcggtttgcgtattgggcgcatattagttacaacatcctatatggtctgacagttaccaatgc-3'to amplify the ampR 
gene from pBR322. $0.2 \mu \mathrm{g}$ gel purified PCR product was then combined with $0.5 \mu \mathrm{g}$ BamHI-digested pCB104 and amplified for 25 cycles using Pfu Turbo Polymerase (Agilent). PCR products were examined by agarose gel electrophoresis and products running larger than $5 \mathrm{~kb}$ were gel purified and transformed into recombineering strain DY329 (Yu et al., 2000) to generate the ampicillin resistant plasmid, pCL04. Primer pairs 5'-ctgcgctcggecettccggctgccaccagcattgctgataaatctgga-3' +5'-tccagatttatcagcaatgct-ggtggcagcggaagggecgagcgcag-3' and 5'-gttgataagtcgcagatcagcaggaggagaagagggact-ggattccaaag-3' $+5^{\prime}$-ctttggaatccagtccctcttcctcctgctgatctgcgacttatcaac-3' were used to amplify overlapping fragments of each plasmid. Fragments were joined with pCL04 as a template and transformed using Gibson assembly (New England Biolabs) to generate pCL02 and pCL06.

\section{Transformation efficiency assay}

Electro-competent cells were prepared by growing a 100-fold dilution of a fresh overnight culture in $10 \mathrm{~mL} \mathrm{LB}$ with thymine (LBthy) to an OD 600 of 0.4. Cells were then pelleted, and serially washed with $30 \mathrm{~mL}$ water, $30 \mathrm{~mL} 10 \%$ glycerol, and then resuspended in $200 \mu \mathrm{L}$ of $10 \%$ glycerol and stored at $-80^{\circ} \mathrm{C} .40 \mu \mathrm{L}$ of competent cells were mixed with $50 \mathrm{ng}$ of plasmid and electroporated at $1.8 \mathrm{kV} 25 \mu \mathrm{FD} 200 \mathrm{Ohms}$ and allowed to recover at $37{ }^{\circ} \mathrm{C}$ for $30-60$ minutes in $1 \mathrm{~mL}$ SOC media. The transformation reactions were then diluted and aliquots were spread on LB thy plates with and without $50 \mathrm{ug} / \mathrm{mL}$ ampicillin to determine the number of transformants and viable cells, respectively. Colonies were counted following overnight incubation at $37^{\circ} \mathrm{C}$. The same preparations of competent cells and plasmid preparations were used for comparisons between strains and plasmids. The relative transformation efficiency of each strain was calculated as the ration of the 
transformants per viable cells in the mutant cultures to the transformants per viable cells in wild-type cultures.

\section{Plasmid stability assay}

Cells from overnight cultures of strains containing the plasmid grown in LBthy medium with $50 \mu \mathrm{g} / \mathrm{ml}$ ampicillin were pelleted and used to inoculate $10 \mathrm{ml}$ cultures of LBthy medium at 1:1000 dilution. Cultures were grown without ampicillin selection at $37^{\circ} \mathrm{C}$ with aeration overnight. The resulting cultures were then sampled to determine the ratio of cells retaining the plasmid and used to reinoculated $10 \mathrm{ml}$ LBthy medium at 1:1000 dilution. This was repeated for three iterations. To determine plasmid retention, $10-\mu l$ aliquots of serial 10-fold dilutions were spotted on LBthy plates in the presence or absence of $50 \mu \mathrm{g} / \mathrm{ml}$ ampicillin. Colonies were counted following overnight incubation at $37{ }^{\circ} \mathrm{C}$ to determine the percent of plasmid-containing cells (Wendel et al., 2014).

\section{Total genomic DNA extraction}

$750 \mu \mathrm{l}$ of cultures was mixed with $750 \mu \mathrm{l}$ of cold $2 x$ NET (100 mM NaCl, $10 \mathrm{mM}$ Tris, $\mathrm{pH}$ 8.0, $10 \mathrm{mM}$ EDTA). Cells were pelleted and frozen at $-80{ }^{\circ} \mathrm{C}$. Samples were resuspended in $140 \mu \mathrm{l}$ of lysozyme $(1 \mathrm{mg} / \mathrm{mL})$ and RNaseA $(0.2 \mathrm{mg} / \mathrm{mL})$ in TE $(10 \mathrm{mM}$ Tris, $\mathrm{pH} 8.0,1 \mathrm{mM}$ EDTA) and lysed for 30 minutes at $37^{\circ} \mathrm{C}$. Then Sarkosyl $(10 \mu \mathrm{l}$ of $20 \%[\mathrm{wt} / \mathrm{wt}])$ and Proteinase $\mathrm{K}(10 \mathrm{ul}$ of $10 \mathrm{mg} / \mathrm{mL})$ was added and incubation continued for 60 minutes. Samples were then serially extracted with 4 volumes phenol/chloroform (1/1) and 4 volumes chloroform followed by dialysis for 1 hour on $47 \mathrm{~mm}$ Whatman 0.05 um pore disks (Whatman \#VMWP04700) which were floated on a 250-mL beaker of TE (1 mM Tris, pH 8.0, 1 mM EDTA). 


\section{Southern analysis of plasmid replication intermediates}

Total genomic DNA was digested with SacII (New England BioLabs) for strains containing pBR322 derived plasmids or NheI (New England BioLabs) for pCB104 derived plasmids. In both cases, plasmids lack restriction sites for these enzymes. Samples were then extracted with 1 volume of chloroform before equal cell equivalents were loaded on to $0.5 \%$ and $1.0 \%$ TAE/TBE (220 mM Tris, $180 \mathrm{mM}$ Borate, $5 \mathrm{mM}$ EDTA, $\mathrm{pH} 8.3$ ) agarose gels and electrophoresed at $1 \mathrm{~V} / \mathrm{cm}$. Gels were transferred to Hybond $\mathrm{N}+$ nylon membranes (Amersham GE Healthcare) and probed with either the pBR322 or the pCL01 P32-labelled plasmid. Radioactive labeling was carried out by nick translation kit (PerkinElmer) (Spivak and Hanawalt, 1995). Radioactivity was visualized using a Storm 840 and its associated ImageQuant Software (Molecular Dynamics).

\section{Copy number analysis}

Strains containing the plasmids or containing a chromosomal copy of the ampR gene (HL946 or CL007) were grown and the genomic DNA purified as described above. Plasmid DNA and chromosomal DNA was digested with EcoRV (New England Biolabs) to linearize plasmid and chromosome species. DNA was then analyzed by standard Southern analysis and quantified as described above.

\section{Strain growth assay}

Cultures containing 1 or 2-replisome plasmids, or neither, were grown in LB plus selection over 800 minutes and continuously cataloged in 20 -minute intervals for absorbance in OD. The strain of E. coli used for this assay was also used to quantify the copy number analysis which has the $a m p R$ gene (HL946 OR CL007). Growth curves 
were graphed showing each cultures ability to replicate until plateauing into stationary phase. 


\section{Tables}

Table 2.1: $E$. coli strains used in this study

\begin{tabular}{|l|l|l|}
\hline Courcelle Catalogue & Genotype & Source \\
\hline CL001 (SR108) & WT & Mellon \& Hanawalt, 1989 \\
\hline CL002 & $\operatorname{recA}$ & Franklin, 1967 \\
\hline CL003 & $\operatorname{recBC}$ & Kushner, 1974 \\
\hline CL004 & $\operatorname{recD}$ & Thaler et al., 1989 \\
\hline CL039 & xonA & Kushner S et al., 1972 \\
\hline CL2344 & $\operatorname{sbcCD}$ & Gibson et al., 1992 \\
\hline CL2357 & xonA sbcCD & Jensen 1993 \\
\hline CL008 & $\operatorname{recG}$ & Chua., et al 1993 \\
\hline CL2542 & $\operatorname{recBC}$ xonA sbcCD & Wendel et al., 2018 \\
\hline
\end{tabular}

\begin{tabular}{|c|c|c|c|c|}
\hline $\begin{array}{l}\text { Courcelle } \\
\underline{\text { Catalogue }}\end{array}$ & Construction & $\frac{\text { Replisome }}{\underline{\mathbf{S}}}$ & $\frac{\underline{\text { Ter }}}{\text { sequenc }}$ & $\underline{c h i}$ \\
\hline pBR322 & (Bolivar et al., 1977) & + & & \\
\hline \multirow[t]{4}{*}{ pCL07 } & $\begin{array}{l}5 \text { '-catgcccggttactggaacggctggtg gtt- } \\
\text { gtgagggtaaacaactgg-3'+ }\end{array}$ & + & & $\begin{array}{c}\stackrel{t}{\text { Leading }} \\
\text { strand }\end{array}$ \\
\hline & 5'-cgccgcatacactattctca-3' & & & \\
\hline & $\begin{array}{l}5 \text { '-ccagttgtttaccctcacaaccaccag- } \\
\text { ccgttccagtaaccgggcatg-3' }\end{array}$ & & & \\
\hline & 5 -tgagaatagtgtatgeggeg-3' & & & \\
\hline \multirow[t]{4}{*}{ pCL08 } & $\begin{array}{l}5 \text { '-ccagttgtttaccetcacaagctggtg gc- } \\
\text { gttccagtaaccgggcatg-3' }\end{array}$ & + & & $\begin{array}{c}\stackrel{ \pm}{\text { Lagging }} \\
\text { strand }\end{array}$ \\
\hline & 5'-cgccgcatacactattctca-3' & & & \\
\hline & $\begin{array}{l}5 \text { '-catgcccggttactggaacgccaccagctt } \\
\text { gtgagggtaaacaactgg-3, }\end{array}$ & & & \\
\hline & $5^{\prime}$-tgagaatagtgtatgcggcg-3' & & & \\
\hline \multirow[t]{4}{*}{ pCLO1 } & 5 '-attgctgataaatctgga-3' + & ++ & & \\
\hline & $\begin{array}{l}5 \text { '-gttgataagtcgcagatcagca } \\
\text { ggaggagaagagggactggattccaaag-3' }\end{array}$ & & & \\
\hline & 5'-tccagattatcagcaat-3' + & & & \\
\hline & $\begin{array}{l}5 \text { '-ctttggaatccagtccetcttcetcctgetgatctgcgacttatcaac- } \\
3\end{array}$ & & & \\
\hline \multirow[t]{2}{*}{ pCLO2 } & 5'-attgctgataaatctgga-3' + & ++ & ++ & \\
\hline & $\begin{array}{l}\text { 5'-gttgataagtcgcagatcagcaggaggagaagag- } \\
\text { ggactggattccaaag-3' }\end{array}$ & & & \\
\hline
\end{tabular}




\begin{tabular}{|c|c|c|c|c|}
\hline & 5'-tccagattatcagcaat-3' + & & & \\
\hline & $\begin{array}{l}\text { 5'-ctttggaatccagtccetcttcctcctgctga- } \\
\text { tctgcgacttatcaac-3' }\end{array}$ & & & \\
\hline pCL03 & $\begin{array}{l}5 \text { '-gtcggttcagggcagggtcgtggatccegcggacccctatttgttt- } \\
\text { 3' and 5'-ggcggtttgcgtattgggeg- } \\
\text {-cggtctgacagttaccaatgc-3' }\end{array}$ & ++ & & $\begin{array}{l}\text { +proximal } \\
\text { to origin }\end{array}$ \\
\hline pCL04 & $\begin{array}{l}\text { 5'gtcggttcagggcagggtcgtggatccactttagttaca- } \\
\text {-acatacttattcgcggaacccetatttgttt-3' } \\
5 \text { 'ggcggtttgcgtattgggcgcatattagttacaacatc- } \\
\text {-ctatatggtctgacagttaccaatgc-3' }\end{array}$ & ++ & ++ & $\begin{array}{l}\text { +proximal } \\
\text { to origin }\end{array}$ \\
\hline \multirow[t]{4}{*}{ pCL05 } & $\begin{array}{l}5 \text { '-ctgcgctcggeccttccg-gctgccaccagcatt- } \\
\text { gctgataaatctgga-3'+ }\end{array}$ & & & $\frac{\text { terminus }}{\text { region }+}$ \\
\hline & $\begin{array}{l}\text { 5'-ctttggaatccagtccetcttcetcetgctga- } \\
\text { tctgcgacttatcaac-3' }\end{array}$ & & & \\
\hline & $\begin{array}{l}5 \text { '-tccagatttatcagcaatgctggtggcagc- } \\
\text { ggaagggecgagcgcag-3'+ }\end{array}$ & & & \\
\hline & $\begin{array}{l}5 \text { '-gttgataagtcgcagatcagcaggaggagaag- } \\
\text { agggactggattccaaag-3' }\end{array}$ & & & \\
\hline \multirow[t]{4}{*}{ pCL06 } & $\begin{array}{l}5 \text { '-ctgcgctcggccettccggetgccaccagcatt- } \\
\text { gctgataaatctgga-3' + }\end{array}$ & ++ & ++ & $\frac{\text { terminus }}{\text { region }+}$ \\
\hline & $\begin{array}{l}5 \text { '-ctttggaatccagtccetcttcetcetgetgatctgcgacttatcaac- } \\
3 \text {, }\end{array}$ & & & \\
\hline & $\begin{array}{l}\text { 5'-tccagatttatcagcaatgctggtggcagcgg- } \\
\text { aagggccgagcgcag-3'+ }\end{array}$ & & & \\
\hline & $\begin{array}{l}5 \text { '-gttgataagtcgcagatcagcaggaggaga- } \\
\text { agagggactggattccaaag-3' }\end{array}$ & & & \\
\hline
\end{tabular}

+: One-replisome plasmid

\section{++: Two-replisome plasmid}

\section{t: Chi inserted}




\section{Chapter III}

Results

\section{Part I - One-replisome versus two-replisome plasmids during completion of replication}

Plasmids containing two-replisomes can be stably transformed, replicated, and grown in cells similar to one-replisome plasmids.

Completion of replication on the chromosome involves an enzymatic process that involves two convergent replisomes resolving with high fidelity (Wendel et al., 2014). The convergent replisomes are thought to transiently bypass each other, before the excess DNA is resected and joined at the point where all DNA has precisely doubled (Wendel et al., 2014). Completion on the chromosome of $E$. coli can be challenging to study because the event occurs once per cell cycle and its location can vary over a $400 \mathrm{~kb}$ stretch of the genome (Campbell and Kleckner, 1990). In order to study the process and enzymes involved in this reaction in more detail, it would be useful if it could be studied on plasmids, which contain higher copy numbers and are only a few kilobases in size. However, most plasmids contain unidirectional origins of replication and are replicated by a single replisome, avoiding the event where two replisomes may converge (Reviewed in del Solar et al., 1998). $\lambda$ phage contains a bidirectional origin of replication that is functionally homologous to that on the E. coli chromosome (Furth et al., 1977; Tabata et al., 1983; Meijer et al., 1979), and has previously been shown to replicate as a minichromosome when placed on a plasmid (Moore et al., 1977). Dr. Brian Wendel therefore constructed a $5 \mathrm{~kb}$ plasmid containing the $\lambda$ origin to determine if it could be used as a model to study the completion reaction (Fig 3.1A), and initially characterized how well it could transform cells, whether it affected cell growth, and the copy number at which it is propagated in cells. 
To examine how the plasmid with two replisomes affected cell growth, we compared the growth of cell cultures containing the two-replisome plasmid, to that of cultures containing the one-replisome plasmid pBR322 utilizing pMB1 (close relative of ColE1) ori (Bolivar et al., 1977), or no plasmid at all. Cultures were grown over 800 minutes and continuously cataloged in 20-minute intervals for absorbance. As shown in Figure $3.1 \mathrm{~B}$, the growth rate of each culture was similar; indicating that the tworeplisome plasmid does not impair growth of the host during replication.

To determine how efficiently the two-replisome plasmid was transformed, $50 \mathrm{ng}$ of plasmid were transformed in $40 \mathrm{ul}$ of wild-type competent cells via electroporation in $2 \mathrm{~mm}$ gap cuvettes at 2.5 kilovolts. After a 60 -minute recovery period, dilutions of the culture were then plated on $\mathrm{LB}$ with $50 \mathrm{ug} / \mathrm{mL}$ of ampicillin as well as on LB plates to determine ratio of viable cells that were transformed (Figure 3.1C). Under transformation similar conditions, both the one-replisome and two-replisome plasmid transformed with similar efficiencies, $\sim 200-400$ transformants $/ 10^{6}$ viable cells, demonstrating the tworeplisome plasmid could enter and initially establish replication similar to other plasmids.

To determine the copy number at which the two-replisome plasmid was maintained, we used Southern analysis in which we used a ${ }^{32} \mathrm{P}$-labeled ampicillin resistance gene as a probe to compare the radioactive intensity of the signal on the plasmid to the signal from a single copy ampicillin resistance gene integrated into the chromosome. To this end, total genomic DNA was purified from cells containing the plasmid pBR322, pCL01, or without plasmid but having an ampicillin resistance gene on the chromosome. The genomic DNA was then digested with a restriction enzyme that linearized each plasmid and then analyzed by Southern analysis following agarose-gel electrophoresis. A representative gel is shown in Figure 3.1D. Overall, we found through 
the radioactive intensity of the signals that the two-replisome plasmid was maintained about 89 copies per chromosome, compared to about 63 copies for pBR322 (Fig. 3.1E). Taken together, the two-replisome plasmid transform, propagate, and are maintained similar to the one-replisome plasmid, pBR322.

Plasmids replicated by two replisomes are less stable than one replisome plasmids and contain more aberrant, multimeric species.

To determine how stably the plasmid is maintained during replication, we monitored the rate of plasmid loss over time in the absence of selection. To this end, wild-type cultures containing either pBR322 or pCL01 were diluted 1/1000 and grown in media without selection overnight, before the process was repeated the next day; similar to the previously published plasmid stability protocol (Wendel et al., 2014). On each passage, dilutions of a passaged sample, to promote proliferation of generations, sample were plated to determine the ratio of cells that maintained the plasmid. Figure 3.2A shows an example of these dilutions for cultures containing both the one-replisome and two-replisome plasmid. We quantified and plotted these ratios over time and the results are shown in Fig 3.2B. Whereas the one-replisome plasmid was stably maintained over the $\sim 30$ generation assay, the proportion of cells that maintained the two-replisome plasmid was reduced by $\sim$ two orders of magnitude over this same time period.

The results shown in Figure 3.1B-E argue that the instability of the two-replisome plasmid, relative to the one-replisome plasmid is unlikely to be due to detrimental effects on cultures growth rates or comparatively lower copy numbers. Further, neither pBR322 or pCL01 encode any partitioning mechanisms, which would control plasmid segregation 
between daughter cells, that could account for the difference in stability (Nordstrom et al., 1980; Austin et al., 1986).

Although the overall copy number between these plasmids were similar, we did observe noticeable differences in the proportion of aberrant non-monomeric, amplified substrates that appeared during the propagation of each plasmid. To examine the form in which the plasmid DNA was maintained in each cell, total genomic DNA was purified from cultures containing each plasmid, and the plasmid DNA was then analyzed by Southern analysis following agarose gel electrophoresis using $\mathrm{P}^{32}$-labeled pBR322 and pCL01 as probe. Representative gels from each are shown in Figure 3.2C and the results are plotted in Figure 3.2D. Overall, the two-replisome plasmid contains elevated amounts of abnormal, multimeric species relative to the one-replisome plasmid.

Similar to the completion of replication on the chromosome, amplifications and genetic instability on two-replisome plasmid are driven by an aberrant RecA-mediated recombination mechanism.

On the chromosome most of the genetic instability and amplifications that arise in the region where replication completes is driven by an aberrant form of RecA-mediated recombination (Wendel et al., 2014; Wendel et al., 2018). To determine if RecA plays a similar role on the plasmid, we examined how its presence or absence affected the stability of the plasmid when grown in the absence of selection, as before. As shown in Figure 3.3A, inactivation of RecA increased the stability of the two-replisome plasmid. The increase in stability brought the two-replisome plasmid to a level that was comparable to the one-replisome plasmid once the ability for homologous recombination was taken away. 
We next examined how the form of the plasmid was maintained became affected by the presence of RecA. To this end, total genomic DNA was purified from both wildtype and $r e c A$ mutant cultures containing plasmid and analyzed by Southern analysis as previously described. The increased stability in the absence of RecA correlated with an overall reduction in the amount of amplified, multimeric species (Figure 3.3B and C). A similar reduction in multimeric plasmid species was also seen with the one-replisome plasmid. The observations are consistent with the idea that RecA is driving the instability on two-replisome plasmid and that the instability arises due to amplification or multimeric species generated in its presence (Wendel et al., 2018).

Transformation of plasmids with two replisomes, but not one replisome, depends on the enzymes required to complete replication on the chromosome.

On the chromosome, the completion of replication requires the RecBCD helicasenuclease (Wendel et al., 2014; reviewed in Courcelle et al., 2015). In its absence, the genomic region where replication forks converge cannot be maintained, is extensively degraded, and growth is severely compromised. Nucleases $\mathrm{SbcCD}$ and ExoI are also required to initiate the completion reaction. In the absence of these gene products, maintaining the region where replication forks converge becomes dependent on the aberrant RecA-mediated reaction. In the absence of RecA, growth is severely compromised in these mutants (Wendel et al., 2014; Wendel et al., 2018). In order to determine if these genes are also involved in completing replication in the two-replisome plasmid, we examined the ability of the two-replisome plasmid to transform mutant strains deficient in completion enzymes. As a control, we also examined the ability of the one-replisome plasmid to transform into these mutants. $50 \mathrm{ng}$ of plasmid DNA was 
transformed by electroporation into each mutant and the transformation efficiency for each strain was determined, relative to wild-type. In the case of the one-replisome plasmid, transformant samples were obtained for each of the mutants examined, and successful transformation in each case occurred independently of recombination or RecA (Figure 3.4A). However, in plasmid replication involving two replisomes, we observed transformants in most of the mutants examined. Additionally, in $\operatorname{rec} B C$ mutants the transformation efficiency was reduced by greater than two orders of magnitude. In some attempts, a few rare microcolonies could be observed on the selective plates following 3 days incubation (as opposed to the normal overnight incubation). However, in these cases, we were unable to grow the transformants in liquid media beyond a single passage (data not shown). Similarly, in mutants lacking the SbcDC ExoI nucleases, transformation efficiency became dependent on the presence of recombination and RecA (Figure $3.4 \mathrm{~A}$ ). No other mutants examined depended on RecA for transformation of the two-replisome plasmid. These genetic requirements for transformation of the tworeplisome plasmid are required to complete replication on the chromosome and suggest that they are similarly required to complete replication on the two-replisome plasmid. Further, the results would argue that the substrates acted upon by these enzymes, in vivo, are specifically created when two replisomes converge, since one-replisome plasmids do not exhibit any requirement for their presence.

\section{Part II: The effect of Replication fork traps and the Completion reaction}

Two-replisome plasmids with two additional ter sequences, terB and ter $C$ from the Escherichia coli chromosome, are replicated and maintained at similar frequencies as two-replisome plasmids without replication fork trap capabilities. 
ter sequences, and their homologs, are found on several bacterial genomes, including E. coli and Bacillus subtillis (Coskun-Ari et al., 1994) and function as replication fork "traps" which bind to a protein called Tus, and halt replisomes approaching from one side, in a polar manner (Kuempel et al., 1977; MacAllister et al., 1990). Their presence ensures replisome convergence at the terminus area of the chromosome. However, deletion of the tus reveals Tus-ter mutants have no observable phenotype on growth or viability, arguing that replication fork traps are not essential (Iismaa et al., 1987; Roecklein et al., 1991). Previous experiments have examined ter elements in unidirectional plasmids. Perhaps not surprisingly, when ter is oriented in a manner that blocks replisomes prior to the point of convergence this causes replication difficulties and induces the SOS response (Hill and Marians., 1990; MacAllister et al., 1990; Hasebe et al., 2018). In order to study how the Tus-ter traps affect the completion reaction in E. coli, we engineered two ter sequences into the two-replisome plasmids in a trapping orientation, similar to that found on the chromosome. The placement of ter $B$ and $\operatorname{terC}$ flanking the terminus region, on the two-replisome plasmid is shown in Figure 3.5A. As replication fork "trap" (Tus-ter) is dependent on the host derived protein Tus. The tus gene is autoregulated and induced in the presence of unbound ter sequences (Natarajan et al., 1991; Roecklein et al., 1991). Thus, the presence of additional ter sequences in the newly constructed pCL02, would be expected to contain sufficient levels of Tus to ensure that the polar arrest off the replication occurs at these sequences (Figure 3.1E).

To determine how the presence of ter traps affects the stability of plasmids containing two replisomes, we monitored the rate of plasmid loss overtime in the absence of selection with similar protocols as described in the previous section. As shown in Figure 3.5B the two-replisome plasmid containing the ter trap approximately 10-fold less 
stable than the non-ter containing plasmid during the $\sim 30$ generations of the experiment. In $r e c A$ mutants, which are deficient in homologous recombination, there is an increase in plasmid stability similar to that seen in non-ter containing plasmids.

Plasmids replicated by two replisomes with the addition of ter sequences contain more RecA-driven aberrant, multimeric species.

I next examined how the presence of ter sequences effect the form of replicating plasmids that contain two replisomes. To this end, plasmids in replicating cultures were purified and examined by Southern analysis as described above. As shown in Figure 3.5C, plasmids containing a ter trap contain a larger fraction of multimeric species, however, these species migrate with a pattern that suggests they are intermediates that form unit circles of dimers, trimers, and tetramers. By contrast, most of the multimeric species in the plasmids lacking ter sequences migrate as a high linear multimers or branched species. In $r e c A$ mutants, fewer multimeric intermediates were observed irrespective of the presence of ter sequences. In Figure 3.5D, I quantified the overall levels of abnormal (non-monomeric) species in each strain. Overall, the results reflect the RecA-catalyzed propagation of abnormal species in both pCL01 vs pCL02. Further, the proportion of abnormal products correlates with the overall level of instability consistent with what is observed on the chromosome; seen more specifically by the overamplified products around the terminus region versus the amplified intermediates of the plasmid substrates.

\section{Part III: The effect of $c h i$ sequences on completing replication}

chi sequences located at sites where replication forks converge promote a RecA-mediated aberrant replication that correlates with instability 
Completion of DNA replication requires RecBCD (Wendel et al., 2014, Courcelle., 2015; Wendel et al., 2018). chi sequences, 5'-GCTGGTGG-3' alter the activity of the RecBCD complex and during recombinational processes; they are associated with the locations where cross-over events are joined to form recombinant molecules (Stahl et al., 1975; Stahl and Stahl, 1975; Stahl et al., 1983; Smith et al., 1984; Ponticelli et al., 1985; Taylor et al., 1985). These sequences are highly over-represented in the chromosome and, intriguingly, their presence is heavily biased on the leading strand of the replication (Smith 2012; Courcelle et al., 2015). This bias is difficult to reconcile with its role in the double-strand break repair, since a break would have two double strand ends, whose 3' ends would be both a chi enriched strand and a chi-depleted strand. Considering RecBCD's role in replication, it is worth considering that $c h i$ sequences may play a role in the completion reaction. In order to examine the influence chi sequences may have on the completion reaction, chi sequences were engineered into the two-replisome plasmid pCL01, proximal to the origin, pCL03, and opposite the origin pCL05 (Fig 3.6A) to evaluate influence inside and outside the convergence zone. As controls, I also engineered chi sites into both the leading strand and lagging strand of the one-replisome plasmid pBR322, to generate pCL07 and pCL08 respectively (Fig 3.6B).

To determine how chi affects the stability of the two-replisome plasmid, each plasmid was monitored over $\sim 15$ generations on plates with and without selection to compare viable cells versus cells still containing plasmid, as done previously. As shown in Figure 3.6C, I observed that the presence of chi destabilized the plasmid. The destabilizing effect was more prominent when chi was located in the terminus region of the plasmid than when it was proximal to the origin. 
To determine if the destabilizing effects of chi was dependent on the aberrant RecA-mediated form of replication, we also examined the stability in recA mutants. I observed that the absence of RecA improved the maintenance of all the plasmids, although it did not eliminate all of the instability observed with one of the chi containing plasmids. The results argue that chi destabilization is at least partially dependent on RecA, but that chi has some effect even in the absence of RecA.

To examine whether the chi-destabilization of the plasmids altered its form during the replication in vivo, we purified the DNA from replicating cultures and examined it by Southern analysis. As shown in Figure 3.6D and E, in the presence of chi, an aberrant high molecular weight intermediate was formed. The intermediate was most prominent when chi was present in the terminus region of the chromosome, but could still be observed when the $c h i$ site was located proximal to the origin of replication. The presence and intensity of the specific aberrant intermediate correlated with the destabilization effect $c h i$ has on the stable propagation of the plasmid.

The effect of $c h i$ appeared to be specific to the plasmid with two-replisomes as no effect on plasmid stability was observed when chi sequences were present in either the leading or lagging strand on the one-replisome plasmid (Fig 3.6F, Fig 3.6G and Fig $6.7 \mathrm{H})$. The observation suggests that $\mathrm{Rec} \mathrm{BCD}$ processing during the completion reaction is altered upon encountering a chi site in a manner that promotes further replication. At least on the plasmid mini-chromosome substrate, this replication is destabilizing in its effect.

Addition of a terB and terC trap reduces the destabilizing effect of chi by limiting the amount of aberrant replication that can occur 
ter sequences are oriented to "trap" replication forks within the region where forks converge. Similarly, the orientation of chi sites is heavily biased towards the direction of replication. Considering these orientation biases, we next examined if ter may influence the effect $c h i$ has on the completion reaction. To this end, ter $B$ and terC traps were engineered into the two-replisome plasmids containing chi sites (Figure 3.7A and the effect on stability and replication was examined as before. As shown in Figure 3.7B, the addition of the ter traps reduced the destabilizing effect of chi overall. Further, the presence of the ter trap also reduced the destabilizing effect of RecA. When I examined the form of the plasmids in replicating cultures, I found that the ter trap similarly reduced or eliminated the presence of the aberrant over-replicated species (Fig 3.7C). The observations suggest that the presence of ter reduces the instability of the tworeplisome plasmid by preventing or limiting the amount of aberrant RecA-mediated replication that occurs during the completion reaction. 
Figures

3.1A)
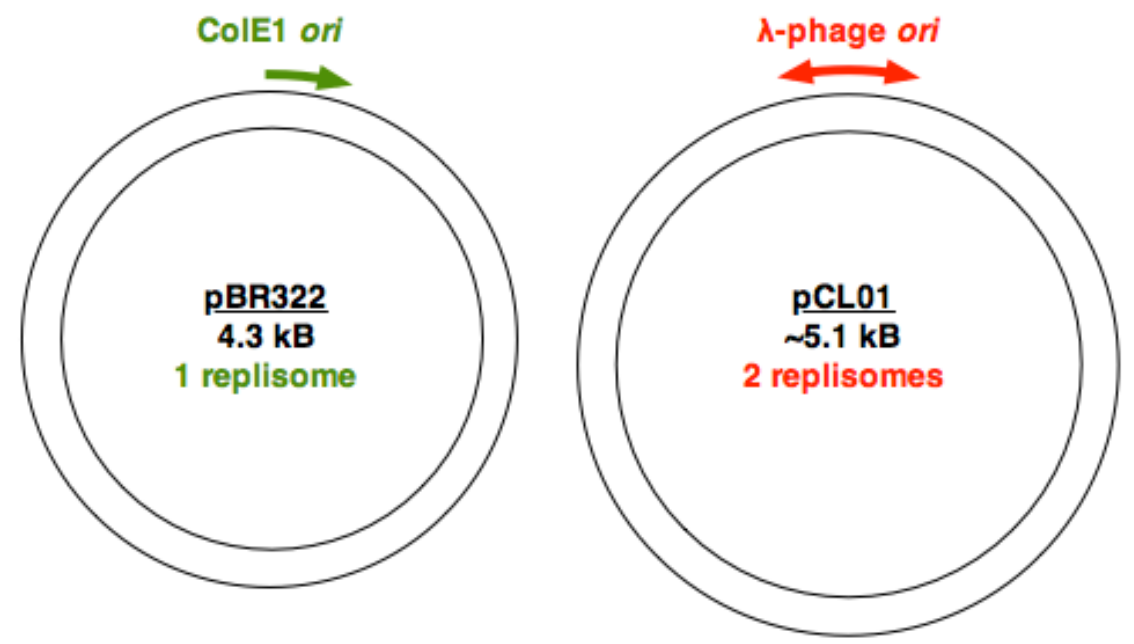

3.1B)

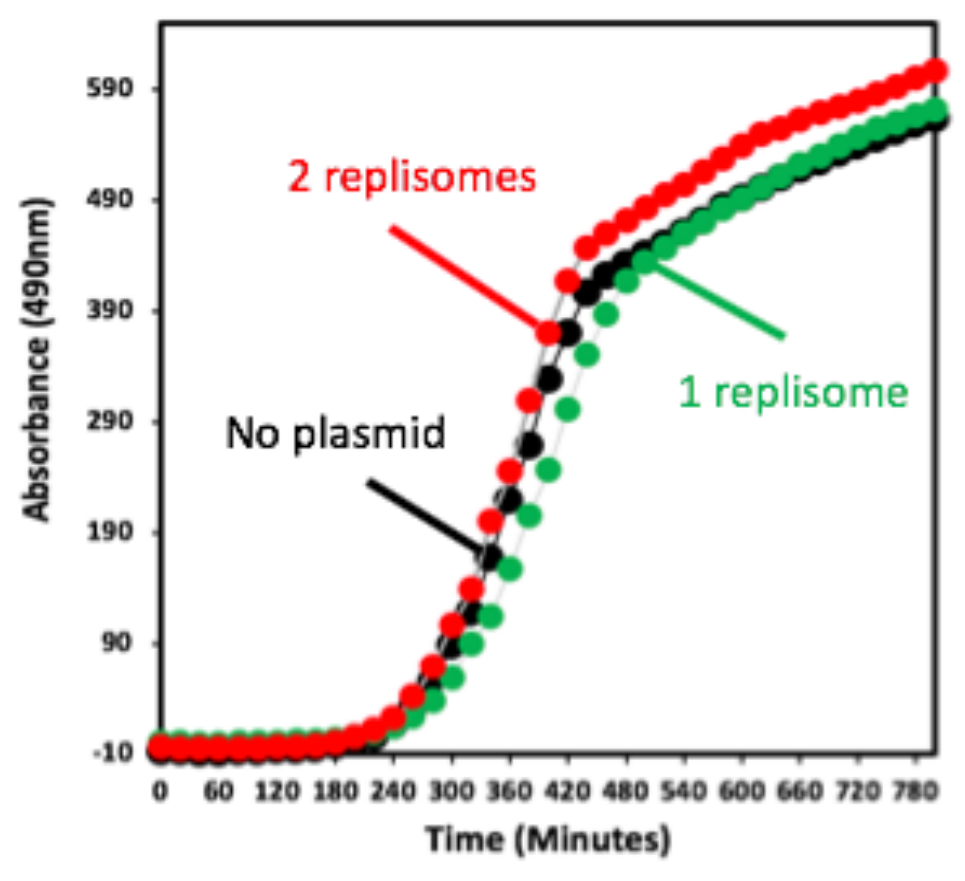


3.1C)

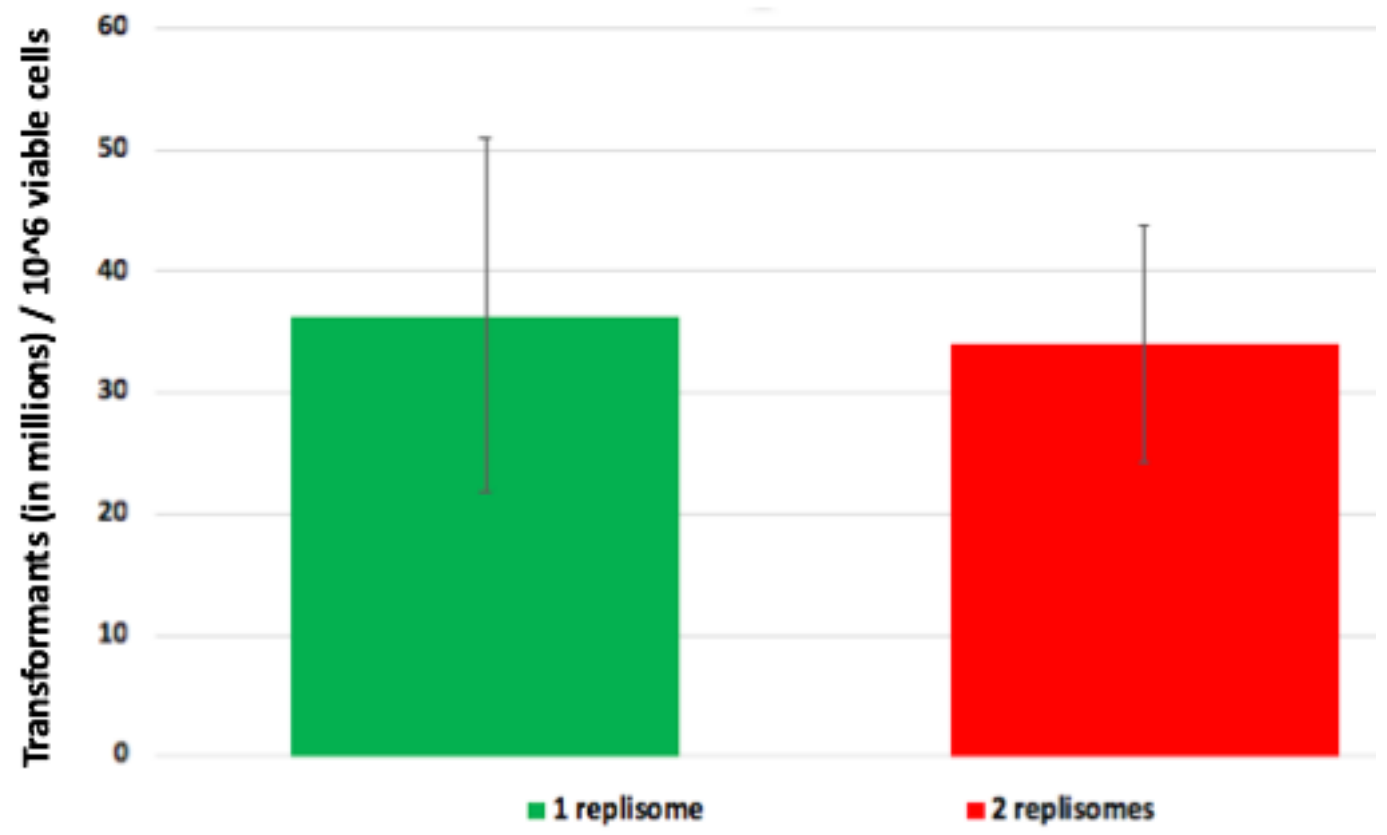

3.1D)

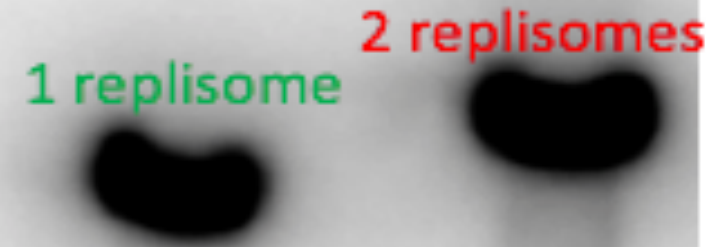

Chromosome 


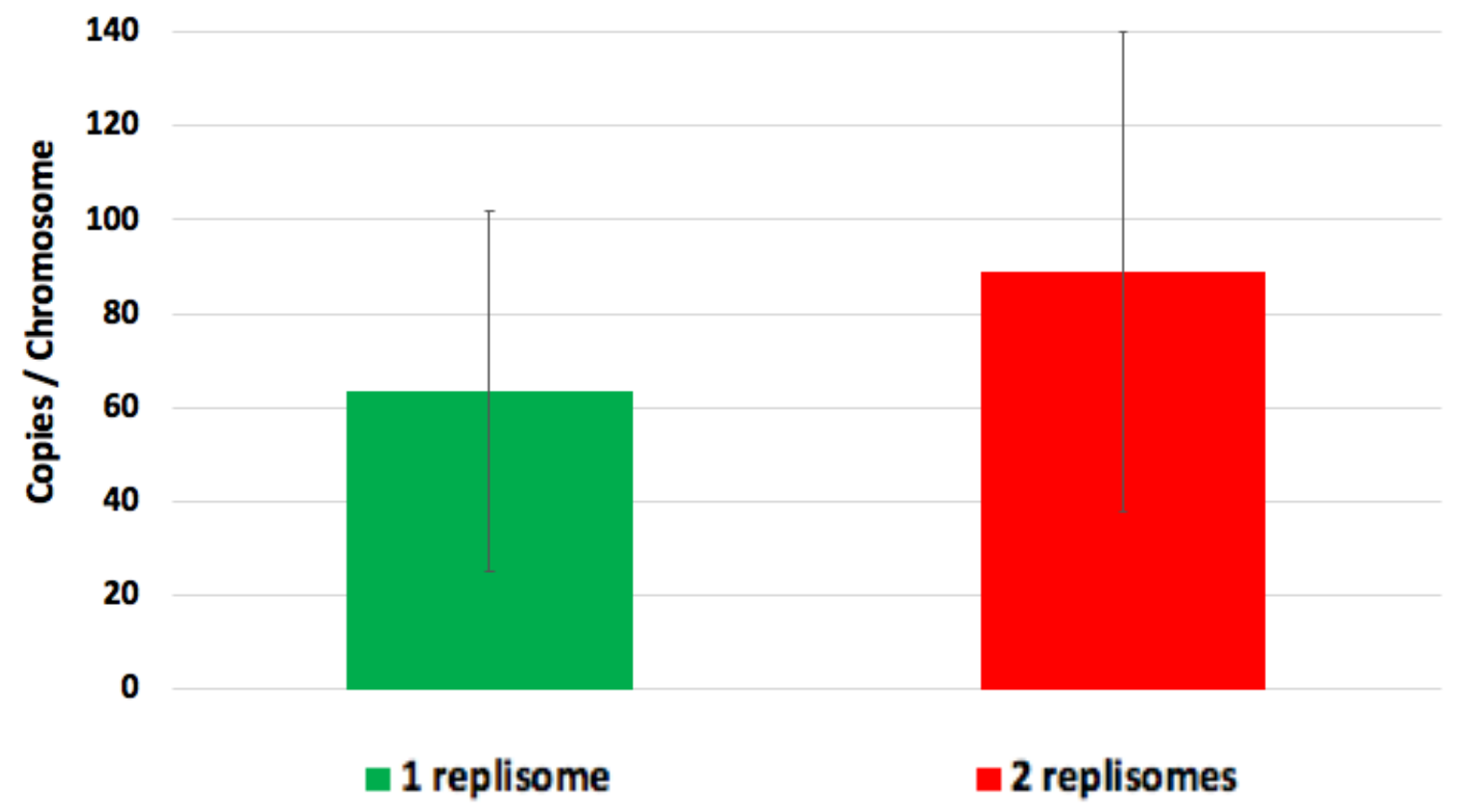

Figure 3.1: The two-replisome plasmid, pCL01, can be stably transformed, replicated, and grown in cells similar to the one-replisome plasmid, pBR322. (A) Schematic of pBR322, containing a unidirectional origin of replication, and pCL01 which contains a $\boldsymbol{\lambda}$ bidirectional origin of replication. (B) Strains containing the two-replisome plasmid grow similar to those containing the one-replisome plasmid or no plasmid; E. coli strain included ampicillin cassette in this assay (includes data from B Wendel, unpublished). The growth of wild type cultures containing each plasmid as monitored by absorbance at $490 \mathrm{~nm}$ is plotted over time. (C) Plasmids containing two replisomes can be stably transformed at frequencies similar to those with one replisome. The frequency of transformants per colony forming units per $\mathrm{mL}$ is plotted following electroporation of 50 ng of each plasmid into WT competent cells. Error bars represent standard error for 3 or more independent experiments. (D) The two-replisome plasmid is maintained at a copy number similar to the one replisome plasmid. A representative southern gel of strains containing the ampicillin resistance gene on the chromosome, on the plasmid pBR322, or the plasmid pCL01 is shown. Total genomic DNA was purified from each strain and digested as mentioned in Southern analysis of plasmid replication intermediates to linearize the plasmids. Equal number of cell equivalents were then loaded and analyzed by Southern analysis using a $\mathrm{P}^{32}$-labeled ampicillin resistance gene as a probe. (E) The copy number of each plasmid, relative to the chromosome is plotted (includes data from B Wendel, unpublished). Error bars represent the standard error for 4 independent experiments. 
$3.2 \mathrm{~A})$

1 replisome

$\underline{2 \text { replisomes }}$

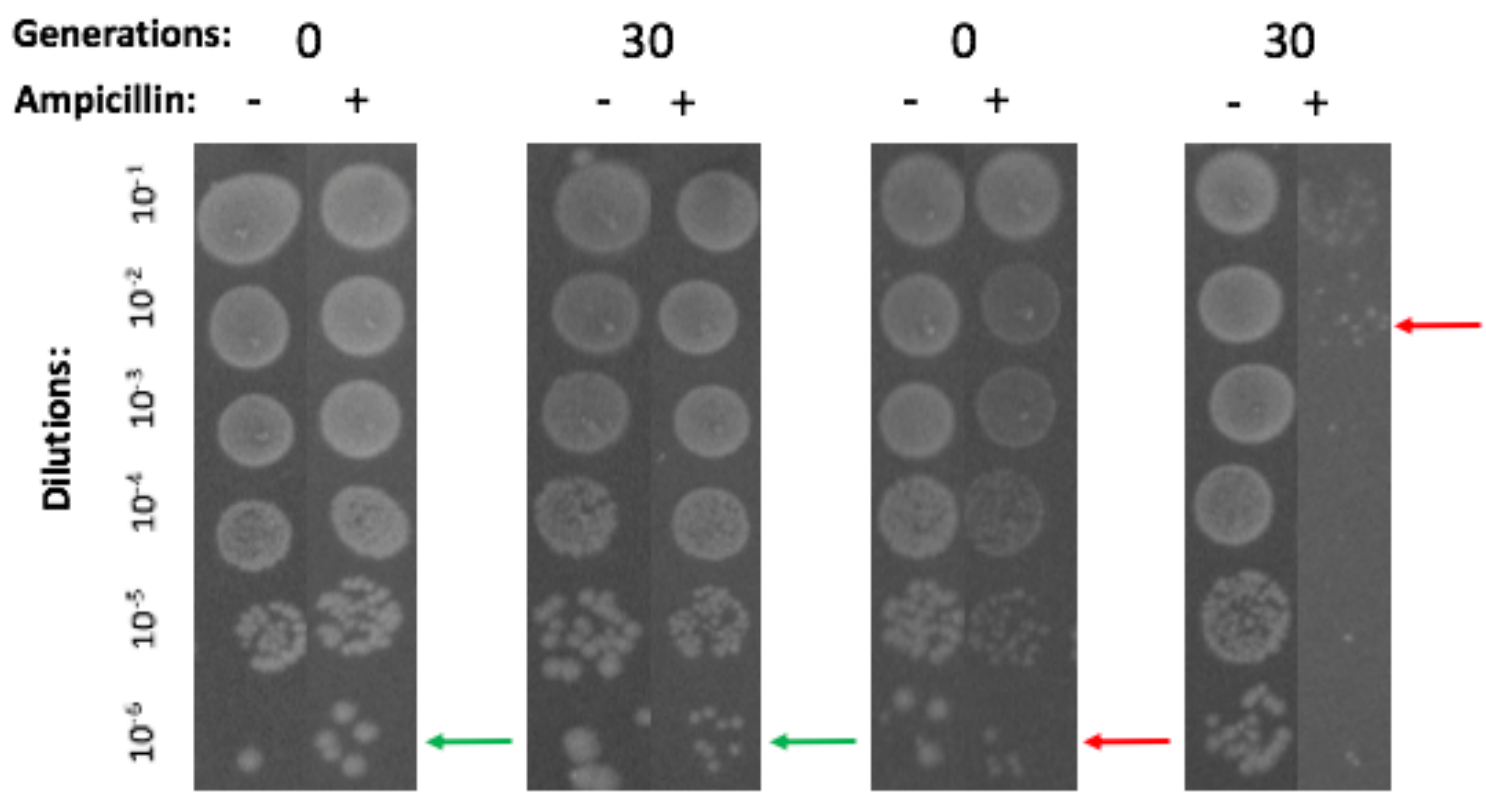

3.2B)

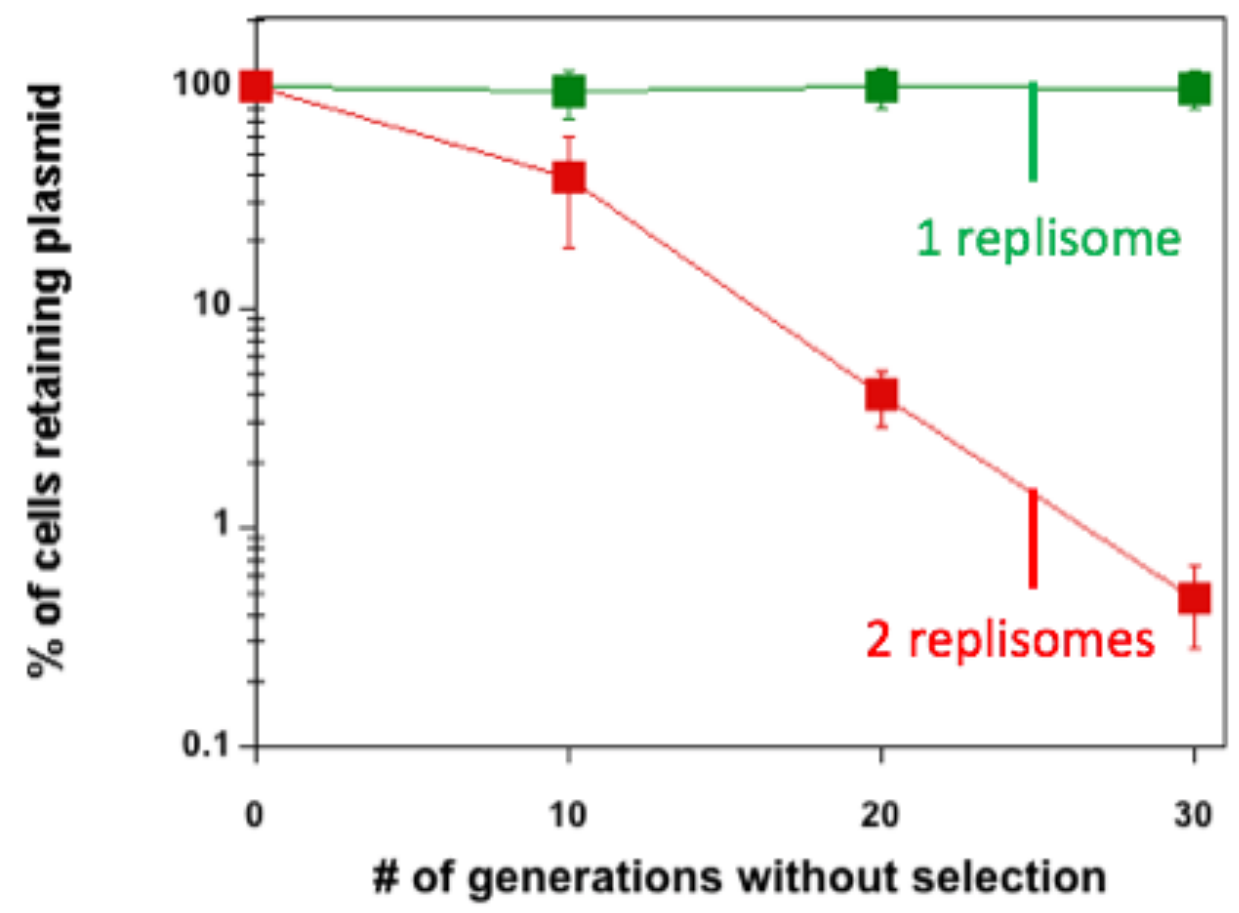


$3.2 \mathrm{C})$

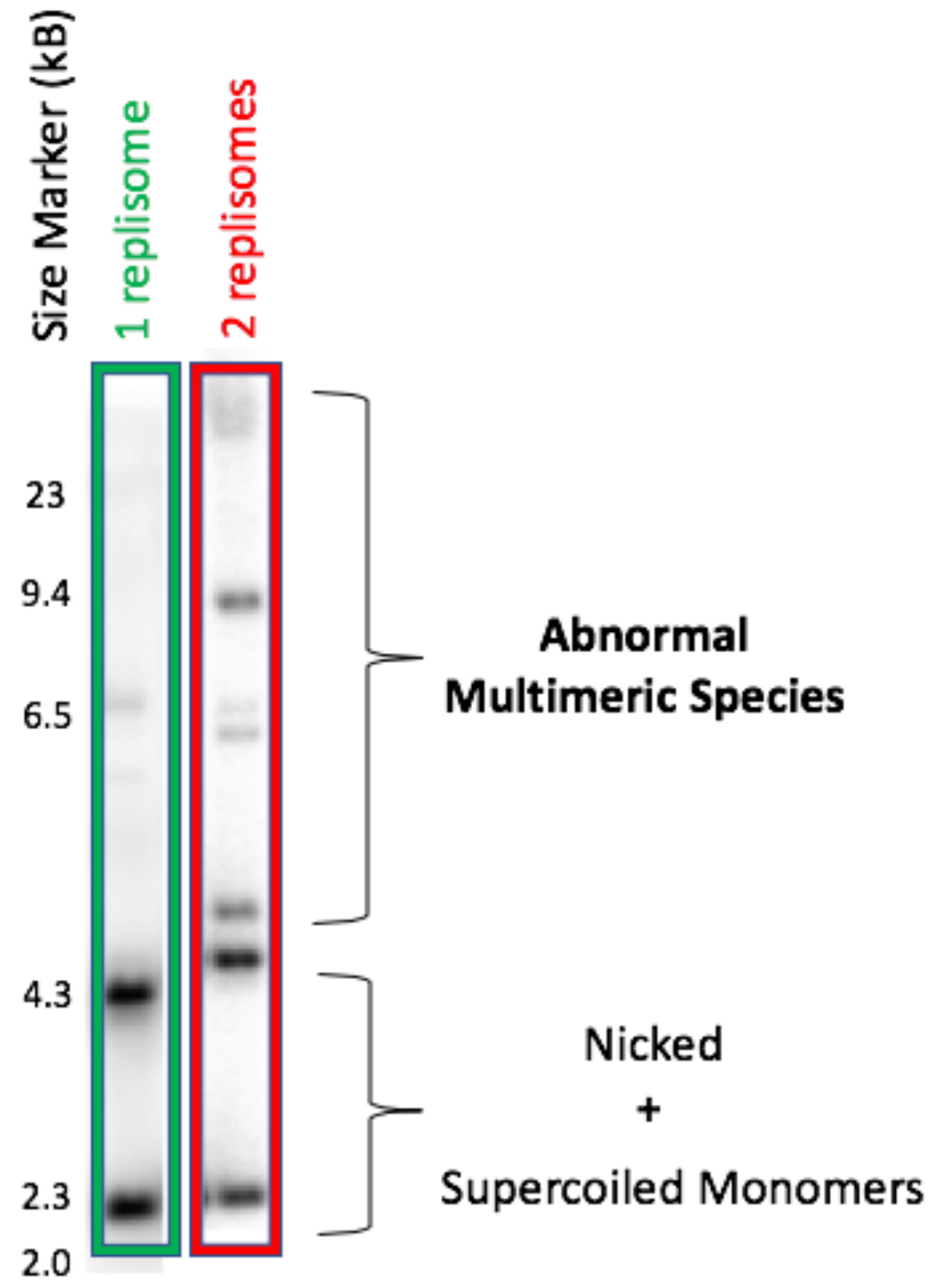


$3.2 \mathrm{D})$

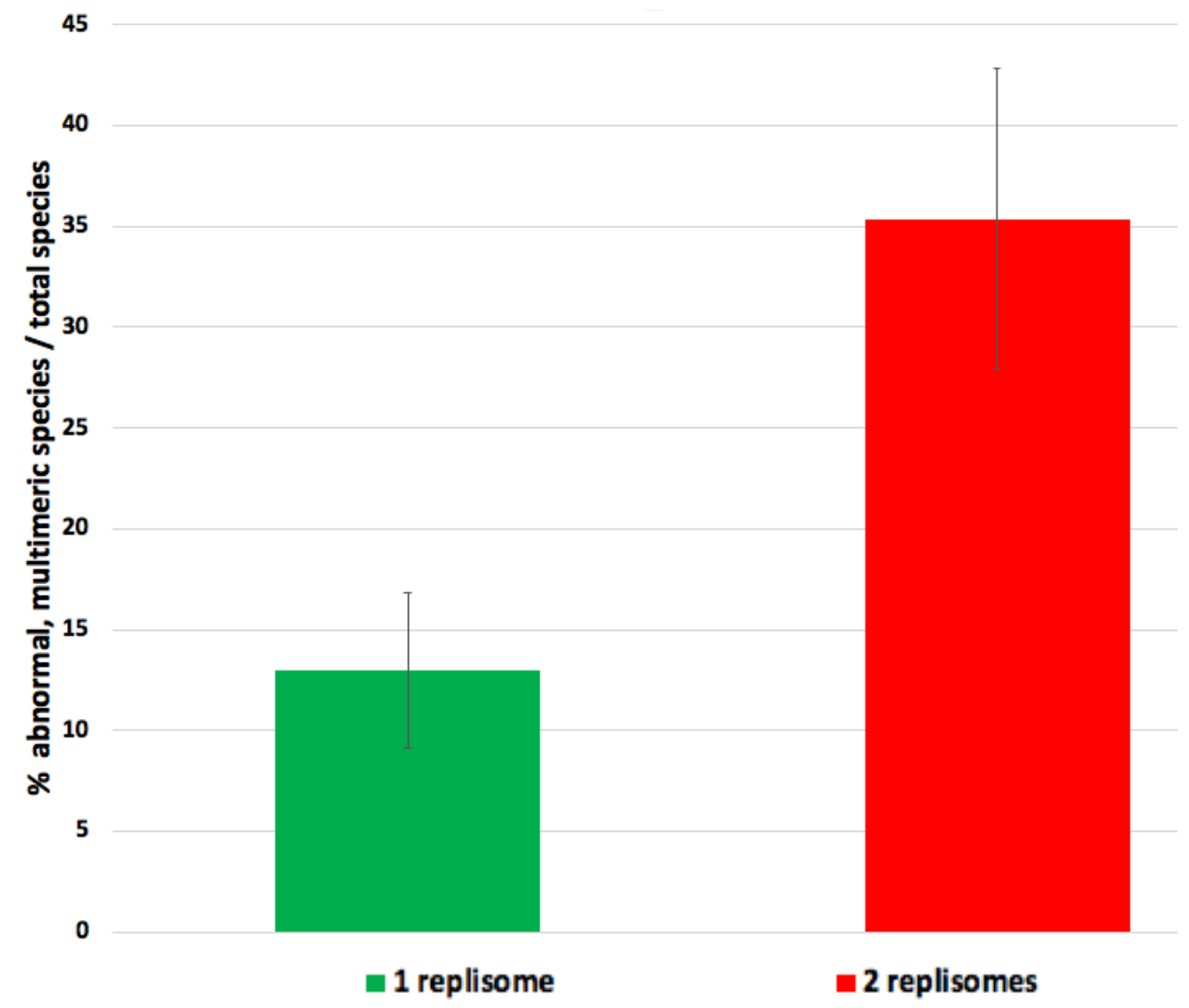

Figure 3.2: Plasmids replicated by two replisomes are less stable than one replisome plasmids and contain more aberrant species. (A) In the absence of selection, the tworeplisome plasmids are lost more rapidly than the one-replisome plasmid. Cultures containing the one-replisome (pBR322) or two-replisome (pCL01) plasmid were grown for $\sim 30$ generations without selection. 10ul drops of 10-fold serial dilutions were plated with and without ampicillin selection to determine the fraction of cells that retain the plasmid. Arrows indicate the highest dilution that was observed to retain the plasmid (B) The fraction of cells retaining the one-replisome and two-replisome plasmid is plotted over time. Error bars represent the standard error of 4 or more independent experiments. (C) The instability of the two-replisome plasmid, relative to the one-replisome plasmid, correlates with the presence of more abnormal, multimeric species. Total genomic DNA from cells containing the one-replisome or two-replisome plasmid was purified and analyzed by Southern analysis following agarose gel electrophoresis using $\mathrm{P}^{32}$-labeled pBR322 or pCL01 as a probe. (D) The fraction of unit length, non-monomeric plasmid in cultures containing the one-replisome and two-replisome plasmid is plotted. Error bars represent the average of four or more independent experiments. 
3.3A)

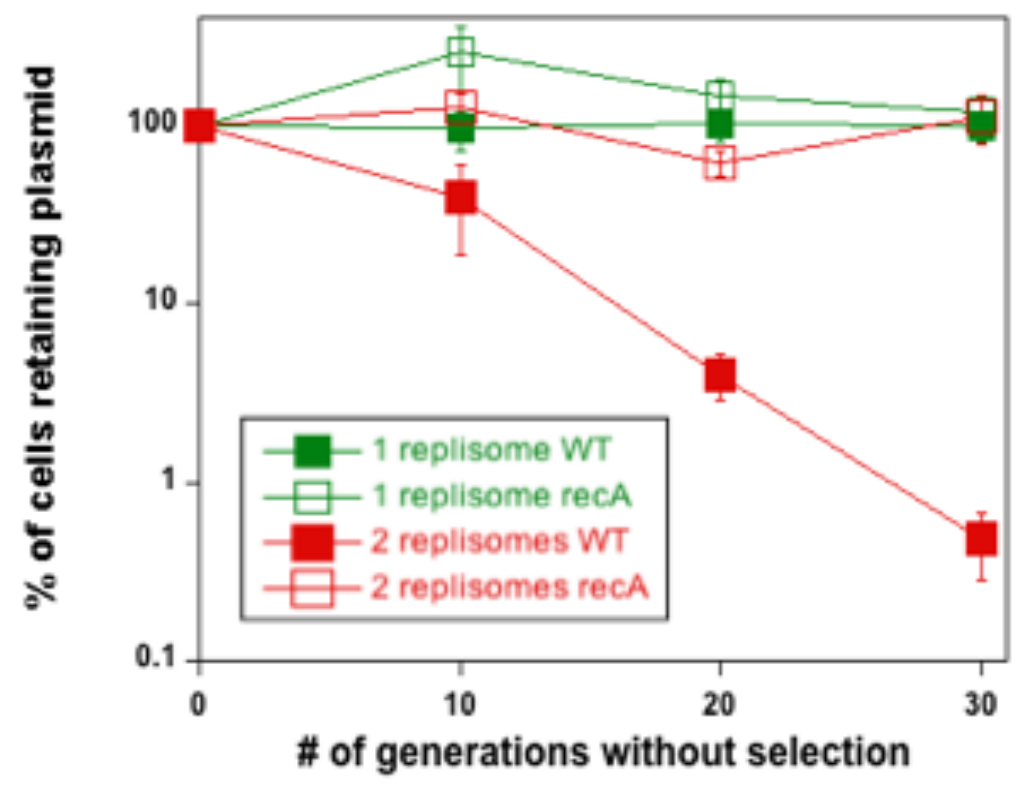

3.3B)

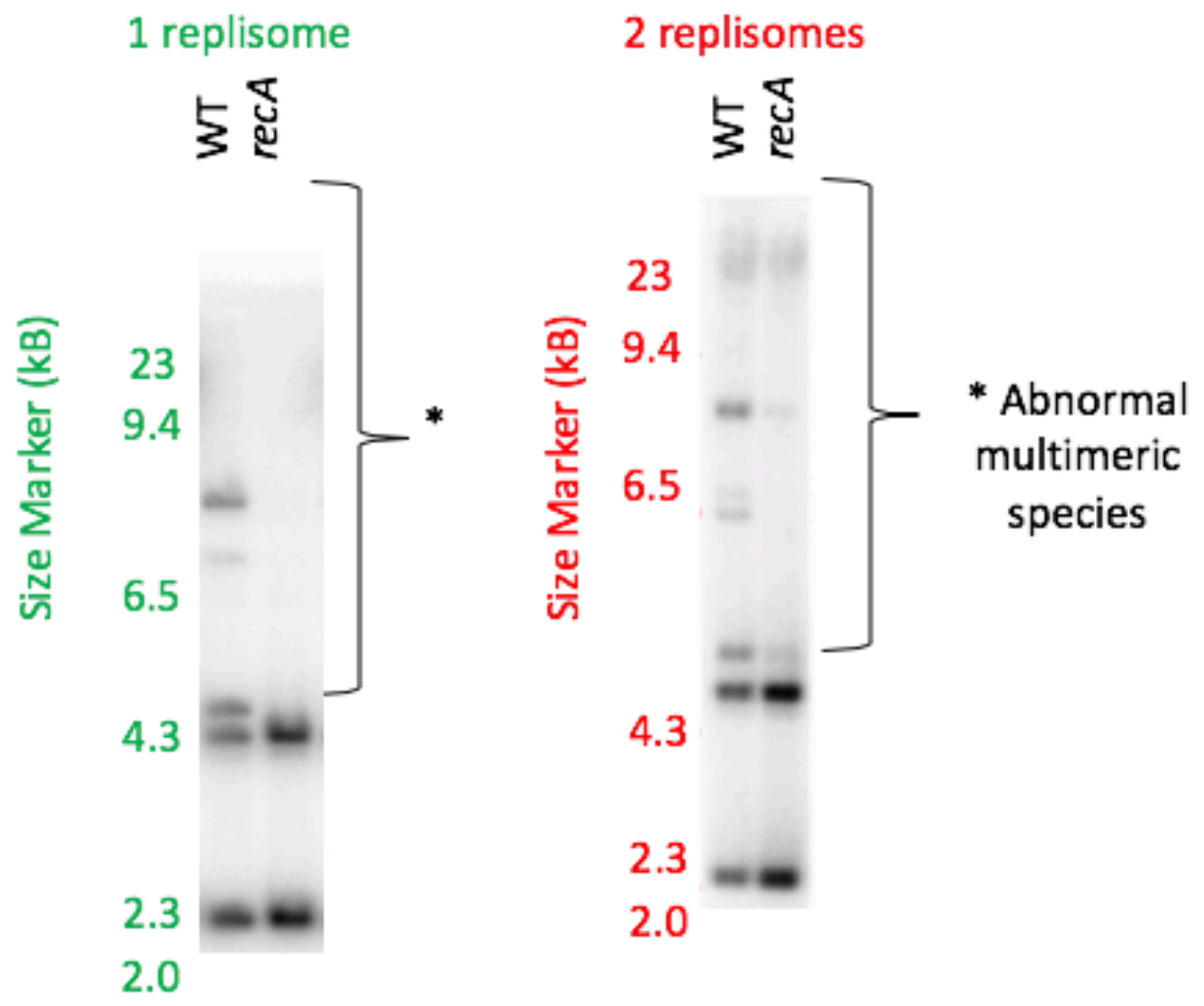




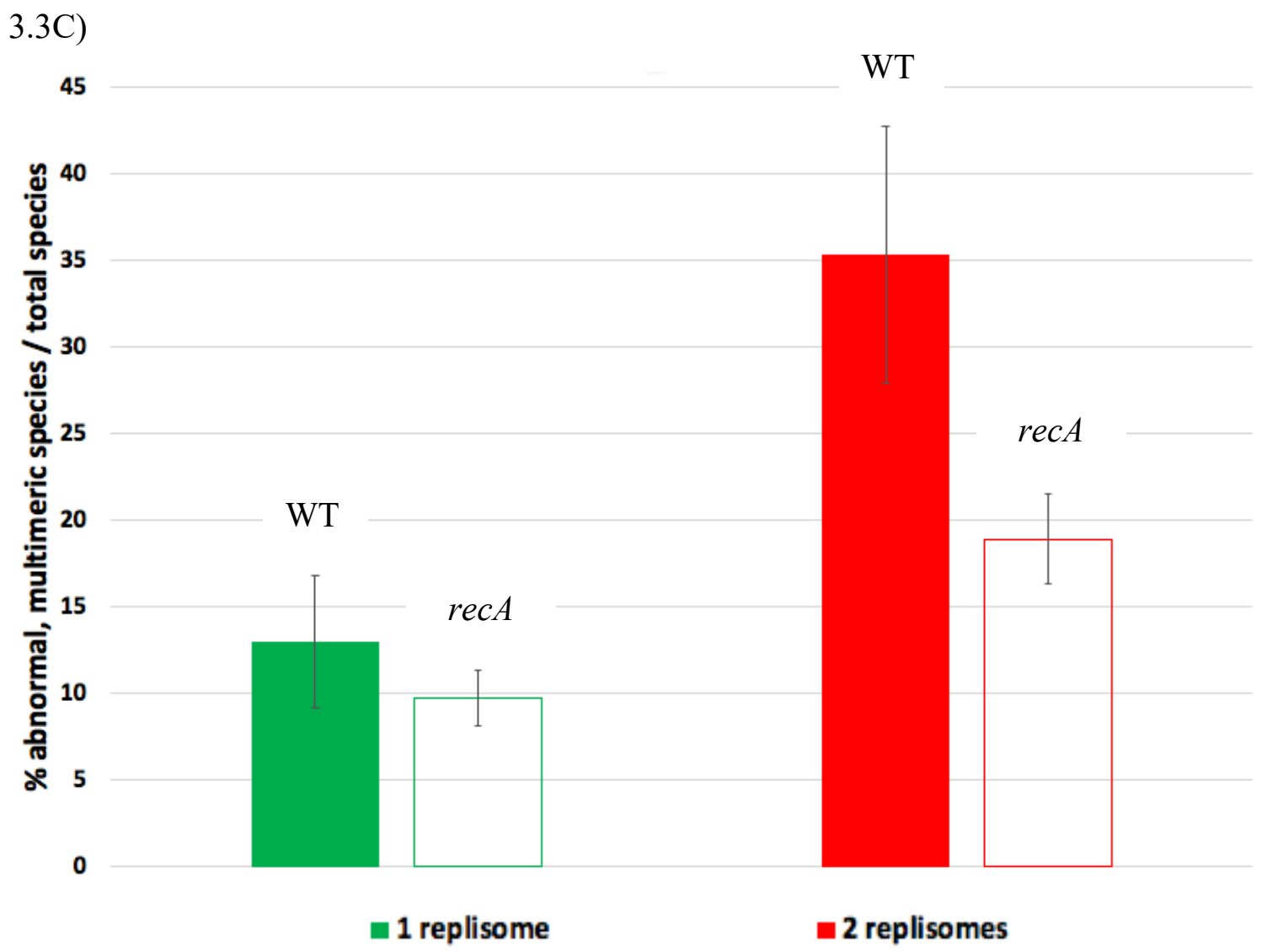

Figure 3.3: Similar to the chromosome, the amplifications and instability on tworeplisome plasmids species are driven by the aberrant recombinational mechanism of completing DNA, RecA. (A) Inactivation of RecA restores the stability of the tworeplisome plasmid to levels that approach that of the one-replisome plasmid. The fraction of cells retaining the one-replisome and two-replisome plasmid in the absence of selection is plotted over time. Error bars represent the standard error of at least 4 independent experiments. (B) The increased stability in the absence of the aberrant recombination pathway correlates with an increase in unit-length monomeric plasmids. Total genomic DNA from cells containing the one-replisome or two-replisome plasmid was purified and analyzed by Southern analysis following agarose gel electrophoresis using $\mathrm{P}^{32}$-labeled pBR322 or pCL01 as a probe. (C) The fraction of non-monomeric plasmid in each culture is plotted for the one-replisome and two-replisome plasmid in the presence and absence of RecA. Graphs represent the average of at least 4 independent experiments. Error bars represent the standard error. 

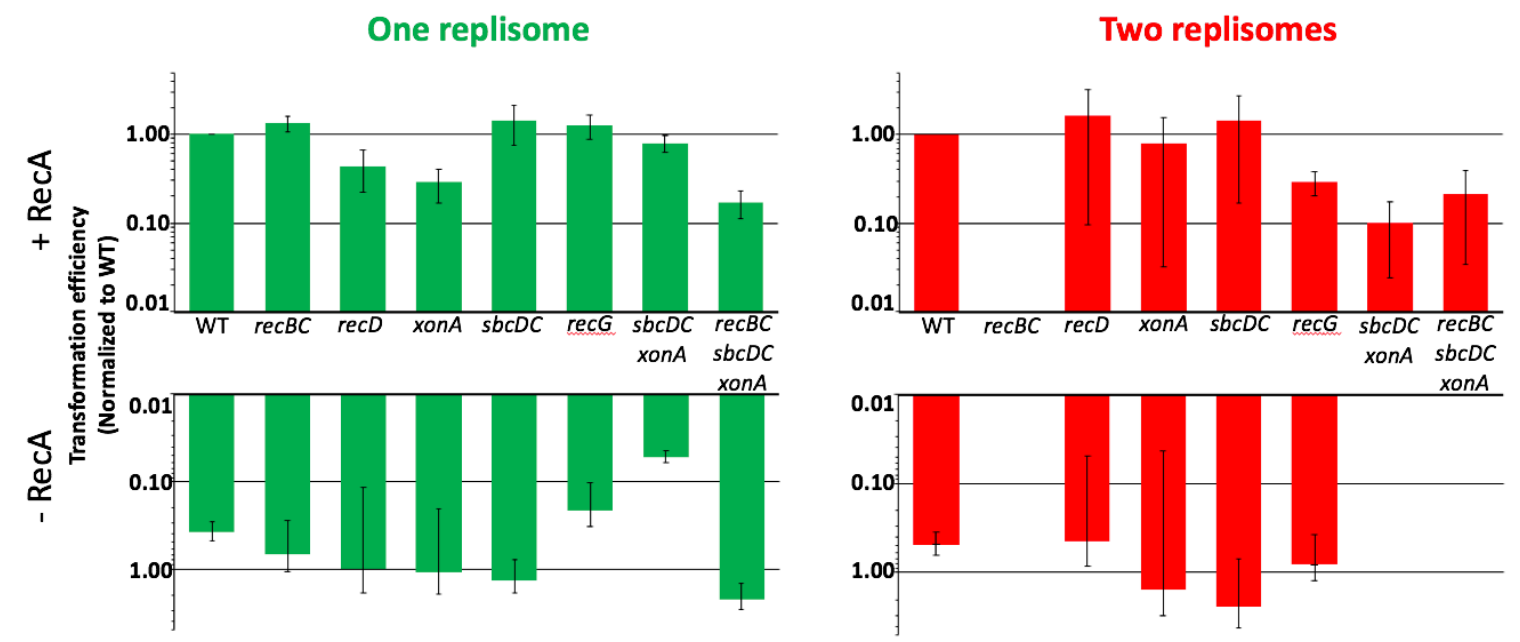

Figure 3.4: Transformation of plasmids with two replisomes, but not one replisome, depends on the enzymes required to complete replication on the chromosome. (A) The transformation efficiency of the one-replisome and two-replisome plasmid, relative to wild type cells, is shown for the strains indicated. Error bars represent the standard error of at least two independent experiments (Includes data from B Wendel, unpublished). 


\section{PART II: No ter vs ters}

$3.5 \mathrm{~A})$
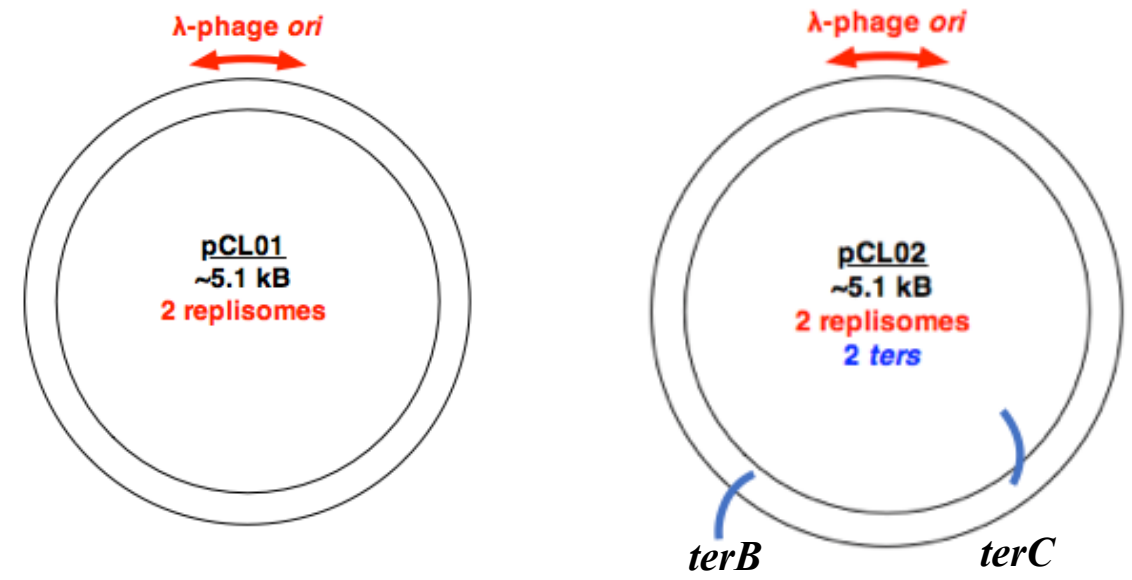

3.5B)

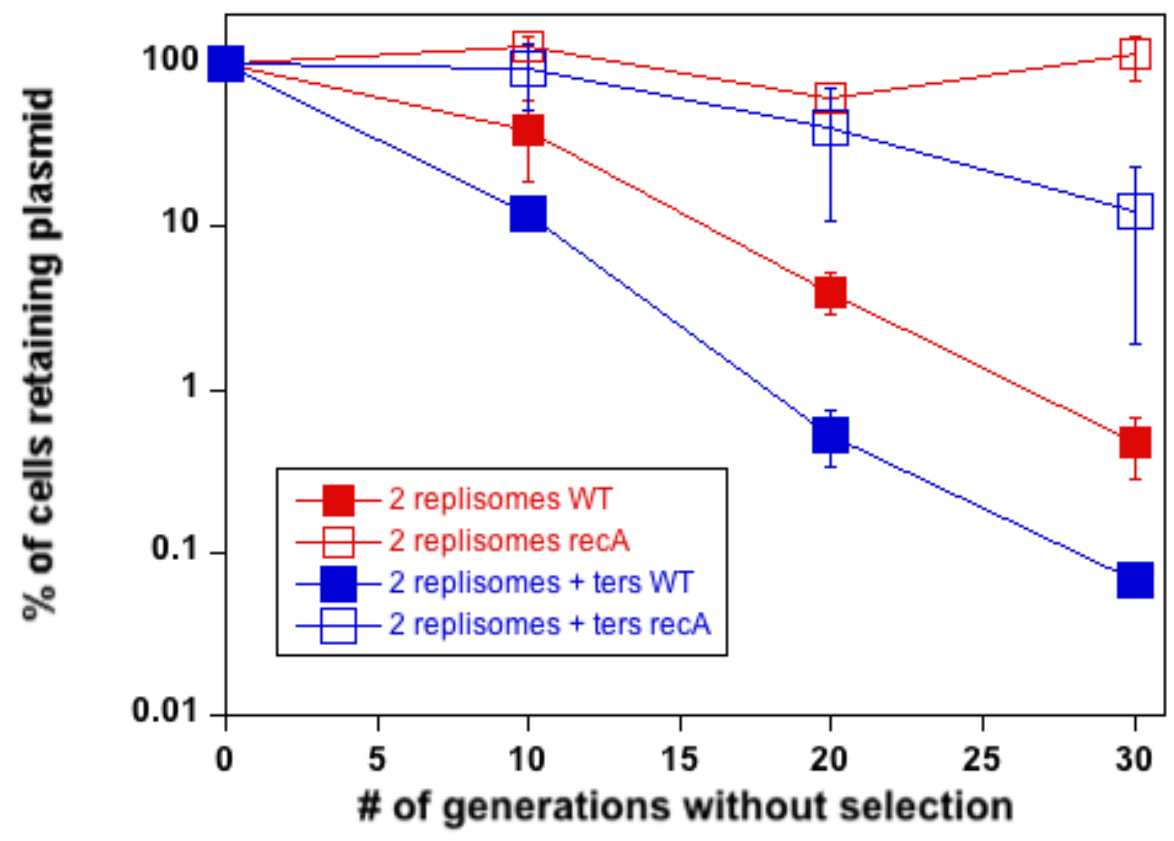


$3.5 \mathrm{C})$

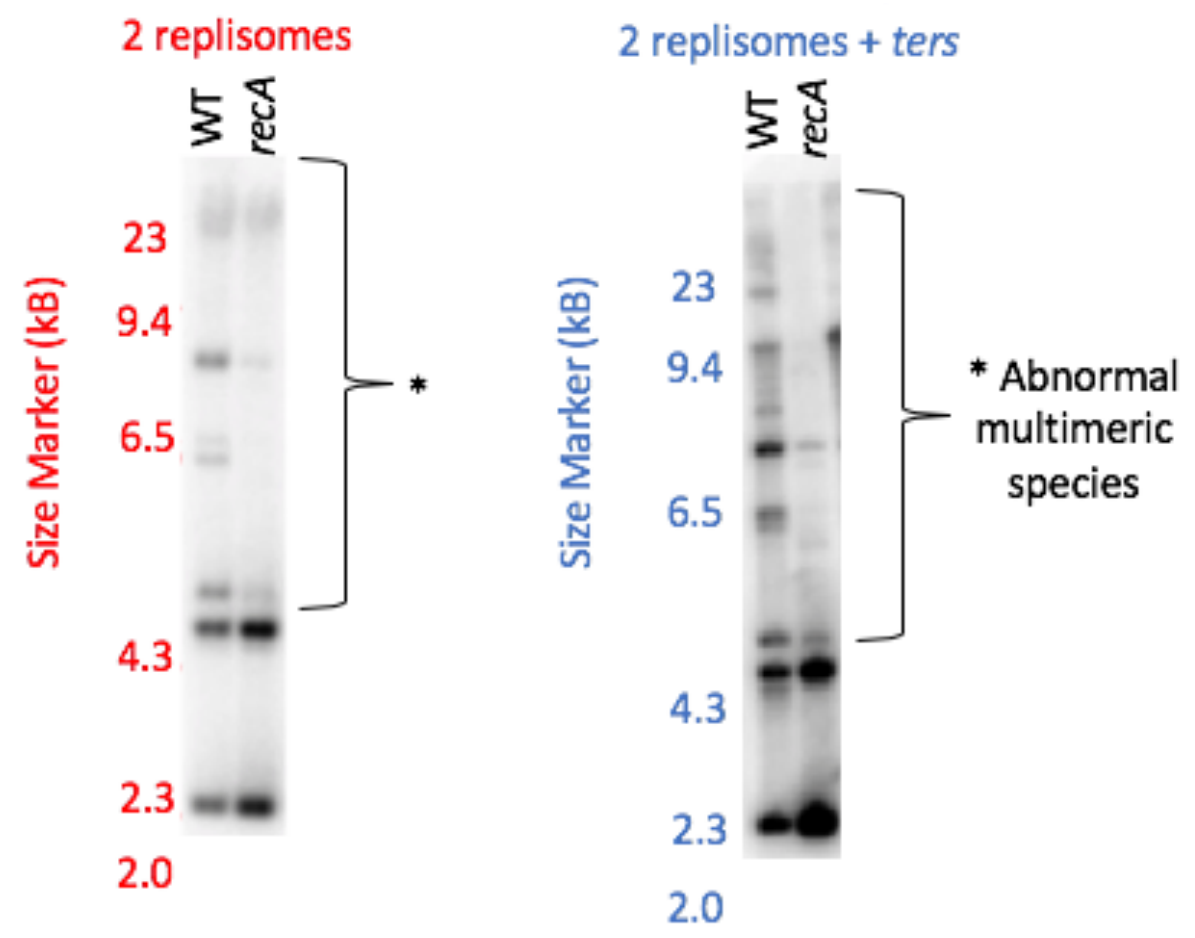

3.5D

100

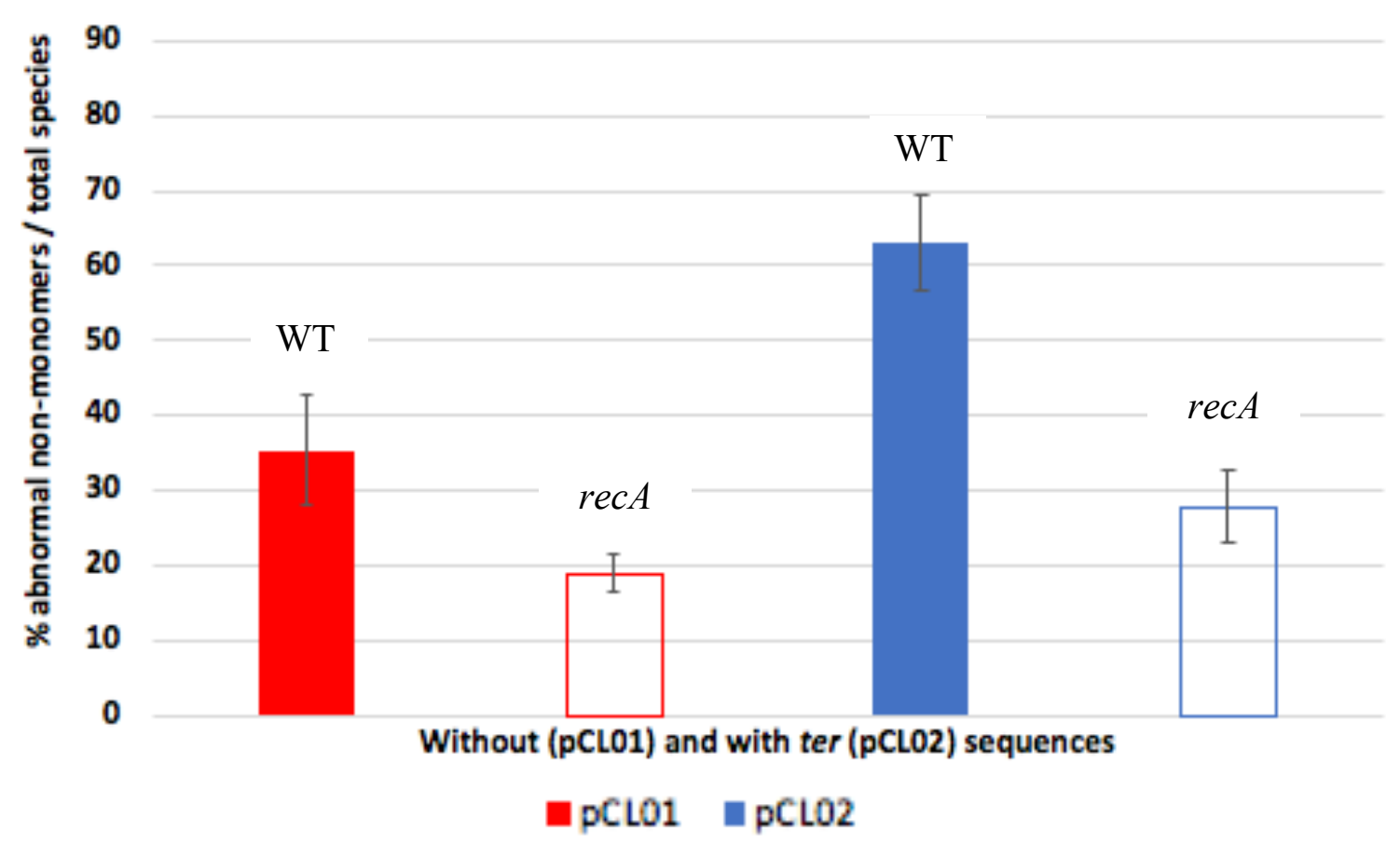


Figure 3.5: ter traps engineered onto the two-replisome plasmid only modestly affect the overall stability of the plasmid but appear to increase the amount of abnormal non-monomeric circular plasmid species (A) Diagram of 2-replisome plasmids with and without ter traps $(\operatorname{ter} B+\operatorname{ter} C)$. (B) The fraction of cells retaining the two-replisome plasmid in the absence of selection is plotted over time. Error bars represent the standard error of at least two independent experiments. (C) Increased amounts of RecAdependent, non-monomeric plasmid species are observed in the presence of ter traps. Total genomic DNA from cells containing the indicated plasmid was purified and analyzed by Southern analysis following agarose gel electrophoresis using $\mathrm{P}^{32}$-labeled pCL01 as a probe. (D) The fraction of non-monomeric plasmid species in each culture is plotted. Graphs represent the average of at least 4 independent experiments. Error bars represent the standard error.

\section{PART III: No $c h i$ versus $c h i$}
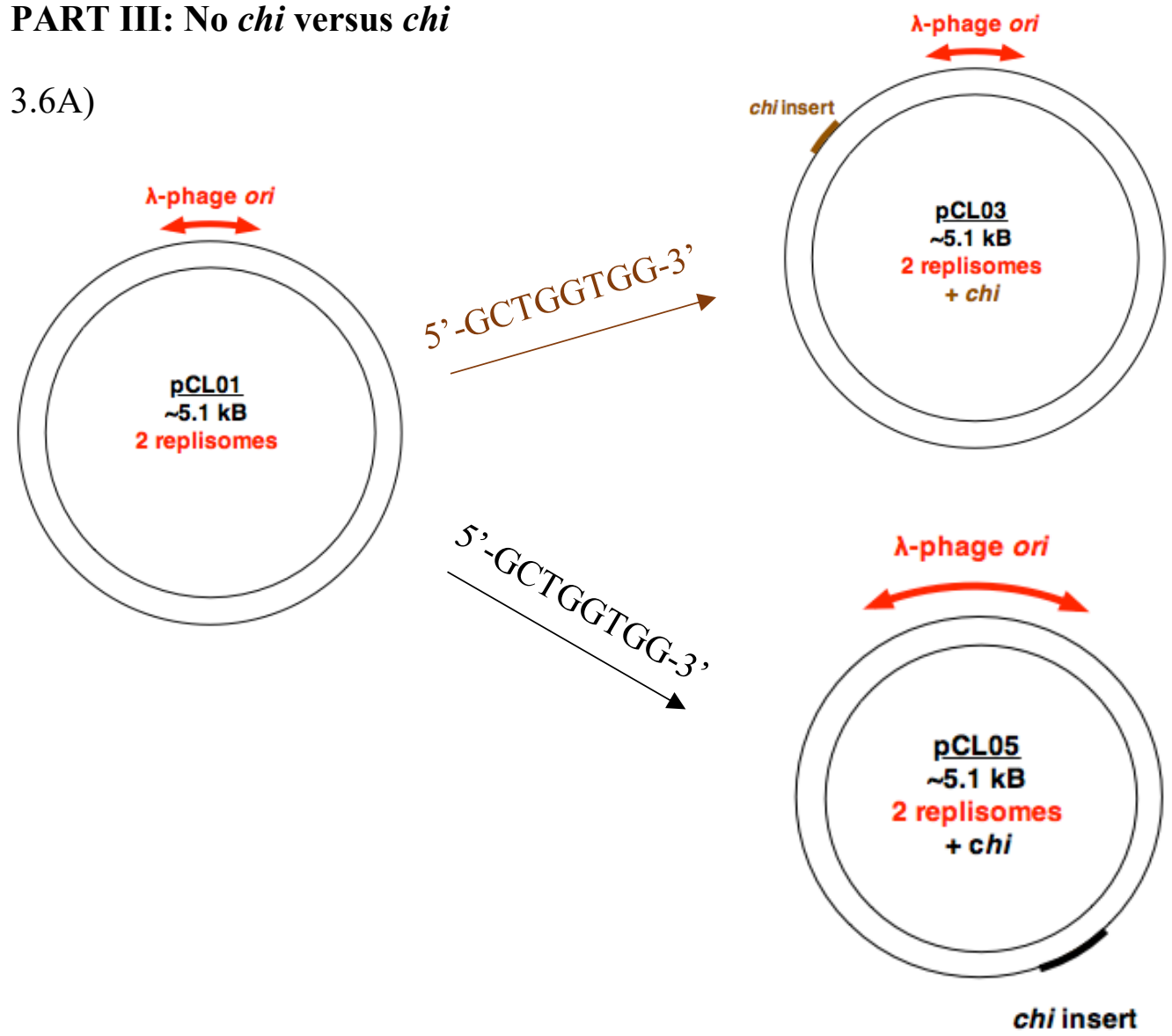
3.6B)

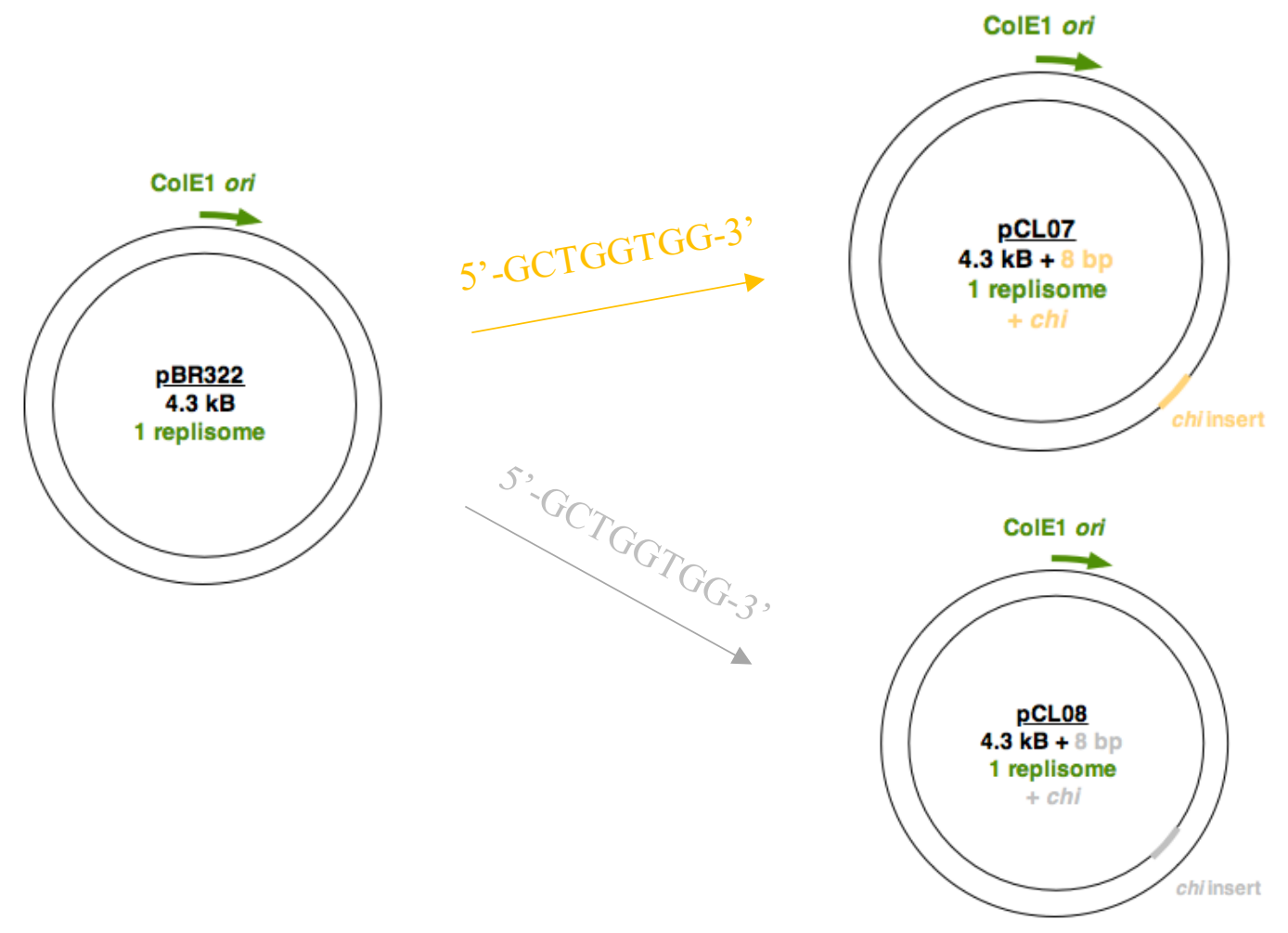

3.6C)

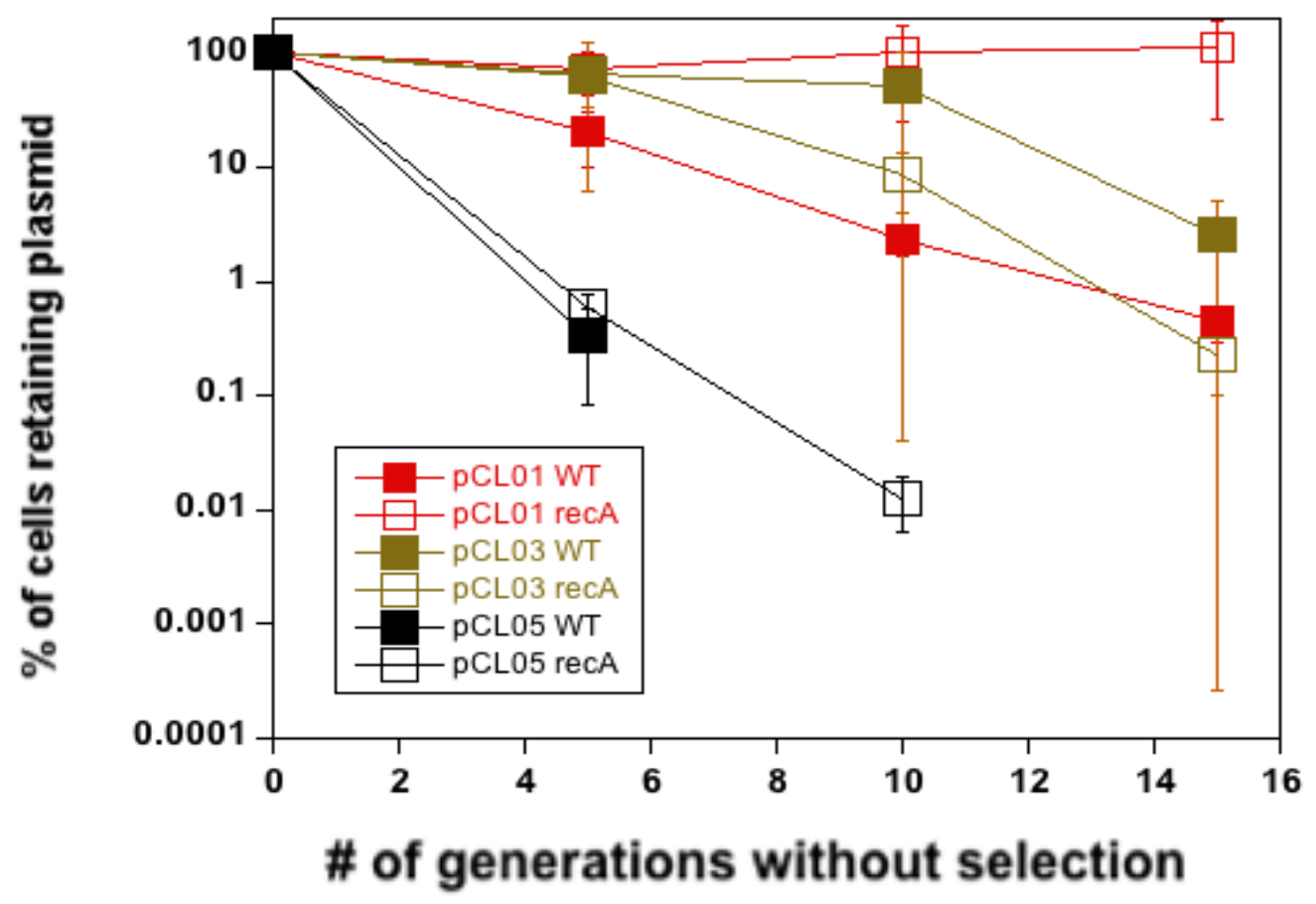


3.6D)

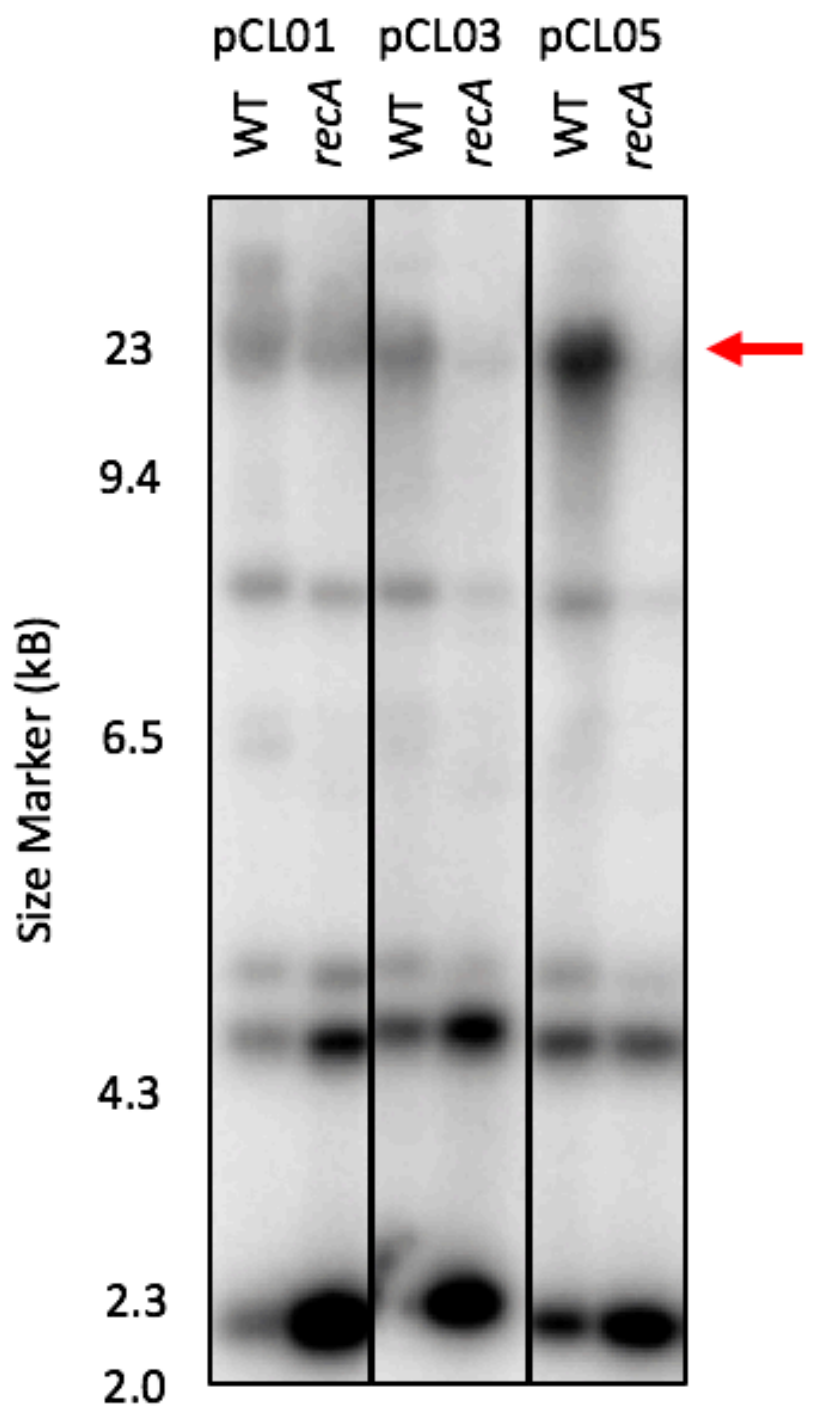


3.6E)

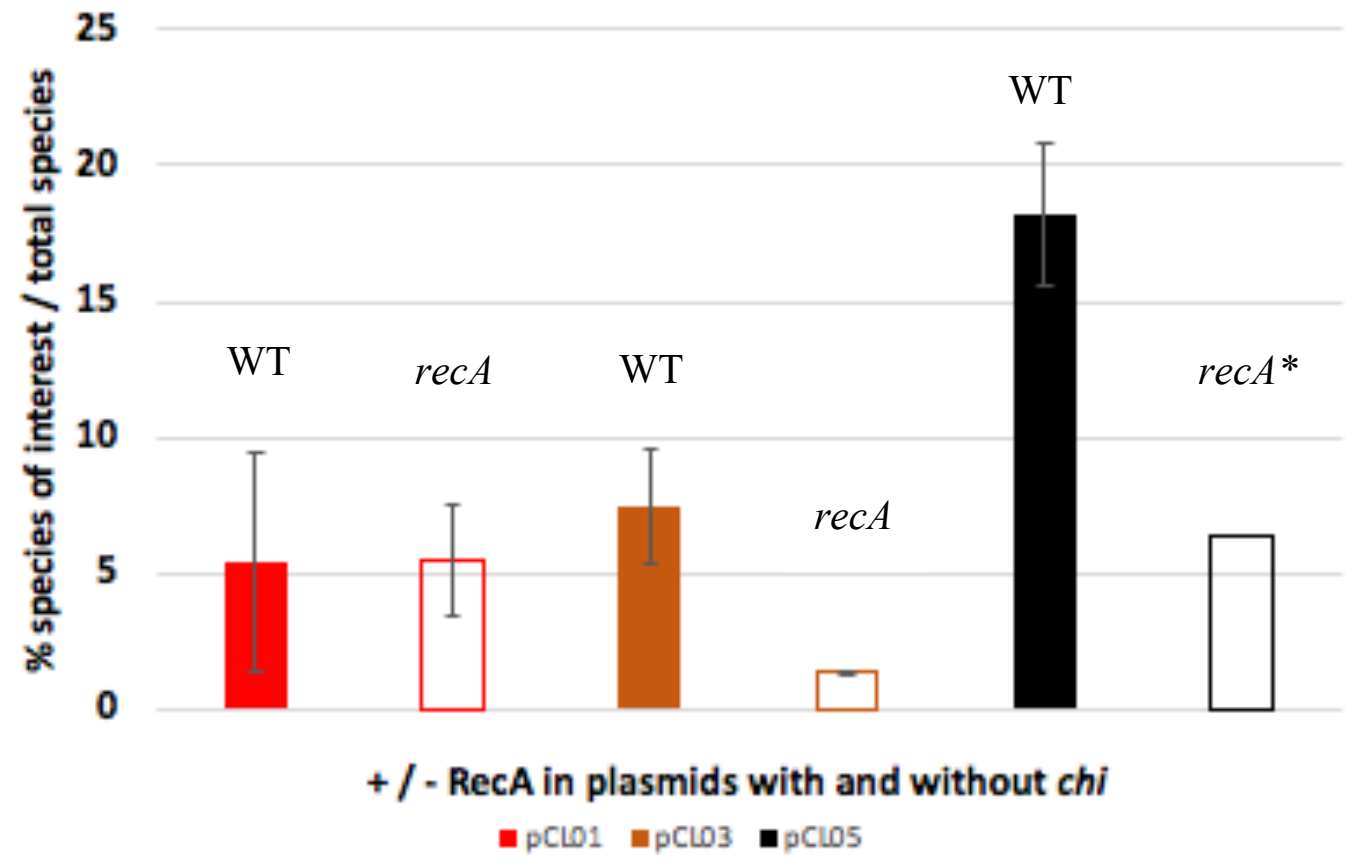

3.6F)

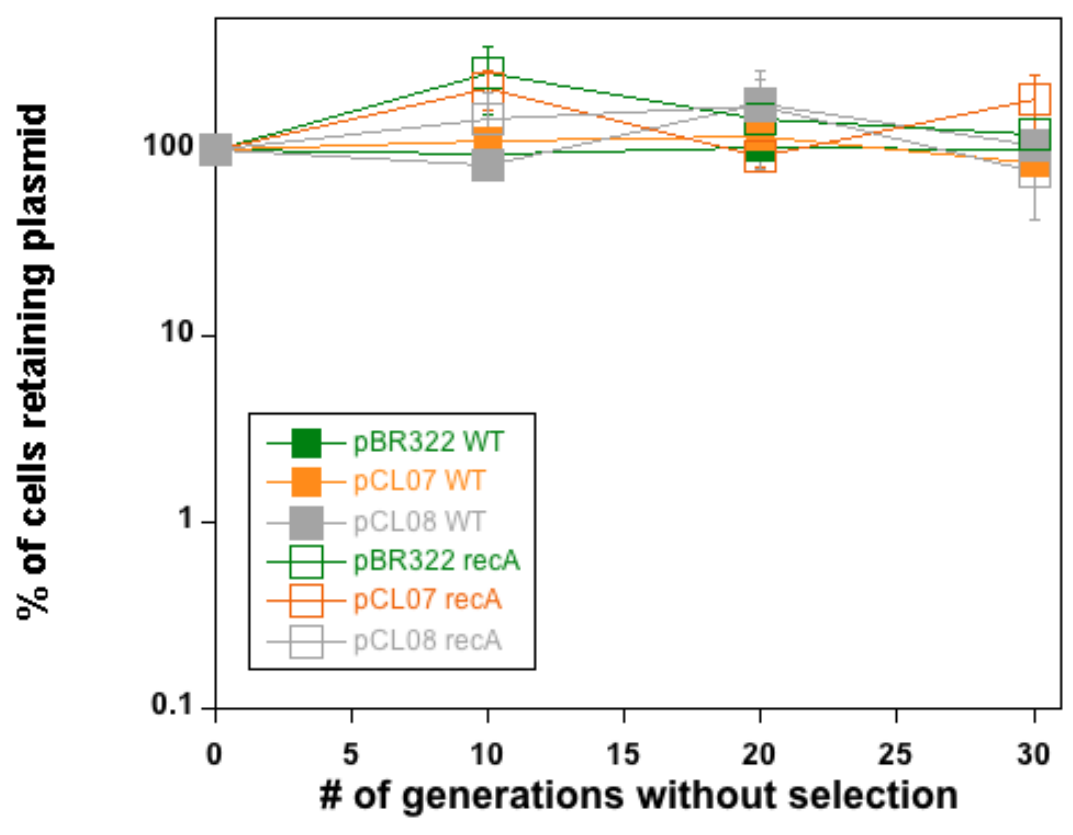


$3.6 \mathrm{G})$

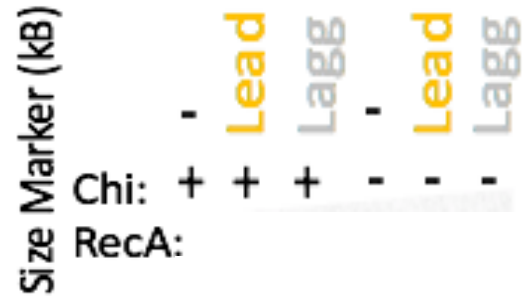

9.4

6.5

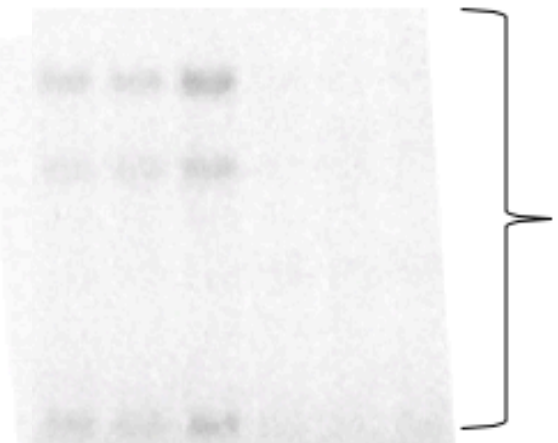

Abnormal

Non- Monomers

4.3

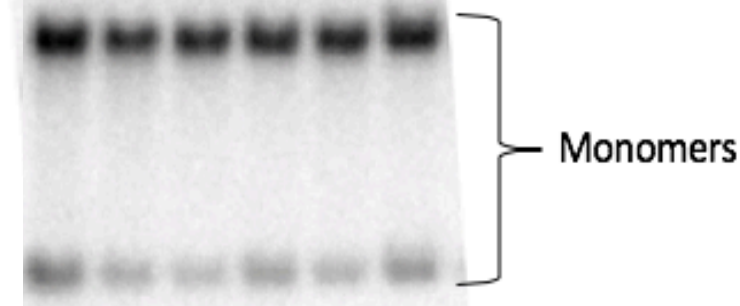

2.3

2.0

$3.6 \mathrm{H})$

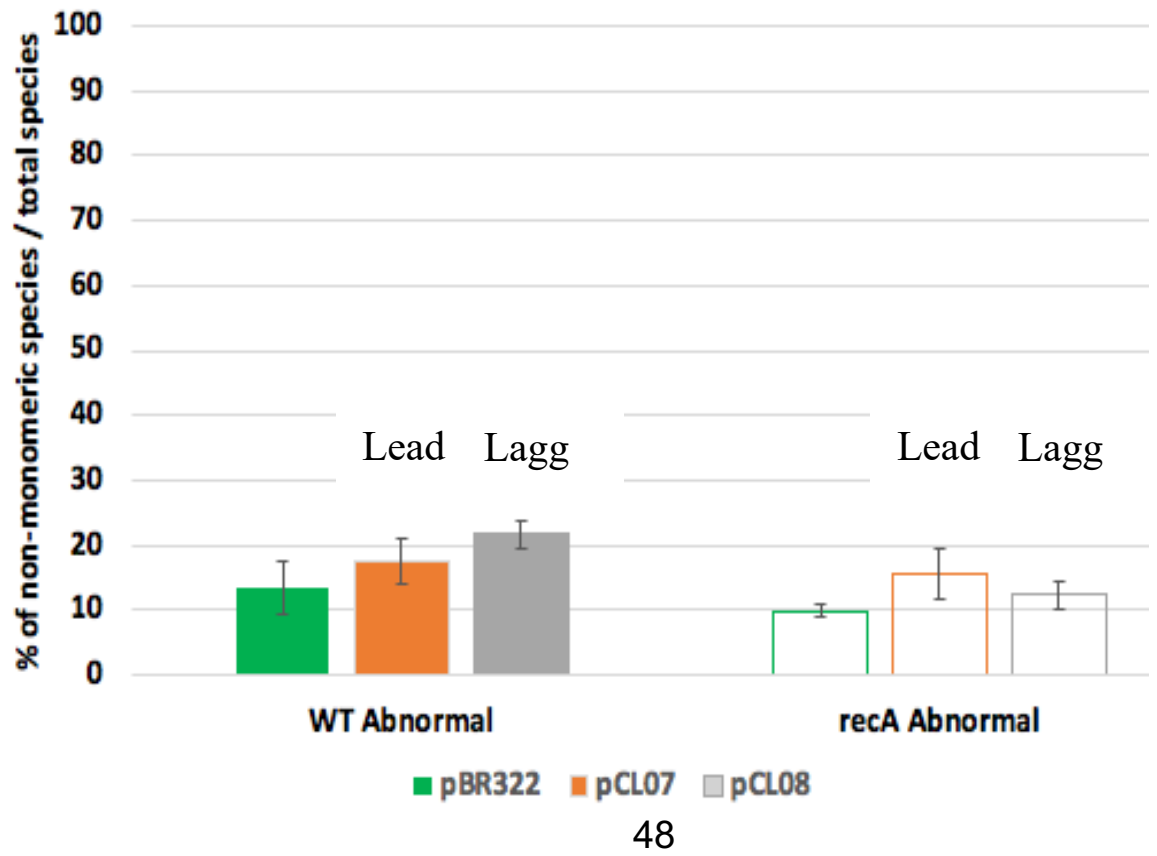


Figure 3.6: Chi decreases the stability of two-replisome, but not one replisome plasmids, in a manner that correlates with the amount of aberrant linear multimeric plasmid that is observed. (A) Diagram of plasmid constructs comparing 2-replisome plasmid, pCL01, no chi control, pCL03 where chi is mutated near the ori site, pCL05 where chi is mutated opposite of ori site. (B) Diagram of one-replisome plasmids containing a chi inserted into the leading, pCL07, or lagging strand, pCL08, pBR322 template. (C) When present in the terminus region, chi destabilized the two-replisome plasmid. The fraction of cells retaining the two-replisome plasmid in the absence of selection is plotted over time. Error bars represent the Standard error of at least two independent experiments. (D) When present in the terminus region of the two-replisome plasmid, chi induces the formation of an aberrant linear plasmid multimeric species. Total genomic DNA from cells containing the indicated plasmid was purified and analyzed by Southern analysis following agarose gel electrophoresis using $\mathrm{P}^{32}$-labeled pCL01 as a probe. Arrow indicates the position of the linear plasmid multimers. (E) The amount of the linear plasmid multimeric species observed is plotted. Graphs represent the average of at least two independent experiments, except for pCL05 rec $A$ which represents a singular experiment. For all other strains, error bars represent the Standard error. (F) The stability of the one-replisome plasmid is not affected by the presence of chi. The fraction of cells retaining the two-replisome plasmid in the absence of selection is plotted over time. Error bars represent the Standard error of at least four independent experiments. (G) No multimeric species are induced by chi on one-replisome plasmids. Total genomic DNA from cells containing the indicated plasmid was purified and analyzed by Southern analysis following agarose gel electrophoresis using $\mathrm{P}^{32}$-labeled pBR322 as a probe. (H) The amount of the linear plasmid multimeric species observed is plotted. Graphs represent the average of at least 5 independent experiments. Error bars represent the standard error. 
3.7A)
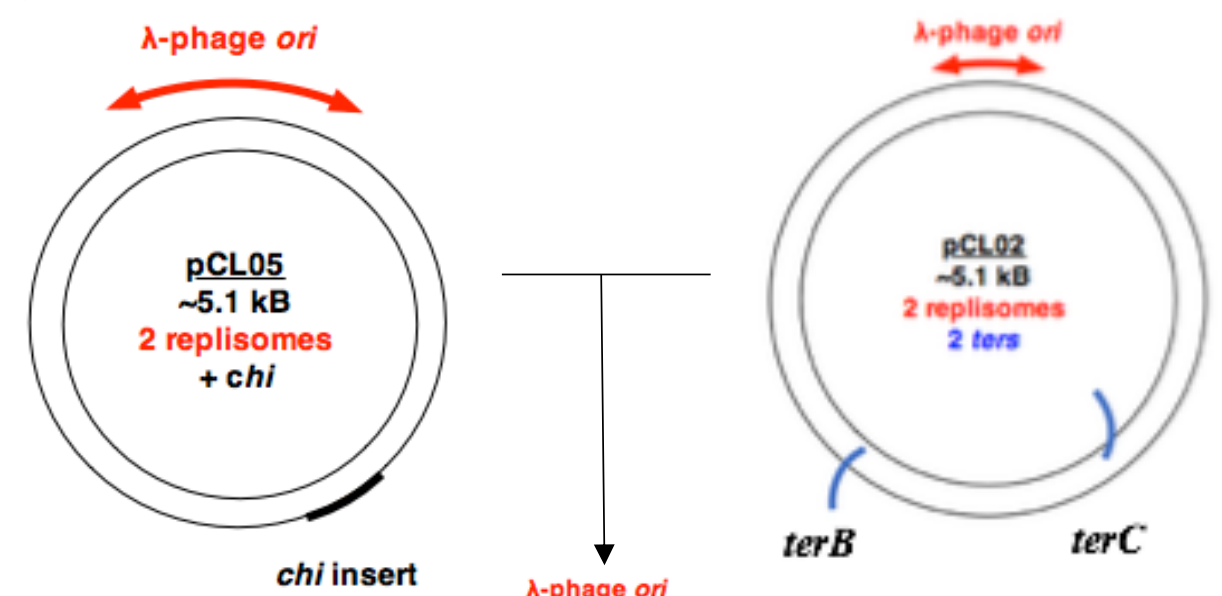

3.7B)
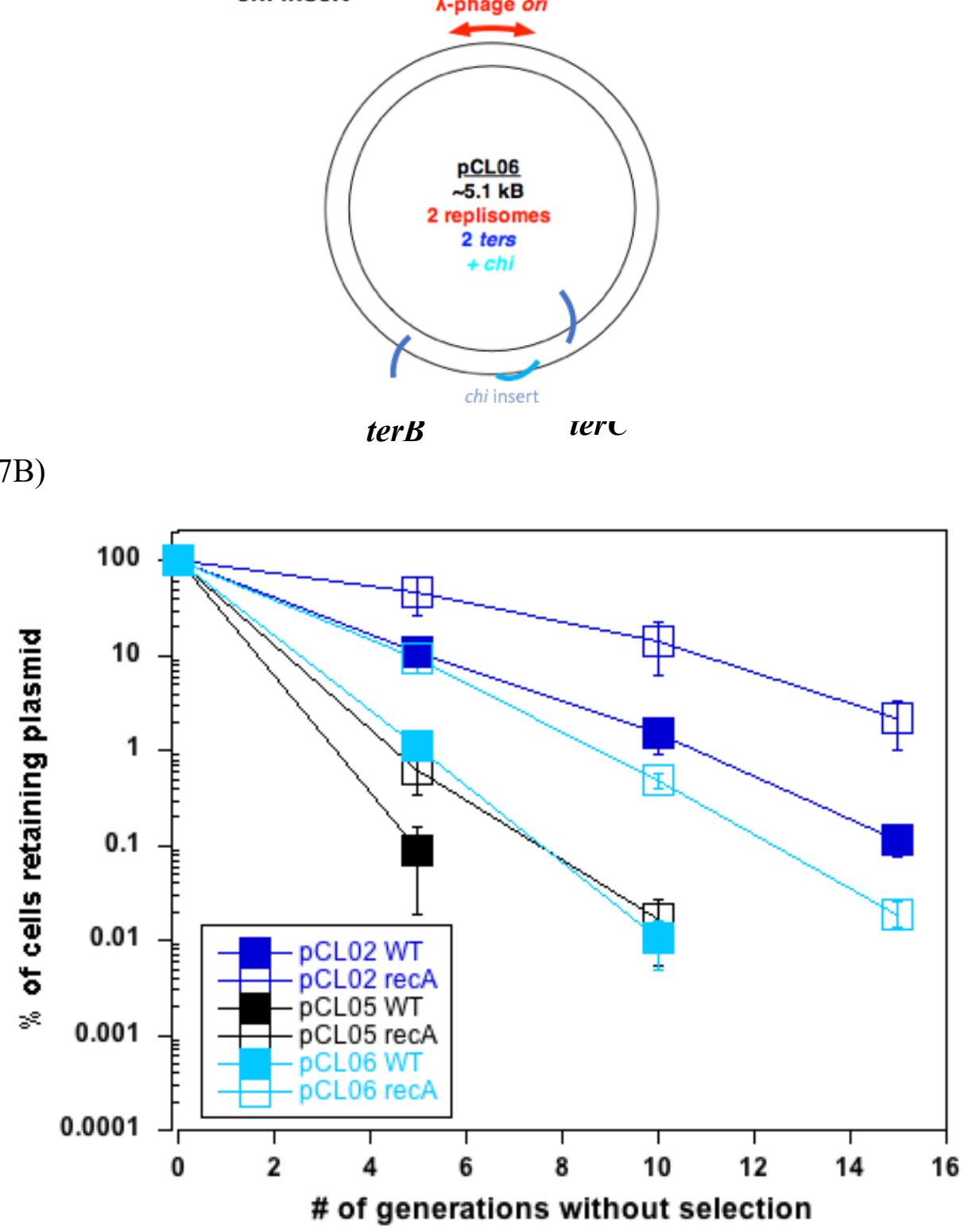
Figure 3.7C)

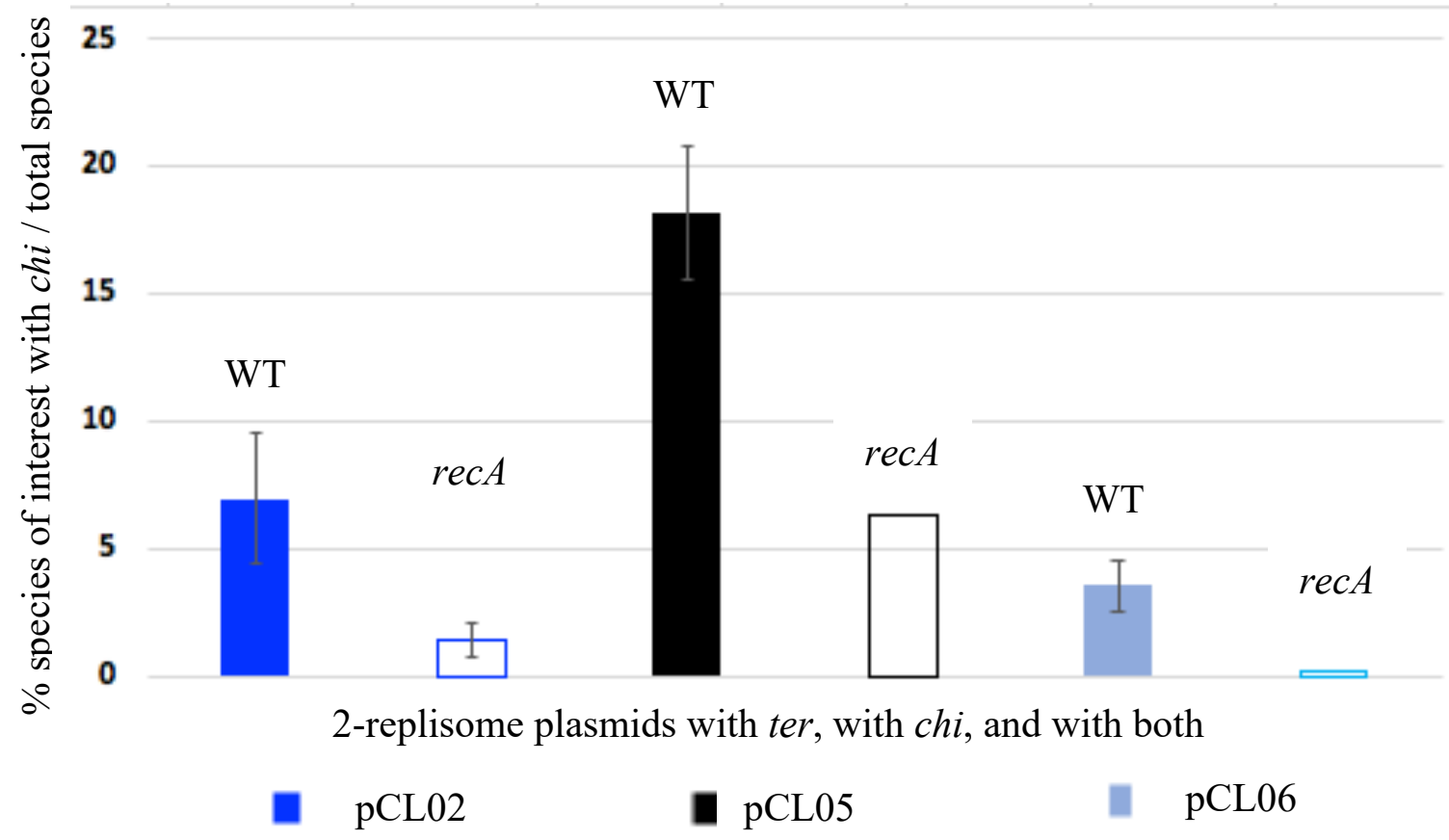

Figure 3.7: The presence of ter traps reduces the destabilization by chi, and prevents the formation of the RecA-mediated linear plasmid multimeric species (A) Diagram of two-replisome plasmids containing either a chi site in the terminus region or ter traps or both. (B) There is less destabilization by chi observed in the presence of a ter trap. The fraction of cells retaining the two-replisome plasmid in the absence of selection is plotted over time. Error bars represent the Standard error of at least two independent experiments (C) The amount of the linear plasmid multimeric species observed is plotted. Graphs represent the average of at least two independent experiments. Total genomic DNA from cells containing the indicated plasmid was purified and analyzed by Southern analysis following agarose gel electrophoresis using $\mathrm{P}^{32}$-labeled pCL01 as a probe. Except for pCL06 rec $A$, which represents only a single experiment. For all other strains, error bars represent the Standard error. 


\section{Chapter IV}

\section{Discussion}

\section{Part I: One-replisome versus two-replisome plasmids during completion of replication}

The completion reaction involves two replisomes which converge, resect, resolve, and join the nascent strands of DNA at the point where all sequences have doubled (Wendel et al., 2014). These events occur thousands of times per cell cycle across human chromosomes, meaning the event must occur with remarkable efficiency to maintain cell viability (reviewed in Cvetic and Walter, 2005; Gao and Zhang, 2007; reviewed in Méchali 2010). Prokaryotes, which contain a single bidirectional origin, offer a chance to characterize this event and reaction in a less complex and better-defined system. The use of plasmids can further simplify this analysis and have been successfully used in other works to characterize the molecular mechanisms of replication initiation and elongation (Reviewed in del Solar et al., 1998). However, commonly-used plasmids, such as pBR322 that have origins of replication derived from ColE1, replicate with onereplisome plasmids are unlikely to ever have a completion event where replication forks converge similar to the chromosome (Abe 1980; Wendel et al., 2014). Thus, in this study, I used a plasmid mini-chromosome that contained a bidirectional origin that could be used to assess and examine the completion reaction. I show that maintaining plasmids containing two replisomes depends on the enzymes needed to complete replication on the chromosome. The completion of chromosomal replication requires RecBCD to join the strands of convergent replication forks. In its absence, DNA ends persist, are extensively degraded, and cells fail to maintain these regions of the chromosome (Dimude et al., 2018A; Wendel et al., 204; Courcelle et al., 2015; Wendel et al., 2018). Similarly, I show that transformation of two-replisome plasmids in $\operatorname{rec} B C$ mutants is severely impaired and 
the plasmids fail to propagate in cells under selection. On the chromosome, the ExoI SbcDC structure-specific nucleases are required to initiate the faithful completion reaction. In the absence of these proteins, normal completion cannot occur, excess overreplicated regions persist, and the reaction is shunted through a RecA-mediated pathway that is associated with amplifications and genetic instabilities (Indiani et al., 2013; Dimude et al., 2018A; Wendel et al., 2014; Courcelle et al., 2015; Wendel et al., 2018). Here, I show that transformation of two-replisome plasmids in $x o n A s b c C D$ mutants similarly depends on the RecA-mediated pathway. Thus, both the normal RecBCDmediated reaction, and the aberrant recombinational process appear to operate on the two-replisome plasmids. Additionally, I show that the requirement for these completion enzymes is specific to plasmids with two replisomes, as transformation was not impaired in the one-replisome plasmid pBR322. The observation implies that the substrate acted upon by ExoI, SbcDC, and RecBCD during the completion reaction is specific to a structure created when two replisomes converge.

Finally, I found that the two-replisome plasmid was less stable than the onereplisome plasmid when propagated in the absence of selection, and showed that this instability was driven by amplifications arising from a RecA-mediated recombination reaction, similar to what is observed on the chromosome at sites where completion occurs (Wendel et al., 2018). Inactivation of RecA increased the stability of the two-replisome plasmid and reduced the proportion of abnormal amplification products that were observed (Fig 3.3A). The high rate of RecA-driven instability on the two-replisome plasmid indicates that the aberrant pathway occurs at relatively high frequency on the plasmid, even when the normal, faithful pathway remains functional. I would speculate that this is likely due to the high copy number of the bidirectional plasmid, and that the 
frequency of aberrant completion events on the chromosome is likely to be much less. Although pBR322 demonstrated relatively similar copy number I would not suggest this to have the same effect as the accumulative assays suggest 1-replisome plasmids do not engage or require the same enzymes to complete DNA replication. Under normal conditions in $E$. coli, the completion enzymes are only required to catalyze a single reaction on the chromosome. Whereas the bidirectional plasmid, which is maintained at $\sim 80$ copies/chromosome (Fig 3.1E), may exceed the reaction-capacity of the faithful pathway, whose genes are not highly expressed (Eichler and Lehman, 1977; Taylor and Smith, 1980), allowing the aberrant mechanism to operate more frequently than would normally occur.

ExoI and SbcDC nuclease complexes are additive in their effect on the completion reaction and inactivation of the normal completion reaction required deletion of both genes (Wendel et al., 2014; Wendel et al., 2018; Dimude et al., 2018A). On the chromosome, in the absence of both nucleases, the over-replicated regions persist, and the ability to maintain growth and the chromosome region where forks converge becomes entirely dependent on RecA; as the triple mutant $x o n A s b c D C$ rec $A$ shows a complete lack of maintenance in the terminus region instead of over amplification (Wendel et al., 2018). In this report, we show that transformation of two-replisome plasmids similarly becomes dependent on RecA only in the absence of both nucleases (Fig. 3.4B). Mechanistically, ExoI and SbcDC could functionally interact to cooperate and enhance their ability to degrade the substrate(s) created by convergent replication forks. This appears to occur in eukaryotes, where the homologous Mre11-Rad50 interacts with Sae2 and increase its exonuclease activity (Lengsfeld et al., 2007; Deng et al., 2015; Andres and Williams, 2017). Consistent with this, a recent study from Dimude et al. found that 
SbcDC alone prevented much of the degradation that occurs in $r e c B C$ mutants (Dimude et al., 2018B), an observation we have confirmed in our lab. In vitro, $\mathrm{SbcCD}$ has been demonstrated to cleave a palindrome-like substrate similar to that predicted to arise when replication forks bypass each other (Lim et al., 2015; Saathoff et al., 2018). Alternatively, ExoI may act independently of SbcDC to suppress the aberrant recombinational pathway. Early studies suggested a strong physical interaction between ExoI exonuclease and RecA (Bedale et al., 1991; Bedale et al., 1993; Kowalczykowski et al., 1994). Association of this 3' exonuclease with RecA would be expected to strongly degrade recombinogenic 3' ends preventing RecA from initiating recombination at these sites.

In an alternative interpretation of $\operatorname{RecBCD}$ function, a recent study and review speculated that chromosome cleavage may frequently occur during septation at cell division, resulting in double strand breaks that require RecBCD for repair (Sinha et al., 2018; Michel et al., 2018). The authors based this argument primarily on the observation that the extensive degradation in $\operatorname{rec} B C$ mutants' centers upon the dif locus, where chromosomes ultimately separate as cells divide. However, several observations argue strongly against this possibility. If the defects in $\operatorname{rec} B C$ mutants were due to the presence of double strand breaks, then $r e c A$ mutants, which is essential for repair of double strand breaks, should be similarly, or more severely affected. Yet, in their initial study, the authors failed to examine or address $r e c A$ mutants (Sinha et al., 2018). However, recA mutants grow at rates similar to wild type cultures, and unlike, $\operatorname{rec} B C$ mutants, maintain this region of the chromosome normally (Courcelle et al., 2015; Wendel et al., 2018). Further, these authors and previous investigators all note that DNA breaks are not detected on the chromosome of $r e c A$ mutants (Sinha et al., 2018; Wendel et al., 2014; Courcelle et al., 2015; Wendel et al., 2018; Pennington and Rosenberg, 2007). To explain 
the absence of DNA breaks in recA mutants, a subsequent study from this group proposed that the septation-induced breaks in $r e c A$ genomes are subsequently degraded and therefore undetectable (Sinha et al., 2018). However, based on the viability of $\operatorname{rec} B C$ mutants, $\sim 90 \%$ of cells in culture would be experiencing these septation-induced breaks. Synthesis and subsequent degradation of these genomes would be expected to slow culture growth considerably and generate partial genomic degradation intermediates that should be easily detectable, neither of which are observed in recA cultures (Sinha et al., 2018; Wendel et al., 2014; Courcelle et al., 2015; Wendel et al., 2018). Further, such models do not consider, and fail to address, how the inactivation of exonucleases SbcDC and ExoI, which are not essential for double strand break repair, would restore $\operatorname{rec} B C D$ mutant growth defects, or why maintaining the terminus region of the chromosome in the absence of these exonucleases would depend on RecA (Templin et al., 1972; Lloyd and Buckman, 1985; Wendel et al., 2018). Finally, as shown here, plasmids containing two replisomes require $\operatorname{RecBCD}$ to propagate but do not require RecA and are actually stabilized in its absence. These plasmids lack dif sequences, and segregate prior to and independent from cell division, and would therefore not be subject to septation-induced breaks. These observations are all inconsistent with the idea that the requirement for RecBCD is due to double strand breaks caused by cell division, and argue strongly in favor of its role in joining DNA ends of convergent forks, which can occur independently of recombination or RecA. It is also worth considering that although current models for RecBCD in double-strand break repair propose that RecBCD acts prior to RecA, the early in vivo studies led several independent labs to conclude that RecBCD acted after RecA, at a later step in completing the recombination reaction (Wilkins 1969; Willets 1975; Hall and Howard-Flanders, 1972; Birge and Low, 1974). Current models placing RecBCD as 
an initiator are heavily derived from biochemical studies in which linear double-stranded substrates were used to characterize enzyme binding, helicase, and exonuclease activities (reviewed in (Yeeles and Dillingham, 2010; Dillingham and Kowalczykowski, 2008; Smith 2012)). The initial concept that RecBC acts late in recombination arose from the observation that although $\operatorname{rec} A$ mutants receiving an $\mathrm{F}^{\prime}$ factor were unable to transfer chromosomal genes to another cell, $\operatorname{rec} B C$ mutants could do so at frequencies that approached those of wild-type cells. However, over time ( $\sim 1$ generation), this ability rapidly declined (Hall and Howard-Flanders, 1972; Wilkins 1969; Willetts 1975). The authors inferred that recombination proceeds beyond the point at which the incoming DNA is joined to the chromosome in $\operatorname{rec} B C$ mutants, but that $r e c A$ mutants are blocked prior to this event. In recombinational crosses between Hfr and F- strains carrying noncomplementing mutations in lacZ, Birge and Low found that although rec $A$ mutants were entirely blocked, $\operatorname{rec} B C$ mutants initially produced beta-galactosidase within two-fold of those seen in wild-type cells, indicating that recombination reactions progressed beyond the point where transcribable, mutation-free copies of LacZ+ were produced (Birge and Low, 1974). However, although these recombination intermediates were detectable, the completion of these recombination events was impaired in the absence of RecBC and viable LacZ+ recombinant progeny were reduced 100-1000-fold. The authors inferred that "early steps in recombination can proceed efficiently in RecBC- and RecC-strains, but that late steps, such as the degradation of excess DNA 'tails', might be defective." Using combinations of single and double mutations, Willetts confirmed these previous studies and suggested that recombination proceeded past the first joining reaction of the two DNA molecules, but that RecBCD was required for a second joining needed "to generate a circular unit” that could be inherited (Willetts 1975). These interpretations are 
strikingly consistent with RecBCD's apparent role in completing replication on the chromosome, and may suggest that RecBCD function during recombinational events is similar to its role in completion of replication (Wendel et al., 2014; Courcelle et al., 2015).

\section{Replication fork traps and the completion reaction}

Although not essential for viability, Tus-ter DNA-protein complexes are important to localize the region where converging replication forks meet on the chromosome (Roecklein et al., 1991; Reviewed in Rothstein et al., 2000). By adding terB and $\operatorname{ter} C$ sequences to the mini-chromosomes, I observed that their presence altered the form of the replicating plasmid, effectively increasing the proportion of the plasmids that migrated as circular forms. This had a modest but detrimental effect on the overall stability of the plasmid, but could be argued to promote a more 'normal' circular DNA product that can be passed on to the next generation, similar to the circular chromosome of the bacterial host. The modest reduction in stability may be due to the unnaturally small plasmid substrate in which the completion must occur. On the chromosome, this reaction takes place within a $400-\mathrm{kb}$ region. On the plasmid we ask the reaction to occur within 5-kb, which may present some formational impediments for the reaction and provide a rationale for why large circular products are observed. In future work, it would be of interest to create a large plasmid substrate, to determine if this improves the efficiency of the completion reaction. If plasmid stability increased with increasing plasmid size, it would suggest that the completion reaction requires larger substrates to occur. Given that RecBCD degrades and unwinds DNA at rates approaching $1000 \mathrm{bp} / \mathrm{sec}$ (Roman et al., 1992) and that the distance between chi sites on the chromosome average 
several kilobases (Burland et al., 1993), it seems reasonable to suspect that large substrates may be required.

Nevertheless, the increased level of circle DNA products in the presence of ter sequences implies that the ter sequences are limiting the amount of aberrant runaway replication that occurs, and may provide more time for the completion to occur. I observed that the presence of the ter sequences seemed particularly critical or beneficial to the reaction, when chi sequences were present, which appear to promote the runaway replication.

\section{Chi sequences and the completion of replication}

Chi sequences have been previously shown to determine where RecBCD promoted crossover events that occur during recombination processes; thus, named crossover hotspot instigator by Franklin Stahl (Lam et al., 1974; Henderson and Weil, 1975; Stahl et al., 1977; Stahl 1979). I examined how the presence of chi effected RecBCD's ability to catalyze the completion reaction on the bidirectional plasmid. I observed that chi sequences increase the aberrant replication on the plasmid, and that this correlates with a reduced stability of the plasmid. This appears to suggest that upon encountering a chi site, RecBCD promotes the recruitment of replication. On the plasmid substrates, this appears detrimental. This could be due to the small size or the absence of other critical sequences on the plasmid. On the chromosome, it seems reasonable to consider that this is likely to be a beneficial step. It may be that the $c h i$ sites induce the RecBCD complex to cease degrading the DNA, perhaps as a 'check' to see if all of the over-replicated regions have been degraded. If it has degraded beyond the over-replicated region, then further synthesis would be needed to complete the replication process. During recombination, chi sequences induce RecBCD to promote crossover events at 
those locations (Stahl et al., 1977; Stahl 1979). We speculatively suggest that this may similarly reflect joining events during the completion of replication or during the repair of double strand breaks. In both cases, it would be critical that the joining occur at the point where excess tails have been degraded, and we postulate that chi is acting to promote this event. This type of activity may also explain why the location of chi sequences is heavily biased to the leading strand template of the chromosome (Burland et al., 1993), as the degradation of excess sequences are always orientated away from the origin of replication, allowing more 'checks' to occur during resection in this direction. 


\section{$\underline{\operatorname{Ch~V}}$}

\section{References}

1. Abe, M. 1980. Replication of ColE1 Plasmid Deoxyribonucleic Acid in a Thermosensitive dnaA Mutant of Escherichia coli. Journal of Bacteriology. 141: 10241030.

2. Al-Hadid Q, Ona Katherine, Courcelle C, Courcelle J. 2008. RecA433 Cells are Defective in recF-Mediated Processing of Disrupted Replication Forks but Retain recBCD-Mediated Functions. Mutation Research. 645: 19-26.

3. Allgood N, Silhavy T. 1991. Escherichia coli xonA (sbcB) Mutants Enhance Illegitimate Recombination. Genetics. 127: 671-680.

4. Amundsen S, Taylor A, Chaudhury A, Smith G. 1986. recD: The Gene for an Essential Third Subunit of Exonuclease V. Proceedings in the National Academy of Sciences of the United States of America. 83: 5558-5562.

5. Amundsen S, Neiman A, Thibodeaux S, Smith G. 1990. Genetic Dissection of the Biochemical Activities of RecBCD Enzyme. Genetics. 126: 25-40.

6. Amundsen S, Smith G. 2007A. Chi Hotspot Activity in Escherichia coli Without RecBCD Exonuclease Activity: Implications for the Mechanism of Recombination. Genetics. 175: 41-54.

7. Amundsen S, Taylor A, Reddy M, Smith G. 2007B. Intersubunit Signaling in RecBCD Enzyme, a Complex Protein Machine Regulated by Chi Hot Spots. Genes \& Development. 21: 3296-3307.

8. Amundsen S, Sharp J, Smith G. 2016. RecBCD Enzyme "Chi Recognition" Mutants Recognize Chi Recombination Hotspots in the Right DNA Context. Genetics. 204: 139-152.

9. Amunugama R, Fishel R. 2012. Homologous Recombination in Eukaryotes. Progress in Molecular Biology and Translational Science. 110: 155-206.

10. Anderson D, Kowalcyzkowski S. 1997A. The Recombination Hot Spot $\chi$ is a Regulatory Element that Switches the Polarity of DNA Degradation by the RecBCD Enzyme. Genes \& Development. 11: 571-581.

11. Anderson D, Churchill J, Kowalczykowski S. 1997B. Chi-Activated RecBCD Enzyme Possesses 5'-3' Nucleolytic Activity, but RecBC Enzyme Does Not: Evidence Suggesting that the Alteration Induced by Chi is Not Simply Ejection of the RecD Subunit. Genes to Cells. 2: 117-128.

12. Anderson D, Churchill J, Kowalcyzkowski S. 1999. A Single Mutation, RecB B108A Eliminates RecA Protein Loading but Not Chi Recognition by RecBCD Enzyme*. The Journal of Biological Chemistry. 274: 27139-27144.

13. Andres S, Williams R. 2017. CtIP/Ctp1/Sae2, Molecular Form Fit for Function. DNA Repair. 56: 109-117.

14. Austin S, Friedman S, Ludtke D. 1986. Partition Functions of Unit-Copy Plasmids can Stabilize the Maintenance of Plasmid pBR322 at Low Copy Number. Journal of Bacteriology. 168: 1010-1013.

15. Bedale W, Inman R, Cox M. 1991. RecA Protein-Facilitated DNA Strand Breaks. A mechanism for Bypassing DNA Structural Barriers during Strand Exchange. Journal of Biological Chemistry. 266: 6499-6510. 
16. Bedale W, Inman R, Cox M. 1993. A Reverse DNA Strand Exchange Mediated by recA Protein and Exonuclease I. The Generation of Apparent DNA Strand Breaks by RecA Protein is Explained. Journal of Biological Chemistry. 268: 15004-15016.

17. Bianco P, Tracy R, Kowalczykowski S. 1998. DNA Strand Exchange Proteins: a Biochemical and Physical Comparison. Frontiers in Bioscience. 3:570-603.

18. Biek D, Cohen S. 1986. Identification and Characterization of $r e c D$, a Gene Affecting Plasmid Maintenance and Recombination in Escherichia coli. Journal of Bacteriology. 167: 594-603.

19. Birge E, Low K. 1974. Detection of Transcibable Recombination Products Following Conjugation in rec+, RecCB- and RecC-strains of Escherichia coli K12. Journal of Molecular Biology. 83: 447-457.

20. Blattner F, Plunkett G, Block C, Perna N, Burland V, Riley M, Colladovides J, Glasner J, Rode c, Mayhew G, Gregor J, Davis N, Kirkpatrick H, Goeden M, Rose D, Mau B, Shao Y. The Complete Genome Sequence of Escherichia coli K-12. Science. 277: 1453-1462.

21. Bolivar F, Rodriquez R, Greene P, Betlach M, Heyneker H, Boyer H, Crosa J, Falkow S. 1977. Construction and Characterization of New Cloning Vehicles. II. A Multipurpose Cloning System. Gene. 2: 95-113.

22. Boyce R, Howard-Flanders P. 1964. Release of Ultraviolet Light-induced Thymine Dimers from DNA in E. coli K-12. Proceedings in the National Academy of Sciences of the United States of America. 51:293-300.

23. Burland V, Plunkett G, Daniels D, Blattner F. 1993. DNA Sequence and Analysis of 136 Kilobases of the Escherichi coli Genome: Organizational Symmetry around the Origin of Replication. Genomics. 16: 551-561.

24. Campbell J, Kleckner N. 1990. E. coli oriC and the dnaA Gene Promoter are Sequestered from dam methyltransferase Following the Passage of the Chromosomal Replication Fork. Cell. 62: 967-979.

25. Casini A, MacDonald J, De Jonghe J, Christodoulou G, Freemont P, Baldwin G, Elllis T. 2014. One-pot DNA Construction for Synthetic Biology: the Modular Overlap-Directed Assembly with Linkers (MODAL) strategy. Nucleic Acids Research. 42: e7.

26. Chattoraj D, Crasemann J, Dower N, Faulds D, Faulds P, Malone R, Stahl F, Stahl M. 1979. Chi. Cold Spring Harbor Symposia On Quantitative Biology. 43: 1063-1066.

27. Chen Z, Yang H, Pavletich N. 2008. Mechanism of Homologous Recombination from the RecA-ssDNA/dsDNA Structures. Nature. 453: 489-494.

28. Cheng K, Smith G. 1987. Cutting of Chi-like Sequences by the RecBCD Enzyme of Escherichia coli. Journal of Molecular Biology. 194: 747-750.

29. Cho C, Chung C, Li Hung. 2018. How Chi Sequences Modifies RecBCD SingleStranded DNA Translocase Activity. ChemphysChem. 19: 243-247.

30. Chow K, Courcelle J. 2004. RecO Acts with RecF and RecR to Protect and Maintain Replication Forks Blocked by UV-Induced DNA Damage in Escherichia coli. Journal of Biological Chemistry. 279: 3492-3496.

31. Clark A, Margulies A. 1965. Isolation and Characterization of RecombinationDeficient Mutants of Escherichia Coli K12*. Proceedings in the National Academy of Sciences of the United States of America. 53: 451-459.

32. Clark A. 1991. Rec Genes and Homologous Recombination Proteins in Escherichia coli. Biochimie. 73: 523-532. 
33. Clark A. 1993, Sharma V, Brenowitz S, Chu C, Sandler S, Satin L, Templin A, Berger I, Cohen A. 1993. Genetic and Molecular Analyses of the C-Terminal Region of the recE Gene from the Rac Prophage of Escherichia coli K-12 Reveal the recT Gene. Journal of Bacteriology. 175: 7673-7682.

34. Coskun-Ari F, Skokotas A, Moe G, Hill T. 1994. Biophysical Characteristics of Tus, the Replication Arrest Protein of Escherichia coli. Journal of Biological Chemistry. 269: 4027-4034.

35. Costa A, Hood I, Berger J. 2013. Mechanisms for Initiating Cellular DNA Replication. Annual Review Biochemistry. 82: 25-54.

36. Courcelle C, Chow K, Casey A, Courcelle J. 2006. Nascent DNA Processing by RecJ Favors Lesion Repair Over Translesion Synthesis at Arrested Replication Forks in Escherichia coli. Proceedings of the National Academy of Science United States of America. 103: 9154-9159.

37. Courcelle J, Carswell-Crumpton C, Hanawalt P. 1997. recF and recR Are Required for the Resumption of Replication at DNA Replication Forks in Escherichia coli. Proceedings of the National Academy of Science United States of America. 94: 37143719.

38. Courcelle J, Crowley D, Hanawalt P. 1999A. Recovery of DNA Replication in UVIrradiated Escherichia coli Requires both Excision Repair and recF Protein Function. Journal of Bacteriology. 181: 916-922.

39. Courcelle J, Hanawalt P. 1999B. RecQ and RecJ Process Blocked Replication Forks Prior to the Resumption of Replication in UV-Irradiated Escherichia coli. Molecular and General Genetics. 262: 543-551.

40. Courcelle J, Khodursky A, Peter B, Brown P, Hanawalt P. 2001. Comparative Gene Expression Profiles Following UV Exposure in Wild Type and SOS Deficient Escherichia coli. Genetics. 158: 41-64.

41. Courcelle J, Donaldson J, Chow K, Courcelle C. 2003. DNA Damage-Induced Replication Fork Regression and Processing in Escherichia coli. Science. 299: 10641067.

42. Courcelle J, Wendel B, Livingstone D, Courcelle C. 2015. RecBCD is Required to Complete Chromosomal Replication: Implications for Double-Strand Break Frequencies and Repair Mechanisms. DNA Repair. 32: 86-95.

43. Cox M, Lehman I. 1982. RecA Protein-Promoted DNA Strand Exchange. The Journal of Biological Chemistry. 257: 8523-8532.

44. Crowley D, Courcelle J. 2002. Answering the Call: Coping with DNA Damage at the Most Inopportune Time. Journal of Biomedicine and Biotechnology. 2: 66-74.

45. Cvetic C, Walter J. 2005. Eukaryotic Origins of DNA Replication: Could you Please Be More Specific? Seminars in Cell and Developmental Biology. 16: 343-353.

46. Dabert P, Ehrlich S, Gruss A. 1992. $\chi$ Sequence Protects Against RecBCD Degradation of DNA in vivo. Proceedings in the National Academy of Sciences of the United States of America. 89: 12073-12077.

47. de Vlaminck Iwijn, Loenhout M, Zweifel L, Blanken j, Hooning K, Hage S, Kerssemakers J. 2012. Mechanism of Homology Recognition in DNA Recombination from Dual-Molecule Experiments. Molecular Cell. 46: 616-624.

48. del Solar G, Giraldo R, Ruiz-Echevarría M, Espinosa M, Díaz-Orejas R. 1998. Replication and Control of Circular Bacterial Plasmids. Microbiology and Molecular Biology Review. 62: 434-464. 
49. Deng S, Yin Y, Petes T, Symington L. 2015. Mre11-Sae2 and RPA Collaborate to Prevent Palindromic Gene Amplification. Molecular Cell. 60: 500-508.

50. Dillingham M, Kowalczykowski S. 2008. RecBCD Enzyme and the Repair of DoubleStranded DNA Breaks. Microbiology and Molecular Biology Review. 72: 642-671.

51. Dimude J, Stein M, Andrzejewska E, Khalifa M, Gajdosova A, Retkute R, Skovgaard O, Rudolph C. 2018A. Origins Left, Right, and Centre: Increasing the Number of Initiation Sites in the Escherichia coli Chromosome. Genes. 9: 2018/08/01.

52. Dimude J, Midgley-Smith S, Rudolph C. 2018B. Replication-Transcription Conflicts Trigger Extensive DNA Degradation in Escherichia coli Cells Lacking RecBCD. DNA Repair. 70: 37-48.

53. Dixon D, Kowalcyzkowski S. 1993. The Recombination Hotspot $\chi$ Is a Regulatory Sequence That Acts by Attenuating the Nuclease Activity of the E. coli RecBCD Enzyme. Cell. 73: 87-96.

54. Dohoney K, Gelles J. 2001. $\chi$-Sequence recognition and DNA Translocation by single RecBCD Helicase/Nuclease molecules. Nature. 409: 370-374.

55. Eichler D, Lehman I. 1977. On the Role of ATP in Phosphodiester Bond Hydrolysis Catalyzed by the RecBC Deoxyribonuclease of Escherichia coli. Journal of Biological Chemistry. 252: 499-503.

56. Errico A, Constanzo V. 2012. Mechanisms of Replication Fork Protection: a Safeguard for Genome Stability. Critical Review of Biochemical Molecular Biology. 47: 222-235.

57. Fan H, Li H. 2009. Studying RecBCD Helicase Translocation Along $\chi$-DNA Using Tethered Particle Motion with a Stretching Force. Biophysical Journal. 96: 1875-1883.

58. Franklin N. 1967. Extraordinary Recombinational Events in ESCHERICHIA COLI. Their Independence of the rec+ Function. Genetics. 1967: 699-707.

59. Friedberg E. 1995. Out of the Shadows and Into the Light: the Emergence of DNA Repair. Trends in Biochemical Science. 20: 381.

60. Furth M, Blattner F, McLeester C, Dove W. 1977. Genetic Structure of the Replication Origin of Bacteriophage Lambda. Science. 198: 1046-1051

61. Gao F, Zhang C. 2007. DoriC: a Database of oriC Regions in Bacterial Genomes. Bioinformatics. 14: 1866-1867.

62. Gibson F, Leach D, Lloyd R. 1992. Identification of $s b c D$ Mutations as CoSuppressors of $r e c B C$ That Allow Propagation of DNA Palindromes in Escherichia coli K-12. Journal of Bacteriology. 174: 1222-1228.

63. Gibson D, Young L, Chuang R, Venter J, Hutchison C, Smith H. 2009. Enzymatic Assembly of DNA Molecules up to Several Hundred Kilobases. Nature Methods. 6: 343-345.

64. Gonzalez M, Frank E, McDonald J, Levine A, Woodgate R. 1998. Structural Insights into the Regulation of SOS Mutagenesis. The Journal of the Polish Biochemical Society and of the Committee of Biochemistry and Biophysics Polish Academy of Sciences. 45: 163-172.

65. Gorden E, Sturk-Andreaggi K, Marshall C. 2018. Repair of DNA Damage Caused by Cytosine Deamination in Mitochondrial DNA of Forensic Case Samples. Forensic Science International: Genetics. 34: 257-264.

66. Hall J, Howard-Flanders P. 1972. Recombinant F' Factors from Escherichia coli K-12 Strains Carrying RecB or RecC. Journal of Bacteriology. 110: 578-584.

67. Hanawalt P, Ford J, Lloyd D. 2003. Functional Characterization of Global Genomic DNA Repair and its Implications for Cancer. Mutation Research. 544: 107-114. 
68. Handa N, Kobayashi I. 2005A. Type III Restriction Is Alleviated by Bacteriophage (RecE) Homologous Recombination Function but Enhanced by Bacterial (RecBCD) Function. Journal of Bacteriology. 187: 7362-7373.

69. Handa N, Bianco P, Baskin R, Kowalcyzkowski S. 2005B. Direct Visualization of RecBCD Movement Reveals Cotranslocation of the RecD Motor after $\chi$ Recognition. Molecular Cell. 17: 745-750.

70. Handa N, Yang L, Dillingham M, Kobayashi I, Wigley D, Kowalcyzkowski S. 2012. Molecular Determinants Responsible for Recognition of the Single-Stranded DNA Regulatory Sequence, $\boldsymbol{\chi}$, by RecBCD Enzyme. Proceedings in the National Academy of Sciences of the United States of America. 109: 8901-8906.

71. Hasebe T, Narita K, Hidaka S, Su'etsugu M. 2018. Efficient Arrangement of the Replication Fork Trap for in vitro Propagation of Monomeric Circular DNA in the Chromosome-Replication Cycle Reaction. Life. 8: 2018/09/28.

72. Henderson D, Weil J. 1975. Recombination-Deficient Deletions in Bacteriophage $\lambda$ And Their Interaction with Chi Mutations. Genetics. 79:143-174.

73. Heyer WD, Ehmsen KT, Liu J. 2010. Regulation of Homologous Recombination in Eukaryotes. Annual Review of Genetics. 44: 113-139.

74. Hill T, Marians K. 1990. Escherichia coli Tus Protein Acts to Arrest the Progression of DNA Replication Forks in vitro. Proceedings in the National Academy of Sciences of the United States of America. 87: 2481-2485.

75. Hopefield J. 1974. Kinetic Proofreading: a new Mechanism for Reducing Errors in Biosynthetic Processes Requiring High Specificity. Proceedings in the National Academy of Sciences of the United States of America. 71: 4135-139.

76. Hopefield J, Yamane T, Yue V, Coutts S. 1976. Direct Experimental Evidence for Kinetic Proofreading in Amino Acalystion of tRNAIle. Proceedings in the National Academy of Sciences of the United States of America. 73: 1164-1168.

77. Horiuchi T, Nishitani H, Kobayashi T. 1995. A New Type of E. coli Recombinational Hotspot Which Requires for Activity Both DNA Replication Termination Events and the Chi Sequence. Advanced Biophysics. 31: 133-147.

78. Howard-Flanders P, Boyce R. 1966A. DNA Repair and Genetic Recombination: Studies on Mutants of Escherichia coli Defective in These Processes. Radiation Research Supplement. 6: 156-184.

79. Howard-Flanders P, Theriot L. 1966B. Mutants of Escherichia Coli K-12 Defective in DNA Repair and in Genetic Recombination. Genetics. 53: 1137-1150.

80. Iismaa T, Wake R. 1987. The Normal Replication Terminus of the Bacillus subtilis Chromosome, $\operatorname{ter} C$, is Dispensable for Vegetative Growth and Sporulation. Journal of Molecular Biology. 195: 299-310.

81. Indiani C, Patel Meghna, Goodman M, O'Donnell M. 2013. RecA Acts as a Switch to Regulate Polymerase Occupancy in a Moving Replication Fork. Proceedings of the National Academy of Sciences of the United States of America. 110: 5410-5415.

82. Jensen K. 1993. The Escherichia coli K-12 "Wild Types” W3110 and MG1655 have an rph Frameshift Mutation that Leads to Pyrimidine Starvation Due to Low pyrE Expression Levels. Journal of Bacteriology. 175: 3401-3407.

83. Karu A, Belk E. 1982. Induction of E. coli RecA protein via RecBC and Alternative Pathways: Quantitation by Enzyme-Linked Immunosorbent Assay (ELISA). Molecular Genomics and Genetics. 185: 275-282. 
84. Kiem P, Lark KG. 1990. The RecE Recombination Pathway Mediates Recombination Between Partially Homologous DNA Sequences: Structural Analysis of Recombination Products. Journal of Structural Biology. 104: 97-106.

85. Klein H, Kreuzer K. 2002. Replication, Recombination, and Repair: Going for the Gold. Molecular Cell. 9: 471-480.

86. Kobayashi I, Murialdo H, Crasemann J, Stahl M, Stahl F. 1982. Orientation of Cohesive End Site cos Determines the Active Orientation of $\chi$ Sequence in Stimulating recA $\cdot$ recBC-mediated Recombination in Phage $\lambda$ Lytic Infections. Proceedings in the National Academy of Sciences of the United States of America. 79: 5981-5985.

87. Köppen A, Krobitsch S, Thoms B, Wackernagel W. 1995. Interactions with the recombination hot spot $\chi$ in vivo converts the RecBCD enzyme of Escherichia coli in to a $\chi$-independent recombinase by inactivation of the RecD subunit. Proceedings in the National Academy of Sciences of the United States of America. 92: 6249-6253.

88. Kowalczykowski S, Dixon D, Eggleston A, Lauder S, Rehrauer W. 1994. Biochemistry of Homologous Recombination in Escherichia coli. Microbiology Review. 58: 401465.

89. Kuempel P, Duerr S, Seeley N. 1977. Terminus Region of the Chromosome in Escherichia coli Inhibits Replication Forks. Proceedings in the National Academy of Science of the United States of America. 74: 3927-3931.

90. Kulkarni A, Julin D. 2004. Specific Inhibition of the E. coli RecBCD Enzyme by Chi Sequences in Single-Stranded Oligodeoxyribonucleotides. Nucleic Acids Research. 32: 3672-3682.

91. Kushner S, Nagaishi H, Templin A, Clark A. 1971. Genetic Recombination in Escherichia coli: The Role of Exonuclease I. Proceedings in the National Academy of Sciences of the United States of America. 68: 824-827.

92. Kushner S, Nagaishi H, Clark A. 1972. Indirect Suppression of recB and recC Mutations by Exonuclease I Deficiency. Proceedings in the National Academy of Sciences of the United States of America. 69: 1366-1370.

93. Kushner S. 1974. Differential Thermolability of Exonuclease and Endonuclease Activities of the recBC Nuclease Isolated from the Thermosensitive $\operatorname{rec} B$ and $\operatorname{rec} C$ Mutants. Journal of Bacteriology. 120: 1219-1222.

94. Kuzminov A, Schabtach E, Stahl F. 1994. $\chi$ Sites in Combination with RecA Protein Increase the Survival of Linear DNA in Escherichia coli By Inactivating ExoV Activity of RecBCD Nuclease. The EMBO Journal. 13: 2764-2776.

95. Lam S, Stahl M, McMilin K, Stahl F. 1974. Rec-mediated Recombinational Hot Spot Activity In Bacteriophage Lambda. Genetics. 77: 425-433.

96. Leanderson P, Tagesson C. 1992. Cigarette Smoke-Induced DNA Damage in Cultured Human Lung Cells: Role of Hydroxyl Radicals and Endonuclease Activation. Chemical Biology Interactions 81: 197-208.

97. Lee J, Terakawa T, Qi Z, Steinfeld J, Redding S, Kwon Y, Gaines W, Zhao W, Sung P, Greene E. 2015. Base triplet stepping by the Rad51/RecA family of recombinases. Science. 349: 977-981.

98. Lengsfeld B, Rattray A, Bhaskara V, Ghirlando R, Paull T. 2007. Sae2 is an Endonuclease that Processes Hairpin DNA Cooperatively with the Mre11/Rad50/Xrs2 Complex. Molecular Cell. 28: 638-651.

99. Lesterlin C, Ball G, Schermelleh L, Sherratt D. 2014. RecA bundles mediate homology pairing between distant sisters during DNA break repair. Nature. 506: 249-253. 
100. Lloyd R, Thomas A. 1983. On the Nature of the RecBC and RecF Pathways of Conjugal Recombination in Escherichia coli. Molecular Genomics and Genetics. 190: $156-161$.

101. Lloyd R, Buckman C. 1985. Identification and Genetic Analysis of $s b c C$ Mutations in Commonly Used $\operatorname{rec} B C \operatorname{sbcB}$ Strains of Escherichia coli K-12. Journal of Bacteriology. 164: 836-844.

102. MacAllister T, Khatri G, Bastia D. 1990. Sequence-Specific and Polarized Replication Termination in vitro: Complementation of Extracts of tus- Escherichia coli by Purified Ter Protein and Analysis of Termination Intermediates. Proceedings of the National Academy of Science of the United States of America. 87: 2828-2832.

103. Lim C, Lai P, Leach D, Maki H, Furukohri A. 2015. A Novel Mode of Nuclease Action is Revealed by the Bacterial Mre11/Rad50 Complex. Nucleic Acids Research. 43: 9804-9816.

104. Mackay V, Linn S. 1974. The Mechanism of Degradation of Duplex Deoxyribonucleic Acid by the recBC Enzyme of Escherichia coli K-12*. Journal of Biological Chemistry. 249: 4286-4294.

105. Malone R, Chattoraj D, Faulds D, Stahl M, Stahl F. 1978. Hotspots for Generalized Recombination in the Escherichia coli Chromosome. Journal of Molecular Biology. 121: 473-491.

106. Mellon I, Hanawalt P. 1989. Induction of the Escherichia coli Lactose Operon Selectively Increases Repair of its Transcribed DNA Strand. Nature. 342: 95-98.

107. Meijer M, Beck E, Hansen F, Bergmans H, Messer W, Meyenburg K, Schaller H. 1979. Nucleotide Sequence of the Origin of Replication of the Escherichia coli K-12

Chromosome. Proceedings of the National Academy of Science. 76: 580-584.

108. Méchali M. 2010. Eukaryotic DNA Replication Origins: Many Choices for Appropriate Answers. Nature Reviews of Molecular Cell Biology. 11: 728-738.

109. Meselson M, Weigle J. 1961. Chromosome Breakage Accompanying Genetic Recombination in Bacteriophage*. Genetics. 47: 857-868.

110. Michel B, Sinha A, Leach D. 2018. Replication Fork Breakage and Restart in Escherichia coli. Microbiology and Molecular Biology Review. 82: 2018/06/15.

111. Moore D, Denniston-Thompson K, Furth M, Williams B, Blattner F. 1977. Construction of Chimeric Phages and Plasmids Containing the Origin of Replication of Bacteriophage Lambda. Science. 198: 1041-1046.

112. Murphy K. 1991. $\lambda$ Gam Protein Inhibits the Helicase and $\chi$-Stimulated Recombination Activities of Escherichia coli RecBCD Enzyme. Journal of Bacteriology. 173: 5808-5821.

113. Natarajan S, Kelley W, Bastia D. 1991. Replication Terminator Protein of Escherichia coli is a Transcriptional Repressor of its Own Synthesis. Proceedings of the National Academy of Science of the United States of America. 88: 3867-3871.

114. Nordstrom K, Molin S, Aagaad-Hansen H. 1980. Partitioning of Plasmid R1 in Escherichia coli. I. Kinetics of Loss of Plasmid Derivatives Deleted of the par Region. Plasmid. 4: 215-217.

115. O'Donnell M, Langston L, Stillman B. 2013. Principles and concepts of DNA replication in bacteria, archaea, and eukarya. Cold Spring Harbor Perspective in Biology. 5: 1-13.

116. Pennington J, Rosenberg S. 2007. Spontaneous DNA Breakage in Single Living Escherichia coli cells. Nature Genetics. 39: 797-802. 
117. Ponticelli A, Schultz d, Taylor A, Smith G. 1985. Chi-Dependent DNA Strand Cleavage by RecBCD Enzyme. Cell. 41: 145-151.

118. Potrykus K, Baranska S, Wegrzyn A, Wegrzyn G. 2002. Composition of the Lambda Plasmid Heritable Replication Complex. Biochemistry Journal. 364: 857862.

119. Qi Z, Redding S, Lee J, Gibb B, Kwon Y, Niu H, Gaines W, Sung P, Greene E. 2015. DNA Sequence Alignment by Microhomology Sampling During Homologous Recombination. Cell. 160: 856-869.

120. Roecklein B, Pelletier A, Kuempel P. 1991. The tus Gene of Escherichia coli: Autoregulation, Analysis of Flanking Sequences and Identification of a Complementary System in Salmonella typhimurium. Research Microbiology. 142: 169-175.

121. Roman L, Eggleston A, Kowalczykowski S. 1992. Processivity of the DNA Helicase Activity of Escherichi coli RecBCD Enzyme. Journal of Biological Chemistry. 267: 4207-4214.

122. Rothstein R, Michel B, Gangloff S. 2000. Replication Fork Pausing and Recombination or "gimme a break". Genes Development. 14: 1-10.

123. Saathoff J, Kashammer L, Lammens K, Byrne R, Hopfner K. 2018 The Bacterial Mre11-Rad50 Homolog SbcCD Cleaves Opposing Strands of DNA by two Chemically Distinct Nuclease Reactions. Nucleic Acids Research. 46: 11303-11314.

124. Sachs R, Chen P, Hahnfeldt P, Hlatky L. 1992. DNA Damage Caused by Ionizing Radiation. Math Bioscience. 112: 271-303.

125. San F, Sung P, Klein H. 2008. Mechanism of Eukaryotic Homologous Recombination. Annual Review of Biochemistry. 77: 229-257.

126. Savir Y, Tlusty T. 2010. RecA-Mediated Homology Search as a Nearly Optimal Signal Detection System. Molecular Cell. 40: 388-396.

127. Sawitzke J, Thomason L, Bubunenko M, Li X, Constantino N, Court D. 2012.

Recombineering: Highly Efficient in vivo Genetic Engineering Using Single-strand Oligos. Methods in Enzymology. 533: 157-177.

128. Seitz E, Brockman J, Sandler S, Clark A, Kowalczykowski S. 1998. RadA protein is an Archaeal RecA Protein Homolog that Catalyzes DNA Strand Exchange. Genes \& Development. 12: 1248-1253.

129. Shiraishi K, Imai Y, Yoshizaki S, Tadaki T, Ogata Y, Ikeda H. 2006. The Role of UvrD in RecET-Mediated Illegitimate Recombination in Escherichia coli. Genes Genetic System. 81: 291-297.

130. Singleton M, Dillingham M, Gaudler M, Kowalczykowski S, Wigley D. 2004. Crystal Structure of RecBCD Enzyme Reveals a Machine for Processing DNA Breaks. Nature. 432: 187-193.

131. Sinha R, Hader D. 2002. UV-Induced DNA Damage and Repair: a Review. Photochemical and Photobiology Science. 1: 225-236.

132. Sinha A, Possoz C, Durand A, Desfontaines J, Barre F, Leach D, Michel B. 2018. Broken Replication Forks Trigger Heritable DNA Breaks in the Terminus of a Circular Chromosome. Public Library of Science Genetics. 14: e1007256.

133. Smith G, Kunes S, Schults D, Taylor A, Triman K. 1981. Structure of Chi Hotspots of Generalized Recombination. Cell. 24: 429-436.

134. Smith G. 1989. Homologous Recombination in E. coli: Multiple Pathways for Multiple Reasons. Cell. 58: 807-809. 
135. Smith G. 2012. How RecBCD Enzyme and Chi Promote DNA Break Repair and Recombination: a Molecular Biologist's View. Microbiology and Molecular Biology Review. 76: 217-228.

136. Spies M, Bianco P, Dillingham M, Handa N, Baskin R, Kowalczykowski S. 2003. A Molecular Throttle: The Recombination Hotspot $\chi$ Controls DNA Translocation by the RecBCD Helicase. Cell. 114: 647-654.

137. Spies M, Dillingham M, Kowalczykowski S. 2005. Translocation by the RecB Motor Is an Absolute Requirement for $\chi$-Recognition and RecA Protein Loading by RecBCD Enzyme. Journal of Biological Chemistry. 280: 37078-37087.

138. Spies M, Amitani I, Baskin R, Kowalcyzkowski S. 2007. RecBCD Enzyme Switches Lead Motor Subunits in Response to $\chi$ Recognition. Cell. 131: 694-705.

139. Spivak G, Hanawalt P. 1995. Determination of Damage and Repair in Specific DNA Sequences. Methods: A Companion to Methods in Enzymology. 7: 147-161.

140. Stahl F, McMilin K, Stahl M, Nozu Y. 1972. Proceedings of the National Academy of Science United States of America. 69: 3598-3601.

141. Stahl F, Crasemann J, Stahl M. 1975. Rec-mediated Recombinational Hot Spot Activity in Bacteriophage Lambda. III. Chi Mutations are Site-Mutations Stimulating Rec-Mediated Recombination. Journal of Molecular Biology. 94: 203-212.

142. Stahl F, Stahl M. 1975. Rec-mediated Recombinational Hot Spot Activity in Bacteriophage Lambda. IV. Effect of Heterology on Chi-Stimulated Crossing over. Molecular Genetics and Genomics. 140: 29-37.

143. Stahl F, Stahl M. 1977. Recombination Pathway Specificity of Chi. Genetics. 86: 715-725.

144. Stahl F. 1979. Special Sites in Generalized Recombination. Annual Review of Genetics. 13:7-24.

145. Stahl M, Kobayashi I, Stahl F, Huntington S. 1983. Activation of Chi, a Recombinator, by the Action of an Endonuclease at a Distant Site. Proceedings of the National Academy of Science United States of America. 80: 2310-2313.

146. Stahl F, Thomason L, Siddiqi I, Stahl M. 1990. Further Tests of a Recombination Model in which $\chi$ Removes the RecD Subunit from the RecBCD Enzyme of Escherichia coli. Genetics. 126: 519-533.

147. Stasiak A, Stasiak AZ, Koller T. 1984. Visualization of RecA-DNA Complexes Involved in Consecutive Stages of an In Vitro Strand Exchange Reaction. Cold Spring Harbor Symposium Quantitative Biology. 49: 561-570.

148. Sung P, Klein H. 2006. Mechanism of Homologous Recombination: Mediators and Helicases Take on Regulatory Functions. Nature Review Molecular Cell Biology. 7: 739-750.

149. Tabata S, Oka A, Sugimoto K, Takanami M, Yasuda S, Hirota Y. 1983. The 245

Base-pair oriC Sequence of the E. coli Chromosome directs Bidirectional Replication at an Adjacent Region. Nucleic Acids Research. 11: 2617-2626.

150. Taylor A, Smith G. 1980. Unwinding and Rewinding of DNA by the RecBCD Enzyme. Cell. 22: 447-457.

151. Taylor A, Schultz D, Ponticelli A, Smith G. 1985. RecBC Enzyme Nicking at Chi Sites During DNA Unwinding: Location and Orientation-Dependence of the Cutting. Cell. 41:153-163.

152. Taylor A, Smith G. 1992. RecBCD Enzyme is Altered Upon Cutting DNA at a Chi Recombination Hotspot. Proceedings in the National Academy of Sciences of the United States of America. 89: 5226-5230. 
153. Taylor A, Smith G. 1995. Strand Specificity of Nicking of DNA at Chi Sites by RecBCD Enzyme. Journal of Biological Chemistry. 270: 24459-24467.

154. Taylor A, Smith G. 2003. RecBCD Enzyme is a DNA Helicase with Fast and Slow Motors of Opposite Polarity. Nature. 423: 889-893.

155. Taylor A, Amundsen S, Guttman M, Lee K, Luo Jie, Ranish J, Smith G. 2014. Control of RecBCD Enzyme Activity by DNA Binding- and Chi Hotspot-Dependent Conformational Changes. Journal of Biological Chemistry. 426: 3479-3499.

156. Taylor A, Amundsen S, Smith G. 2016. Unexpected DNA Context-Dependence Identifies a New Determinant of Chi Recombination Hotspots. Nucleic Acids Research. 44: 8216-8226.

157. Templin A, Kushner S, Clark A. 1972. Genetic Analysis of Mutations Indirectly Suppressing recB and recC Mutations. Genetics. 72: 105-115.

158. Thaler D, Sampson E, Siddiqi I, Rosenberg S, Thomason L, Stahl F, Stahl M. 1989. Recombination of Bacteriophage $\lambda$ in recD Mutants of Escherichia coli. Genome. 31: 53-67.

159. Wang T, Smith K. 1986. Inviability of dam recA and dam recB Cells of Escherichia coli Is Correlated with Their Inability to Repair DNA Double-Strand Breaks Produced by Mismatch Repair. Journal of Bacteriology. 165: 1023-1025.

160. Wendel B, Courcelle C, Courcelle J. 2014. Completion of DNA replication in Escherichia coli. Proceedings in the National Academy of Science of the United States of America. 111: 16454-16459.

161. Wendel B, Cole J, Courcelle C, Courcelle J. 2018. SbcC-SbcD and ExoI process convergent forks to complete chromosome replication. Proceedings in the National Academy of Science of the United States of America. 115: 349-354.

162. Wilkins B. 1969. Chromosome Transfer from F-lac+ Strains of Escherichia coli K12 Mutant at recA, recB, or recC. Journal of Bacteriology. 98: 599-604.

163. Willetts N. 1975. Recombination and the Escherichia coli K-12 Sex Factor F. Journal of Bacteriology. 121: 36-43.

164. Wong C, Rice R, Baker N, Ju T, Lohman T. 2006. Probing 3'-ssDNA Loop Formation in E. coli RecBCD/RecBC-DNA Complexes Using Non-Natural DNA: A Model for "Chi" Recognition Complexes. Journal of Biological Chemistry. 362: 2643.

165. Yang L, Handa N, Liu B, Dillingham M, Wigley D, Kowalczykowski S. 2012. Alteration of $\chi$ Recognition by RecBCD Reveals a Regulated Molecular Latch and Suggests a Channel-Bypass Mechanism for Biological Control. Proceedings in the National Academy of Sciences of the United States of America. 109: 8907-8912.

166. Yeeles J, Dillingham M. 2010. The Processing of Double-Stranded DNA Breaks for Recombinational Repair by Helicase-Nuclease Complexes. DNA Repair. 9: 276285.

167. Yu M, Souaya J, Julin D. 1998. Identification of the Nuclease Active Site in the Multifunctional RecBCD Enzyme by Creation of a Chimeric Enzyme. Journal of Molecular Biology. 283: 797-808.

168. Yu D, Ellis H, Lee E, Jenkins N, Copeland N, Court D. 2000. An Efficient Recombination System for Chromosome Engineering in Escherichia coli. Proceedings of the National Academy of Sciences of the United States of America

169. Zeman M, Climprich K. 2014. Causes and Consequences of Replication Stress. Nature Cell Biology. 16: 2-9. 